\title{
Co-receptor signaling in the pathogenesis of neuroHIV
}

\author{
E. A. Nickoloff-Bybel ${ }^{1}$, L. Festa ${ }^{2}$, O. Meucci ${ }^{1,3}$ and P. J. Gaskill ${ }^{1 *}$ (i)
}

\begin{abstract}
The HIV co-receptors, CCR5 and CXCR4, are necessary for HIV entry into target cells, interacting with the HIV envelope protein, gp120, to initiate several signaling cascades thought to be important to the entry process. Co-receptor signaling may also promote the development of neuroHIV by contributing to both persistent neuroinflammation and indirect neurotoxicity. But despite the critical importance of CXCR4 and CCR5 signaling to HIV pathogenesis, there is only one therapeutic (the CCR5 inhibitor Maraviroc) that targets these receptors. Moreover, our understanding of co-receptor signaling in the specific context of neuroHIV is relatively poor. Research into co-receptor signaling has largely stalled in the past decade, possibly owing to the complexity of the signaling cascades and functions mediated by these receptors. Examining the many signaling pathways triggered by co-receptor activation has been challenging due to the lack of specific molecular tools targeting many of the proteins involved in these pathways and the wide array of model systems used across these experiments. Studies examining the impact of co-receptor signaling on HIV neuropathogenesis often show activation of multiple overlapping pathways by similar stimuli, leading to contradictory data on the effects of co-receptor activation. To address this, we will broadly review HIV infection and neuropathogenesis, examine different co-receptor mediated signaling pathways and functions, then discuss the HIV mediated signaling and the differences between activation induced by HIV and cognate ligands. We will assess the specific effects of co-receptor activation on neuropathogenesis, focusing on neuroinflammation. We will also explore how the use of substances of abuse, which are highly prevalent in people living with HIV, can exacerbate the neuropathogenic effects of co-receptor signaling. Finally, we will discuss the current state of therapeutics targeting co-receptors, highlighting challenges the field has faced and areas in which research into co-receptor signaling would yield the most therapeutic benefit in the context of HIV infection. This discussion will provide a comprehensive overview of what is known and what remains to be explored in regard to co-receptor signaling and HIV infection, and will emphasize the potential value of HIV co-receptors as a target for future therapeutic development.
\end{abstract}

Keywords: HIV, NeuroHIV, CCR5, CXCR4, Co-receptor, Signaling

\section{Introduction}

Infection with human immunodeficiency virus (HIV), the cause of acquired immunodeficiency syndrome (AIDS), has been a major public health issue since the emergence of the virus in the early 1980 s and more than 38 million people are currently infected with HIV [1]. Today,

*Correspondence: pjg63@drexel.edu

${ }^{1}$ Department of Pharmacology and Physiology, Drexel University College of Medicine, 245 N. 15th Street, Philadelphia, PA 19102, USA

Full list of author information is available at the end of the article more than $50 \%$ of people living with HIV (PLWH) use combined antiretroviral therapy (cART), and for these individuals, HIV positivity has become a manageable, rather than life threatening, condition. While cART has ameliorated many of the symptoms and comorbidities associated with infection, antiretroviral drugs can only suppress, but not eliminate, viral infection. Suppressed, chronic HIV infection is still associated with a variety of comorbid conditions, including cardiovascular, metabolic and neurological complications [2]. Indeed, $20-50 \%$ of infected individuals still suffer from the constellation original author(s) and the source, provide a link to the Creative Commons licence, and indicate if changes were made. The images or other third party material in this article are included in the article's Creative Commons licence, unless indicated otherwise in a credit line to the material. If material is not included in the article's Creative Commons licence and your intended use is not permitted by statutory regulation or exceeds the permitted use, you will need to obtain permission directly from the copyright holder. To view a copy of this licence, visit http://creativecommons.org/licenses/by/4.0/. The Creative Commons Public Domain Dedication waiver (http://creativeco mmons.org/publicdomain/zero/1.0/) applies to the data made available in this article, unless otherwise stated in a credit line to the data. 
of neuropathologic, behavioral and cognitive symptoms now known as neuroHIV [3]. Thus, it remains critical to delve further into the neuropathogenesis of HIV to develop novel and more effective therapeutic strategies for the treatment of this disease.

Infection with HIV is almost always mediated by interactions between the HIV envelope protein, gp120, the $\mathrm{CD} 4$ receptor and a co-receptor, generally the chemokine receptors CCR5 or CXCR4. These chemokine receptors [4-7], were first associated with HIV infection in the mid-1990's [8-14]. Initially, the use of CCR5 or CXCR4 was considered cell type specific, with viruses that infected T-cells using CXCR4 and viruses that infected macrophages and microglia using CCR5 [15-17]. This was due, in part, to the use of transformed T-cell lines that predominantly express CXCR4, whereas primary macrophages express more CCR5. Consequently, early researchers classified viruses based on their cell tropism: T-cell (T)-tropic and macrophage (M)-tropic. However, both primary lymphocytes and macrophages express CCR5 and CXCR4 [18-21], and while viruses that infect myeloid cells generally use CCR 5 as a co-receptor, this is not an absolute rule [13, 22, 23]. Use of CXCR4 is now generally associated with later stages of infection rather than a specific cell type [24]. Viral tropism is now defined by the co-receptor used for entry; $\mathrm{R} 5$ tropic viruses use CCR5, X4 tropic viruses use CXCR4, and viruses that can use either CCR5 or CXCR4 are known as dual-tropic viruses $[25,26]$. HIV may be able to use other chemokine receptors as co-receptors $[9,27]$, but most data indicate CCR5 and CXCR4 are the primary receptors mediating viral entry; therefore, these receptors are the focus of this review.

Much of the current research on CCR5 and CXCR4 focuses on their role as HIV co-receptors. However, both CXCR4 and CCR5 are also chemokine receptors, and their activation mediates complex signaling cascades that initiate a variety of other functions under both pathological and homeostatic conditions [28-30]. As members of the G-protein coupled receptor (GPCR) superfamily, CCR5 and CXCR4 translate ligand binding into intracellular signals through the activation of $G$ proteins. Canonically, both receptors were thought to signal through coupling to $G_{\alpha i}$ [30-33] but there is significant evidence that they also act through $G_{\alpha q}$ and through non- $G_{\alpha}$ protein pathways, including those initiated by $\mathrm{G}_{\beta \gamma}$ and $\beta$-arrestins $[29,34-36]$. There has been substantial research into the use of small molecule antagonists, endogenous chemokines and chemokine analogues, and blockade of co-receptor function as HIV therapeutics [37-41]. However, these efforts continue to be hindered by an incomplete understanding of how co-receptor signaling and specific co-receptor conformations contribute to viral infection. Blocking co-receptor activity affects many more processes than just HIV neuropathogenesis, and co-receptor inhibitors often have unwanted sideeffects in regard to disruption of homeostatic function [42, 43], further complicating the development of targeted therapeutics for these receptors. There is currently only one FDA-approved antiretroviral targeting an HIV co-receptor, the CCR5 inhibitor Maraviroc, and its efficacy often decreases with disease progression due to mutations that interfere with gp 120 binding to CCR5 [37, $44,45]$.

Despite these challenges, there is a critical need for novel drugs and strategies that target co-receptor signaling. This is particularly true in the context of neuroHIV, where the interaction of HIV virions with CCR5 and CXCR4 expressed on both myeloid and neuronal cell populations seems to play a role in persistent neuroinflammation and neuronal dysfunction [46-51]. Unfortunately, research into the mechanism(s) by which co-receptor signaling promotes the development of neuroHIV has slowed in recent years, in part owing to the complexity and contradictory data involved in the examination of GPCR signaling. The aim of this review is to reinvigorate this area of research by providing a comprehensive overview of co-receptor signaling and its role in HIV infection, with a specific focus on co-receptor signal transduction and how this influences viral entry, replication, and the pathogenesis of neuroHIV. We will then discuss how substance abuse, which is highly prevalent in the HIV-infected population, alters co-receptor signaling to promote neuropathogenesis. Finally, we will assess the new technologies and recent research in this area, describing the current state of therapeutics specifically targeting co-receptors, and discuss specific experimental questions that are particularly important to the ongoing development of therapeutics capitalizing on co-receptor signaling.

\section{HIV pathogenesis}

While the number of new HIV infections per year has declined since 2000, and people are now living longer with HIV, nearly 2 million new infections and 800,000 HIV-associated deaths still occurred in 2019 [1]. The reductions are due to the evolution of cART, first developed in the mid-1990's. Prior to cART, HIV infection led to uncontrolled viral replication, loss of CD4+T-cells and impaired immune function $[52,53]$. This left individuals susceptible to opportunistic infections and a rapid progression to AIDS, invariably resulting in death. The use of cART prevents this by suppressing viral replication, leading to a recovery in CD4+ T-cell levels and immune function, although it does not eliminate the virus $[52,54,55]$. Additionally, evidence suggests that 
viral replication is incompletely suppressed in the CNS [56-60]. Thus, cART is not a cure, although it does dramatically lengthen the quality and quantity of life for chronically HIV infected individuals [3, 54, 55, 61]. Further, the use of cART has also created new health issues, as PLWH suffer from a variety of new comorbidities associated with chronic infection and long-term therapy [62-66].

These comorbidities result from HIV infection and associated inflammation in organs throughout the body. HIV primarily infects CD4+ T-cells and myeloid lineage cells including monocytes and tissue specific macrophages such as microglia and alveolar macrophages $[52,53,67,68]$. In addition to co-receptors, viral entry requires the CD4 receptor, which is bound by the HIV envelope protein, a dimer of trimers comprised of a trimer of heavily glycosylated gp120 proteins and a connected trimer of gp41 proteins $[69,70]$. The interaction between a host $\mathrm{CD} 4$ receptor and a gp120 trimer on the external surface of the viral membrane induces a conformational shift in the envelope protein. This exposes further binding sites, allowing gp120 to bind to the viral co-receptors CXCR4 or CCR5 [71, 72], inducing a further conformational shift which causes the trimeric gp41 to "spring out" and insert itself into the host-cell membrane $[73,74]$. This initiates membrane fusion, merging the host and viral membranes and enabling the viral capsid, which contains the viral RNA genome and viral proteins such as reverse transcriptase and integrase, to enter the cell $[69,70]$.

Following entry, the viral capsid undergoes remodeling by host proteins in a process called uncoating, and the viral reverse transcriptase enzyme converts the HIV RNA into proviral DNA, although the precise order of these operations is still not completely clear [75]. There is some debate as to whether the capsid is completely disassembled or remains intact, though more recent evidence supports the latter hypothesis [76-78]. Following uncoating and reverse transcription, the newly generated proviral DNA and additional viral proteins such as reverse transcriptase, Vpr, matrix and integrase proteins, is incorporated into a pre-integration complex made up of a number of cellular proteins as well as the capsid core $[76,79]$. This complex then is then transported through a nuclear pore complex into the nucleus, where the viral integrase enzyme then incorporates the proviral DNA into the host genome [79]. In the nucleus, host transcriptional machinery transcribes the viral DNA into mRNA, which is spliced, exported and translated into the early proteins Tat and Rev. These proteins regulate further HIV gene expression, with the Tat protein facilitating transcription elongation and the generation of full-length viral RNA, while the Rev protein facilitates the export of unspliced and incompletely spliced viral mRNA into the cytoplasm to generate the viral polyproteins and accessory proteins [80]. Following translation, individual Gag proteins as well as Gag polyproteins traffic to the plasma membrane where they mediate the essential events in virion assembly within specialized membrane microdomains. During this process, viral envelope proteins are concentrated at the assembly site, the spherical particle is assembled through protein-protein interactions and viral RNA is packaged into the assembling virion [81-83]. In T-cells, this occurs on the inner surface of the plasma membrane, while in macrophages and other myeloid cells it takes place on the surface of internal, plasma membrane connected compartments [84-86]. The viral proteins and viral RNA are incorporated into an immature viral particle that buds off from the membrane $[81,82]$. After budding, the viral protease cleaves the viral polyproteins, and the gag proteins assemble into a capsid containing the viral RNA and proteins, forming a mature, infectious virion, which can spread the virus to other cells $[81,82]$.

\section{NeuroHIV}

Neurological symptoms associated with HIV infection have existed since the start of the epidemic $[87,88]$, and still affect $20-50 \%$ of the infected population despite cART $[3,63,89,90]$. The presentation and severity of these issues has changed with cART, but infected individuals still suffer from a spectrum of neuropathologic, cognitive, motor, and behavioral sequelae known as HIVassociated neurocognitive disorders (HAND) or neuroHIV [63, 91, 92]. NeuroHIV is initiated by HIV entry into the central nervous system, which occurs rapidly after initial infection $[88,93,94]$. There are several proposed mechanisms by which HIV is thought to enter the brain, but the most widely accepted is the "trojan horse hypothesis" [95], which suggests HIV enters the CNS within infected $\mathrm{CD} 14^{+} / \mathrm{CD} 16^{+}$monocytes, and possibly infected $\mathrm{CD} 4+\mathrm{T}$-cells, which transmigrate across the blood-brain barrier (BBB) and release virus into the CNS [93, 96-100]. In the brain, HIV targets primarily myeloid lineage cells such as microglia and different populations of CNS macrophages [67, 101, 102]. These infected cells drive the development of neuroHIV through production of new virions as well as the elaboration of inflammatory factors such as cytokines and viral proteins [101-103]. The inflammatory and neurotoxic milieu created by these factors has been proposed to drive neuronal dysfunction and synaptic injury, which in turn is thought to contribute to cognitive deficits observed in patients $[47,48,104-$ 108]. In addition to myeloid cells, studies also suggest astrocytes may be infected with HIV at low levels [109111]. It is not clear if astrocyte infection is productive 
and/or if these cells substantially contribute to viral replication, and there is some controversy as to whether they are infected at all [112-115]. Although central to the development of neurological symptoms, neurons are not infected by HIV $[67,116]$ and neuronal dysfunction is thought to be initiated by the inflammatory mediators secreted by other infected and activated cells [3].

Prior to cART, HIV-associated neuropathology was characterized by the formation of multinucleated giant cells, presence of microglial nodules, infiltration of lymphocytes, activated CNS macrophages, and neuronal loss $[87,107,117-120]$. These effects were particularly prominent in dopamine-rich brain regions, specifically in the substantia nigra, prefrontal cortex (PFC) and striatal substructures including the caudate nucleus, putamen, and nucleus accumbens [57, 66, 87, 121-125]. Severe behavioral and cognitive symptoms were common [118, 120, 126], and some studies found HIV encephalitis (HIVE) in more than $50 \%$ of infected individuals $[119,127]$. Viral proteins, including gp120, were observed in the brains of patients, particularly those with HIVE [46, 128, 129], suggesting a neurotoxic role of gp120. A number of studies additionally found CSF viral loads correlated with neurological dysfunction [130-132], further suggesting a link between viral persistence and neuroHIV. With the use of cART, HIVE has almost disappeared, and the symptoms of neuroHIV tend to be subtler, with gradual, non-linear growth over time $[3,126,133]$. NeuroHIV remains prevalent in cART treated individuals despite the suppression of viral replication $[90,104]$, but the presentation has shifted and overt neuronal loss is no longer readily observed [133]. Instead, PLWH present with hippocampal and cortical changes in synaptic number, reduced frontostriatal connectivity, increases in myeloid cell activation and accumulation of infected myeloid cells, neuroinflammation, oxidative stress, and white matter abnormalities [134-139]. This suggests the etiology of this disease is not solely derived from active viral replication [140-142], although HIV entry into and spread within the CNS is essential to the initiation of neuroHIV.

Current data indicate chronic neuroinflammation is a key factor in neuropathogenesis in cART-treated individuals [138, 143-145], likely resulting from interactions between host CNS cells and the infected cells comprising a stable reservoir of HIV in the brain [146-148]. A number of studies have found markers of immune activation in the plasma $[149,150]$, CSF [145, $151,152]$, and post-mortem brain tissue [142] of cARTtreated individuals, even in the absence of detectible virus. Additionally, markers of neuronal injury, including alterations in dendritic spine length and density [106, 153-155], subcortical atrophy [135, 156, 157], and changes in metabolites like $\mathrm{N}$-acetylaspartate $[139,158$,
159] are observed, and associated with impaired neurocognition [104-106]. These changes are thought to occur through two distinct, but not mutually exclusive, mechanisms. The direct injury hypothesis suggests that shed viral proteins, including gp120, directly promote neurotoxicity by binding to both CXCR4 and CCR5 on neurons. The bystander effect theory proposes that neuronal injury is caused by the secretion of neuroinflammatory mediators, such as inflammatory cytokines and chemokines, by infected and activated macrophages and microglia [160]. There is substantial debate within the field about these processes, particularly regarding the role of viral proteins in directly promoting neurotoxicity. While in vitro and in vivo rodent studies demonstrate neurotoxic effects of individual viral proteins $[49,106,128,161-171]$, it is not clear whether the concentrations of these proteins produced during cARTtreated infection mediate similar effects in the human CNS [172]. Therefore, the source of gp120-mediated coreceptor activity in the CNS in PLWH on cART is not clear and is likely to be the gp 120 found on intact virions, rather than shed gp120. Thus, much of the discussion below applies to co-receptors activated through interactions with virions during the process of attachment and entry.

Studies indicate that CNS viral infection is incompletely suppressed by cART, suggesting that neuronal injury and inflammation associated with co-receptor signaling in cART-treated individuals may be due to intact virions. HIV RNA is detectable in the CSF and CNS of cART treated populations, indicating the persistence of viral replication [56-60], although it is not clear if this is directly associated with worsening pathology $[56,60,173]$. This viral persistence may be due to a CNS viral reservoir, likely established well before cART is initiated [174]. These reservoirs are thought to be predominantly composed of myeloid cells, namely perivascular macrophages and microglia, which are long-lived, non-dividing and resistant to HIV-induced apoptosis [96, 175-177]. Due to these properties, as well as the poor CNS penetration of many antiretrovirals [178-181], CNS reservoirs are unaffected by a number of antiretroviral drugs [182], and can produce virus long after initial infection [177]. Given that the interaction of HIV virions with CXCR4 and CCR5 can drive signaling pathways that can directly lead to neuroinflammation and activation of other myeloid populations, it is possible that many of the long-term effects may be due to the activation of coreceptors by viral particles. Taken with the central role for CXCR4 and CCR5 in the spread of the HIV infection throughout the CNS, these co-receptors and the signal transduction processes associated with them make attractive targets for antiretroviral therapeutics targeting 
both the spread of infection and the development of neuropathogenesis.

\section{Chemokine receptors}

Both CCR5 and CXCR4 are G-protein coupled, 7-transmembrane receptors (GPCR) that belong to a family of 20 proteins known as chemokine receptors. These receptors are expressed on a wide range of cell types and are classified into four subgroups depending on which subfamilies of chemokines they bind: $\mathrm{CXC}, \mathrm{CC}, \mathrm{XC}$, and $\mathrm{CX}_{3} \mathrm{C}$ receptors $[28,30,183]$. While chemokines are known to act as chemoattractants, chemokine receptor activation also mediates a broad array of physiological processes, including cell migration, cytoskeletal rearrangement, cell survival, and inflammation [28, 184]. These receptors are often upregulated in response to tissue damage or in diseases such as cancer and HIV, attracting immune cells to respond to the damage or insult $[30,185,186]$. While many different chemokines and chemokine receptors play a role in HIV neuropathogenesis [183, 187, 188], CCR5 and CXCR4 are considered the major co-receptors used by HIV-1 strains and are thought to mediate many of the resulting chemokine responses [189, 190], making them appealing targets for antiretroviral development.

Like other GPCRs, chemokine receptors transmit signals resulting from ligand binding via an associated complex of three distinct $G$-proteins; $G_{\alpha}, G_{\beta}$, and $G_{\gamma}$ subunits [191]. In the inactive state, GPCRs are coupled to a trimer of these G-proteins, one of each type. Ligand binding initiates a conformational shift in the GPCR, activating the $G_{\alpha}$ subunit by exchanging a bound guanine diphosphate (GDP) for a guanine triphosphate (GTP). This causes the $G_{\alpha}$ subunit to dissociate from the receptor to initiate distinct downstream signaling cascades [192]. There are four distinct subtypes of $G_{\alpha}$ proteins: $G_{\alpha s}, G_{\alpha i}, G_{\alpha q}$, and $G_{\alpha 12 / 13}$, each associated with distinct signaling cascades, though distinct G-proteins can activate the same downstream effectors or have overlapping functions [191]. The signal transduction pathways initiated by $G_{\alpha}$ proteins are more frequently studied, but $G_{\beta}$ and $G_{\gamma}$ subunits, which form an obligate dimer $\left(G_{\beta \gamma}\right)$, can also activate several signaling mechanisms [193-195]. There are also several G-protein independent signaling cascades, which vary with chemokine receptor, cell type and effector [196, 197]. These G-protein independent pathways are mediated by $\beta$-arrestins 1 and 2 , which can serve as scaffolds for downstream signaling molecules [196, 198-200]. This often involves the recruitment of Src kinases [199, 201], which are also activated by $G_{\alpha i}$ signaling [202], and can lead to downstream activation of mitogen activated protein kinase (MAPK) signaling pathways [203-205] as well as the PI3 kinase (PI3K) signaling pathway $[199,206]$.
Chemokine receptor signal transduction is also regulated by blocking receptor signaling. This involves GPCR kinases (GRKs) phosphorylating several different residues on the active carboxyl terminus of the GPCR, recruiting $\beta$-arrestins $[207,208]$. Following their recruitment, $\beta$-arrestins carry out two main functions. First, they occlude the G-protein binding site on the chemokine receptor, blocking signaling and desensitizing the receptor $[208,209]$. Next, $\beta$-arrestins can recruit the cellular machinery required for clathrin-mediated internalization, initiating either receptor recycling $[209,210]$ or lysosomal degradation of the receptor [211]. Some studies suggest that the strength of the interaction between the arrestin and the receptor regulates this choice, with weaker interactions resulting in degradation and stronger interactions leading to receptor recycling [212]. Irrespective of the precise mechanism, GRK/ $\beta$-arrestin-mediated desensitization and internalization works in conjunction with ligand stimulation to mediate chemokine receptor signaling.

The primary function of chemokine receptors is to mediate cell migration, and much of the signaling originating from these receptors promotes cell movement. Classically, these receptors couple to $G_{\alpha i}[4,31,36$, 213-215]. Activation of this G protein inhibits adenylate cyclase, decreasing cyclic AMP (cAMP) production [29, $35,215-217] . G_{\alpha i}$ can also activate Src and Lyn kinases [202, 218, 219], which in turn activate the small GTPases Ras and/or Raf resulting in MEK and ERK phosphorylation [220-222] and leading to chemotaxis [223-228]. Release of the $\mathrm{G}_{\beta \gamma}$ subunits can also stimulate cell movement [195, 228, 229], activating PI3K and the serine/ threonine kinase AKT [224, 230]; the GTPases Rac and Rho [231]; or phospholipase C- $\beta$ (PLC $\beta$ ) [232, 233], which hydrolyzes phosphatidylinositol 4,5-bisphosphate $\left(\mathrm{PIP}_{2}\right)$ to diacylglycerol (DAG) and inositol triphosphate $\left(\mathrm{IP}_{3}\right)$, initiating intracellular calcium $\left(\mathrm{Ca}^{2+}\right)$ release from the endoplasmic reticulum as well as activation of protein kinase C (PKC). Several of these cascades, including activation of PI3K and AKT $[199,206]$, or Src and ERK1/2 [203-205], can also be triggered by recruitment of $\beta$-arrestins and are associated with a number of downstream functions, including chemotaxis and apoptosis [196, 198-200].

These are just some of the vast network of signaling pathways associated with chemokine receptor activation, and both CCR 5 and CXCR4 have a number of important pathways specifically associated with their activity. The complexity of these and other signaling networks initiated by co-receptor binding is often amplified by the use of different types of cell systems. The use of different types of cells has enabled more precise interrogation of specific signaling processes, but it has also led to 
confusing and contradictory data, as co-receptors in distinct cell types often show different responses to similar stimuli. This is particularly problematic when comparing transfected cells and cell lines to primary cells and in vivo systems, as it can create confusion about the physiologically relevant actions of co-receptors during disease. These signaling processes, their downstream effects and the caveats associated with their study are discussed below, and those involved in HIV pathogenesis are described in detail in the subsequent section. Further discussion on the functions and pathways activated by chemokine receptor signaling can be found in additional reviews [29, 34, 234-236].

\section{CCR5}

The CCR5 receptor was first identified as a human monocyte chemokine receptor in 1996, following the discovery of its primary ligands CCL3 (MIP1 $\alpha)$, CCL4 (MIP1 $\beta$ ), and CCL5 (RANTES) [4-6, 237]. Only CCL4 binds exclusively to CCR5, with CCL3 also binding to CCR1 and CCL5 acting as a ligand for both CCR1 and CCR3 $[28,238]$. Several other ligands including CCL2 (MCP1), CCL7 (MCP-3), CCL8 (MCP-2), CCL13 (MCP-4) and CCL11 (eotaxin), have shown some affinity for CCR5 in vitro in binding studies or competition assays [237], but the in vivo relevance of these interactions is unclear [37, 186]. CCR5 is expressed on a number of cell types, including macrophages [18, 239], microglia [18, 240], T-cells $[18,20,21]$, and numerous other immune cells $[18]$ as well as astrocytes $[114,240]$ and neurons $[49,185$, 241].

Under homeostatic conditions, chemokine signaling through CCR5 is associated with numerous physiological processes including leukocyte migration [218, 223, 242-244], regulation of inflammation through cytokine and chemokine release [245, 246], and the activation of cell survival pathways [219]. These functions are thought to be particularly important in the context of viral infection or cellular injury. For example, CCR5 is upregulated during inflammation on $\mathrm{CD} 8+\mathrm{T}$-cells, promoting the migration of these cells towards the site of infection and thereby increasing the likelihood of encountering antigen specific cells to enhance the adaptive immune response [247]. This receptor may also play a role in the recruitment of immune cells to the CNS [248], the formation of atherosclerotic plaques [186], and tumor cell migration and survival $[249,250]$. These effects require a number of intracellular signaling cascades, some of which may be distinct to CCR 5 activation by specific ligands, such as CCL5 [35, 251].

Due to its broad influence, CCR5 signaling is tightly regulated by several processes, generally triggered by phosphorylation of serine residues on its $\mathrm{C}$-terminus and the Asp-Arg-Tyr (DRY) motif leading to GRK/arrestin mediated receptor desensitization and internalization [34, 252]. The early steps of CCR5 desensitization are similar to that of other chemokine receptors and involve C-terminal phosphorylation, recruitment of $\beta$-arrestins, and clathrin-dependent endocytosis [34, 207, 253]. Upon internalization, CCR5 is directed through the endosomal recycling compartment to the trans-golgi network (TGN), where it is then recycled back to the cell surface upon resensitization [254, 255]. Importantly, different ligands can induce different fates for CCR 5 once it is internalized. Some, like the chemokine analogues PSC-RANTES and AOP-RANTES, promote sequestration of CCR5 in the endosome recycling compartment or TGN $[254,256,257]$, while others, like the physiological ligand CCL5, induce recycling back to the cell surface $[255,258]$. This appears to be due to the ability of these ligands to alter the structure of the intracellular CCR5 loops via GRK recruitment and/or binding of different $\beta$-arrestins [256, 259]. Given that the sequestration of CCR5 is a promising method of blocking viral entry [38, $212,258,260-263]$, further examination of the processes mediating CCR5 desensitization and recycling may have important implications for HIV infection and potential antiretroviral activity.

\section{CCR5 signaling}

The CCR5 receptor can signal through several distinct G-protein mediated pathways. Signaling through $G_{\alpha i}$ inhibits the activation of adenylate cyclase, regulating the production of cAMP $[35,215,216,251]$ and MAPKs [191, 221, 264], and functions such as T-cell proliferation and chemotaxis [34, 214, 230, 265-267]. Signaling through $G_{\alpha i}$ can be influenced by the formation of oligomers, changing the responses to select ligands [268]. For example, in HEK293 cells co-transfected with CCR5 and/or CCR2, the $G_{\alpha i}$ inhibitor pertussis toxin (PTX) block CCL5-induced $\mathrm{Ca}^{2+}$ release in cells expressing only CCR5, but not in cells co-expressing CCR5 and CCR2 and treated with CCL2 and CCL5 [268]. Homodimerization or dimerization with either CCR2 or CXCR4 may also prevent gp120 binding [244, 269, 270], although whether this has any in vivo relevance is unclear.

However, several CCR5 signaling pathways are insensitive to pertussis toxin, indicating the involvement of alternative G-proteins and/or G-protein independent signaling mechanisms [271-273]. Much CCR5initiated signal transduction can also occur through intracellular $\mathrm{Ca}^{2+}$ release and PLC $\beta$ activation, which can be mediated by $G_{\beta \gamma}[32,215,219,232,233,242$, 274]. Moreover, many studies rely solely on pertussis toxin, which may have $G_{\alpha i}$-independent effects via its B-oligomer [32, 275], or do not make use of specific 
G-protein inhibitors, making it is difficult to define the specific G-proteins initiating each pathway. Further, while not specific to CCR5, studies have suggested that the release of $G_{\beta \gamma}$, rather than $G_{\alpha i}$ is essential for chemotaxis mediated by $G_{\alpha i}$-coupled receptors [195, 229]. Both the PLC $\beta$ and PI3K signaling cascades mediate the chemotactic response to CCR 5 binding by activating a number of Ser/Thr protein kinases, particularly members of the PAK and FAK families, in macrophages [230, 242, 273, 276] and T-lymphocytes [213, 214, 276]. Signaling via the PLC $\beta$ signaling cascade also activates MAPKs [221, 267], which is associated with the production of inflammatory mediators [31, 267, 277] and chemotactic responses [223, 278, 279]. Activation of PI3K is specifically required for CCL5 mediated chemotaxis in macrophages and T-lymphocytes and cytoskeletal rearrangement induced by Rho GTPases [230, 242, 280], and can also activate AKT and MAPK signaling [221, 267]. These data demonstrate the importance of PLC $\beta$ and PI3K in CCR5-chemokine signaling, suggesting the release of $\mathrm{G}_{\beta \gamma}$ may be more critical in mediating the effects of CCR5 than $G_{\alpha i}$.

CCR5 may also couple to $G_{\alpha q}$, which can also initiate $\mathrm{IP}_{3}$-mediated intracellular $\mathrm{Ca}^{2+}$ release $[36,215,251$, 281]. A recent study showed that both CCL4 and CCL5 could initiate $\mathrm{Ca}^{2+}$ flux in HEK.CCR5 cells, and this was inhibited by the $G_{\alpha q}$ inhibitor $Y M-254,890$ [215]. The physiological relevance and extent of $G_{\alpha q}$-specific CCR5 signaling is unclear, due to the extensive overlap between $G_{\beta \gamma}$ and $G_{\alpha q}$ signaling. However, the centrality of $\mathrm{G}_{\beta \gamma}$-mediated PI3K signaling to chemotaxis suggests CCR5 mainly acts through $G_{\alpha i}$ and $G_{\beta \gamma}$ in response to physiological ligands [195, 229]. In addition, the binding of HIV gp120 may push CCR5 towards $G_{\alpha q}$ signaling, as siRNA against $\mathrm{G}_{\alpha \mathrm{q}}$, but not $\mathrm{G}_{\alpha \mathrm{i}}$, prevented CCR5-mediated changes in viral fusion [281] and gp120 induces several $G_{\alpha i}$ independent signaling effects [273, 282-285].

In addition to $G_{\alpha i}, G_{\alpha q}$, and $G_{\beta \gamma}$ signaling, several signaling processes may be independent of G-protein activity. Stimulation of CCR 5 by either CCL2, CCL3, or CCL5 leads to activation of janus kinases 1 and 2 (JAKs) [214, $271,272]$, and activation of JAK2 was insensitive to both pertussis toxin and U73122, an inhibitor of PLC $\beta$ [272]. This suggests JAK2 activation is mediated via G-protein independent mechanisms, potentially through a direct JAK-CCR5 interaction, which can lead to the phosphorylation and dimerization of the receptor. Activation of the PI3K/AKT signaling could also be initiated by G-protein independent signaling through $\beta$-arrestins, as CCL4 stimulates macrophage chemotaxis by inducing the formation of a $\beta$-arrestin signaling complex comprised of PI3K, Pyk2 and Lyn, leading to downstream ERK activation [218].
The responses to CCR5 binding are mediated by a number of effectors, including but not limited to MAPKs [219, 223, 271, 273, 276, 277, 282, 286], signal transducer and activator of transcription (STAT) proteins [214, 272, 287], AMP-activated protein kinases (AMPKs) [242], and small GTPases (Rac, Rho) [266] or FAKs like Pyk2 [213, 243, 272, 273, 276, 282], which play a critical role in chemokine-mediated cellular migration in both lymphocytes and macrophages [223, 230, 243, 266, 276]. Many of these effectors are activated by one or more endogenous CCR5 ligands, such as the phosphorylation of the MAPK ERK $1 / 2$ by both CCL3 and CCL4 [223]. Multiple overlapping pathways are linked to MAPK signaling, including the release of pro-inflammatory chemokines, cell survival, cell death, the activation of STATs, and the activation of matrix metalloproteinases (MMPs) [279, 288, 289]. For example, induction of CCL5 in response to influenza infection leads to $G_{\alpha i}$-mediated activation of both the MEK/ERK and PI3K/AKT signaling cascades, reducing apoptosis in mouse macrophages [219]. Stimulation with CCL5 also leads to $\mathrm{Ca}^{2+}$ mobilization and the activation of JAK1/STAT5, triggering cell polarization and migration. However, this did not occur with AOP-RANTES, a synthetic CCL5 derivative that can also bind to CCR5 but does not induce chemotaxis [261, 290], due to differences in the length of $G_{\alpha i}$-association and subsequent release of $\mathrm{G}_{\beta \gamma}$ [214]. Many of these pathways may also be regulated by PI3K and PLC $\beta$ activity. For example, both of these proteins were necessary to promote CCL5-mediated chemotaxis through AMPK in RAW264.7 rodent macrophages [242]. This demonstrates that activation of CCR 5 by a single ligand can simultaneously activate several different G-proteins and downstream pathways, regulating multiple cellular functions, a commonality among GPCRs. Indeed, CCR5-mediated activation of JAK/STAT pathways may play a role in T-cell activation and proliferation, although it is unclear whether this is solely due to CCR 5 or a combination of CCR receptors, including CCR2 [34, 268, 271, 287, 291]. These data show that CCR5 can initiate signaling through both G-protein dependent and independent pathways and demonstrate the substantial overlap between CCR5 signaling cascades activated by distinct G-proteins (Fig. 1A). These overlaps, combined with the likelihood that the coupling of CCR5 to certain G-proteins and pathways may be different in distinct cell types and species, shows the challenges involved in defining how the specific ligands activate certain signaling pathways and highlights an important area for future studies.

\section{Conformation mediated changes in CCR5 signaling}

In addition to complications due to overlapping pathways and distinct effects in different cell types [214, 

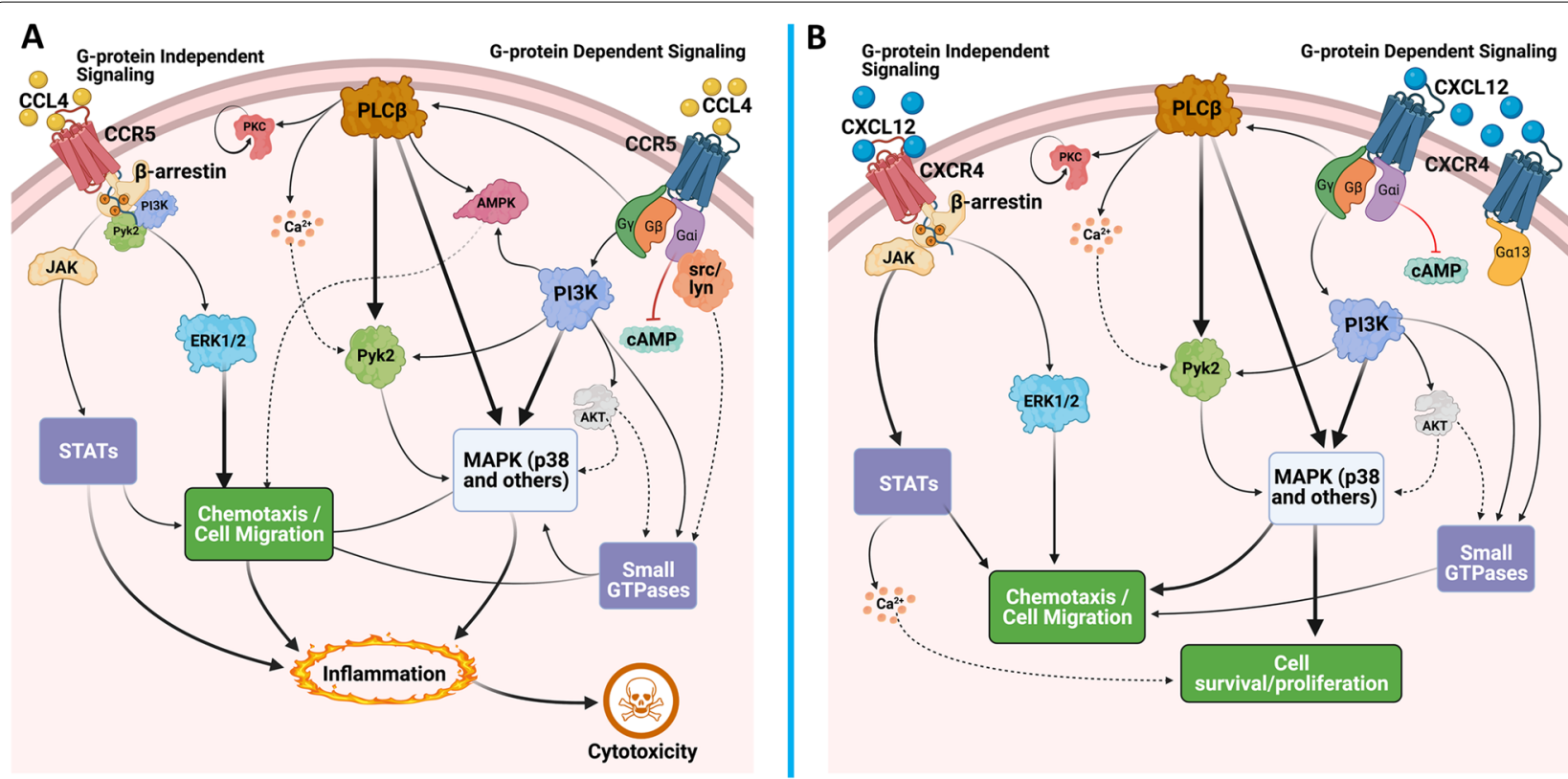

Fig. 1 Chemokine signaling through CCR5 and CXCR4. Both CCR5 and CXCR4 can signal through a multitude of pathways, only some of which are represented here. $\mathbf{A}$ In response to its cognate ligands CCL3, CCL4, and CCL5 (CCL4 shown as a representative ligand), CCR5 can signal through a variety of $\mathrm{G}$-protein dependent and independent pathways. These signaling processes broadly modulate chemotaxis and inflammation. While CCR5 acts through $G_{a i} G_{a q}$ (not shown) and $G_{\beta \gamma}$, the $G_{\beta \gamma}$ subunit may regulate the majority of downstream signaling, including PLC $\beta$ activation, PI3K activation, and the downstream activation of AMPKs and MAPKs, particularly p38 MAPK. $G_{a i}$ can also interact with Src family kinases, leading to the activation of MAPKs via small GTPase activation, which in turn regulates the chemotactic effects of this receptor. Independent of $G$ proteins, CCR5 signaling can also be mediated through interaction with $\beta$-arrestins and the JAK family, activating ERK1/2 and STAT respectively. B CXCR4 signaling is also mediated through $\mathrm{G}_{\mathrm{ai}}$ and $\mathrm{G}_{\beta \gamma^{\prime}}$ and in certain contexts $\mathrm{CXCR4}$ can also couple to $\mathrm{G}_{\alpha 13}$. In addition to regulating chemotaxis, $\mathrm{CXCR4}$ signaling also has significant effects on cell survival and proliferation. As with CCR5, PI3K and MAPK activation are central to these signaling pathways and are largely responsible for mediating the effects of CXCL12-CXCR4. The similarities in the signaling pathways between these two receptors highlight how the same effectors can regulate vastly different physiological effects, demonstrating the complexity of studying chemokine receptor signaling. Solid arrows represent defined, published pathways while dashed arrows represent pathways that have not been directly demonstrated but are likely to occur based on the current understanding of GPCR signaling

271, 272], analysis of CCR5 signaling is complicated by the existence of conformationally heterogenous populations of CCR5 on the cell surface [257, 292-294]. The conformational differences center on the degree of exposure of binding sites in the N-terminal (NT) and second extracellular loop (ECL2) regions [40, 292], and the interaction of the N-terminus with the transmembrane helix bundles [34, 295]. These differences seem to have a broad impact on receptor function, changing the affinity for different ligands, the coupling to specific G-proteins and the functional potency of $2^{\text {nd }}$ messenger induction [215, 257, 294, 296, 297]. In CCR5 transfected L1.2 lymphocytes, antibodies against the ECL2 region of CCR5 efficiently blocked the binding and functional response of CCL3, CCL4, and CCL5, whereas an antibody against the $\mathrm{N}$-terminal region blocked only CCL4 binding and signaling, not CCL5 [292, 298]. Moreover, an CCR5 antibody mapped to multiple ECL domains was able to increase $G_{\alpha i}$-associated GTPYS binding, but not $\mathrm{Ca}^{2+}$ flux, suggesting stabilization of specific conformations of CCR5 is associated with distinct signaling cascades [292].

Other studies show differences in the $\beta$-arrestin mediated internalization of specific CCR5 populations, suggesting subpopulations of CCR5 conformations may be resistant to chemokine-induced internalization in macrophages, but not T-cells [299]. This is consistent with studies showing subpopulations of CCR5 may differ between cell types $[257,300]$. These differences may involve changes in receptor occupancy based on the ability of different ligands to bind to distinct CCR 5 conformations [215]. Notably, natural chemokines only bind to a few distinct conformations, but gp120 may interact with a much wider number of CCR5 populations, potentially due to the interaction of the flexible $\mathrm{V} 3$ region of gp120 with the N-terminus of CCR5 [215, 257, 293, $300,301]$. Indeed, changes in the exposure of the NT or ECL2 regions can increase the binding affinity for specific sequences in CCR5 tropic viral envelopes [300], likely playing a role in the maintenance of gp120-CCR5 
binding in the presence of natural ligands and some antagonists. Thus, defining not only the CCR5 signaling pathways, but the shifts in ligand binding and signaling associated with those structural changes, could initiate or enhance the development of a number of novel antiretroviral effectors [40, 293, 301, 302].

\section{CXCR4}

The CXCR4 receptor was first identified on peripheral blood lymphocytes in 1994 [7] and is highly expressed in a variety of cell types including lymphocytes, hematopoietic stem cells, neural cells, and stromal fibroblasts [30]. Expression of CXCR4 is relatively low on myeloid cells such as macrophages and microglia [303]. The primary ligand for CXCR4 is the chemokine CXCL12 (SDF-1), which is ubiquitously expressed in both embryonic and adult tissues, including liver, pancreas, spleen, brain, and heart [304]. The CXCL12/CXCR4 signaling axis was long considered monogamous until 2007 when it was discovered that macrophage migration inhibitory factor (MIF) was an alternative ligand for CXCR4 [305]. Additionally, both pharmacologic antagonism and knockdown studies have shown that extracellular ubiquitin (eUb), is also a natural ligand for CXCR4 [306].

In adults, CXCL12-CXCR4 binding promotes the survival and trafficking of immune cells [307, 308]. During embryogenesis, CXCL12 is important for proliferation, migration, and differentiation of immature progenitors $[309,310]$. The CXCL12/CXCR4 signaling axis is also important in CNS homeostasis, where it regulates the migration of neural precursors [311, 312], establishment of neural circuitry [313, 314], modulation of NMDA subunit composition [315], and alterations in dendritic spine number and morphology [316, 317]. MIF also plays an important role in cell recruitment and arrest through binding to CXCR2 and CXCR4 [305], and can exert protective functions in liver fibrosis, myocardial ischemiareperfusion injury and in the developing cerebral cortex upon tissue damage [318]. In contrast to CXCL12, MIF is not associated with homeostatic function, but rather pro-inflammatory and pro-atherogenic activity [305, 319], and is considered an inflammatory cytokine [320]. Similar to other CXCR4 ligands, eUb can also mediate chemotaxis, but the chemotactic activity is weaker than induced by CXCL12 [321]. Furthermore, the interaction of eUb with CXCR4 is independent of the N-terminal receptor domain used by $\mathrm{CXC} 12$ and instead relies on binding sites in the $2^{\text {nd }}$ and $3^{\text {rd }}$ extracellular loop [321].

Like CCR5 and other GPCRs, CXCR4 signaling is regulated by desensitization (homologous and heterologous), internalization, and degradation. Direct activation of PKC by phorbol esters [322, 323], T or B cell receptor engagement [324, 325], CXCR1 activation [326], or CCR5 activation [327] are able to induce CXCR4 internalization. CXCR4 can recycle back to the plasma membrane following PKC-mediated internalization [322]; however, the receptor recycles poorly following CXCL12 stimulation [328]. CXCR4 has been shown to be ubiquitinated, sorted to the lysosome, and degraded [329], which is mediated by the E3 ubiquitin ligase AIP4 [330]. Targeting CXCR4 with specific agonists or molecules that promote the internalization and sequestration has not been as widely explored as for CCR5, owing in part to the physiological requirements for CXCR4 binding. However, there has been some progress in finding drugs that can induce signaling while preventing viral binding $[43,331]$.

\section{CXCR4 signaling}

Like CCR5 and other chemokine receptors, CXCR4 signals primarily through G-protein dependent pathways, primarily $G_{\alpha i}$ mediated inhibition in cAMP production. Recombinant overexpression systems, such as HEK293T and Sf9 cells show that CXCR4 can activate different $G_{\alpha i}$ proteins, including $G_{\alpha i 1}, G_{\alpha i 2}, G_{\alpha i 3}$, and $G_{\alpha o}$ in response to CXCL12 stimulation [332], although it seems that CXCR4 couples more efficiently to the $G_{\text {oi1 }}$ and $G_{\alpha i 2}$ rather than $G_{\alpha i 3}$ and $G_{\alpha o}[333,334]$. Activation of CXCR4 coupled to $G_{\alpha i}$ triggers activation of MAPK and PI3K pathways [335], mediating effects on migration [336-338] as well as cell survival and proliferation [313, 339]. CXCR4 can also act through other $G$ proteins, such as the noncognate $G$ protein $G_{\alpha 13}$ [340] or $G_{\alpha q}[341,342]$, although this may be context specific. CXCR4 only couples to $G_{\alpha q}$ in dendritic cells and granulocytes but not $T$ and $B$ cells [343], and coupling to $G_{\alpha 13}$ may have particular relevance in cancer, where $G_{\alpha 13}$ is overexpressed [344, 345]. As with CCR5, activation of CXCR4 coupled to $\mathrm{G}_{\alpha q}$ can induce $\mathrm{IP}_{3}$ mediated $\mathrm{Ca}^{2+}$ release through $\operatorname{PLC} \beta$ [341, 342]; this pathway can also be activated via the released $\mathrm{G}_{\beta \gamma}$ subunit $[235,346]$. Activation of CXCR4 coupled to $G_{\alpha 13}$ in Jurkat T cells mediates cell migration via activation of Rho [340], and also mediates CXCR4 trafficking into Rab11 + vesicles during CXCL12-induced endocytosis in T cells [347].

Like CCR5, CXCR4 can also signal through G protein independent mechanisms, such as $\beta$-arrestin-mediated signaling. Both $\beta$-arrestin- 1 and -2 enhance CXCR4mediated ERK activation [338], and $\beta$-arrestin-2 is involved in p38 activation and migration following CXCL12 stimulation [348]. Additionally, upon CXCL12 stimulation, CXCR4 can dimerize and become phosphorylated at intracellular tyrosines by rapid recruitment and activation of JAK2 and JAK3 [349]. This leads to STAT dimerization and activation of the STAT pathway, which is unaffected by pertussis toxin treatment [349]. The JAK/ STAT pathway leads to diverse cellular effects, including 
mobilization of $\mathrm{Ca}^{2+}$ from intracellular stores, and after its nuclear translocation, the transcription of several target genes [349]. Studies using a JAK-specific inhibitor have shown that in a T-lymphoblast cell line, the association of $G_{\alpha i}$ with CXCR4 is dependent on JAK, further supporting a co-dependent mechanism between members of the JAK/STAT pathway and G-protein coupled signaling [350] (Fig. 1B). Activation of the JAK/STAT pathway may also be affected by the oligomerization state of this receptor, as homodimerization of CXCR4 is necessary to elicit $G$ protein independent activation of JAK/STAT and enhance the response of CXCR4 to CXCL12 [349]. The heterodimerization/oligomerization of CXCR4 to other receptors may have a number of other potential effects on chemokine signaling responses as well, interfering with the binding to one receptor in the oligomer or altering its ability to interact with or signal through intracellular mediators [351]. This is exemplified by the potential ability of ACKR3 to interact with CXCR4 and affect CXCR4 trafficking and/or coupling to other proteins [352].

\section{HIV activation of co-receptors}

In the context of HIV infection, CCR5 and CXCR4 are primarily studied as co-receptors that interact with gp 120 to mediate efficient membrane fusion $[16,70]$. In addition to mediating viral entry, gp120 binding also activates CXCR4 and CCR5, but the signaling processes associated with this interaction remains poorly understood. Additionally, it remains unclear if co-receptor signaling is a requirement for efficient viral entry and replication. Early studies in primary CD4+T-cells, macrophages, and transformed $\mathrm{T}$-cell lines suggested that uncoupling CCR5 from $G_{\alpha i}$ signaling does not alter HIV entry [33, 353-357], but more recent data contradict these findings, showing a requirement for G-protein signaling for viral entry and fusion [281, 358-360], or even post-entry stages of infection [361-366]. At least one recent study also indicates that co-receptor binding by shed or recombinant gp120 provokes different responses than does binding by virus associated gp120 [364], suggesting that some of the difference between studies could be due to the type of gp120 used.

While many gp120 induced signaling processes overlap with those initiated by cognate ligands, there are a number of pathways in which the response, kinetics, G-proteins and downstream effectors involved differ from those activated by endogenous ligands. Indeed, relative to endogenous ligands, gp120-co-receptor interactions stimulate the expression of a substantial number of different genes [364, 367]. This section will focus on the most well documented signaling pathways, which are detailed in Fig. 2. In general, we will discuss the effects of gp120, reflecting both the fact that this is the major protein interacting with co-receptors on intact virions and that the literature in the field has historically relied on the use of monomeric gp120. While this provides more precise insight into specific co-receptor driven signaling processes, it is important to note that the concentrations of gp120 used in many of the following studies are unlikely to represent levels in cART-treated individuals. Further, the gp120 driving these processes in the CNS of cART-treated PLWH are likely to present on the virion surface in complex with gp41 and have a different structure than free gp120 [70,364], and may require interaction with CD4 [71, 74], even if the downstream signaling effects are driven solely by the co-receptors. However, while some studies suggest there may be some differences between the responses of shed gp120 and virus associated gp120 [364], many indicate that monomeric gp120 and virus-associated gp120 largely initiate the same signaling cascades [213, 264, 285, 365, 366, 368-370]. Therefore, we have focused on studies that use gp120 to show clearly defined roles for co-receptors, rather than CD4, in specific signaling mechanisms, to better define specific co-receptor driven signaling processes. Finally, given the extensive overlap between R5 and X4 signaling pathways, they will be discussed together, with specific differences pointed out when necessary.

\section{Calcium and ion channels}

$\mathrm{Ca}^{2+}$ flux is important to viral infection [281, 371, 372] and a number of studies have specifically examined the role of $\mathrm{Ca}^{2+}$ in HIV entry [281, 373]. In human monocyte derived macrophages (hMDM), both R5 and X4 gp120 can increase intracellular $\mathrm{Ca}^{2+}$, although the magnitude of the $\mathrm{Ca}^{2+}$ release elicited by X4 gp120 is less than that induced by R 5 gp120 [369, 374]. In microglia, this effect is not seen in response to gp41 [375], suggesting it may be exclusive to the gp120 portion of the envelope protein. The response in T-cells is less clear. Some data show that human $\mathrm{CD} 4+\mathrm{T}$-cells release $\mathrm{Ca}^{2+}$ in response to $\mathrm{X} 4$ but not $\mathrm{R} 5 \mathrm{gp} 120$, and that this is dependent on CD4 binding [369]. Other studies show that R5 gp160 from both HIV and SIV increases $\mathrm{Ca}^{2+}$ release, but this does not occur in response to X4-tropic envelope proteins [265, $361]$, although the differences may be due to the specific envelope proteins and cell types used. In cultured rat and human neurons, gp120 appears to directly disrupt neuronal $\mathrm{Ca}^{2+}$, via alteration of the $\left[\mathrm{Ca}^{2+}\right]_{\mathrm{I}}$ mediated by NMDARs [49, 161], $\mathrm{Ca}^{2+}$-gated and $\mathrm{Na}^{+}$-gated channels [376]. However, it is unclear whether interactions between gp120 and neuronal CXCR4 and CCR5 contribute to these rises in $\mathrm{Ca}^{2+}$, or if the signaling is mediated by interactions between HIV and co-receptors on 


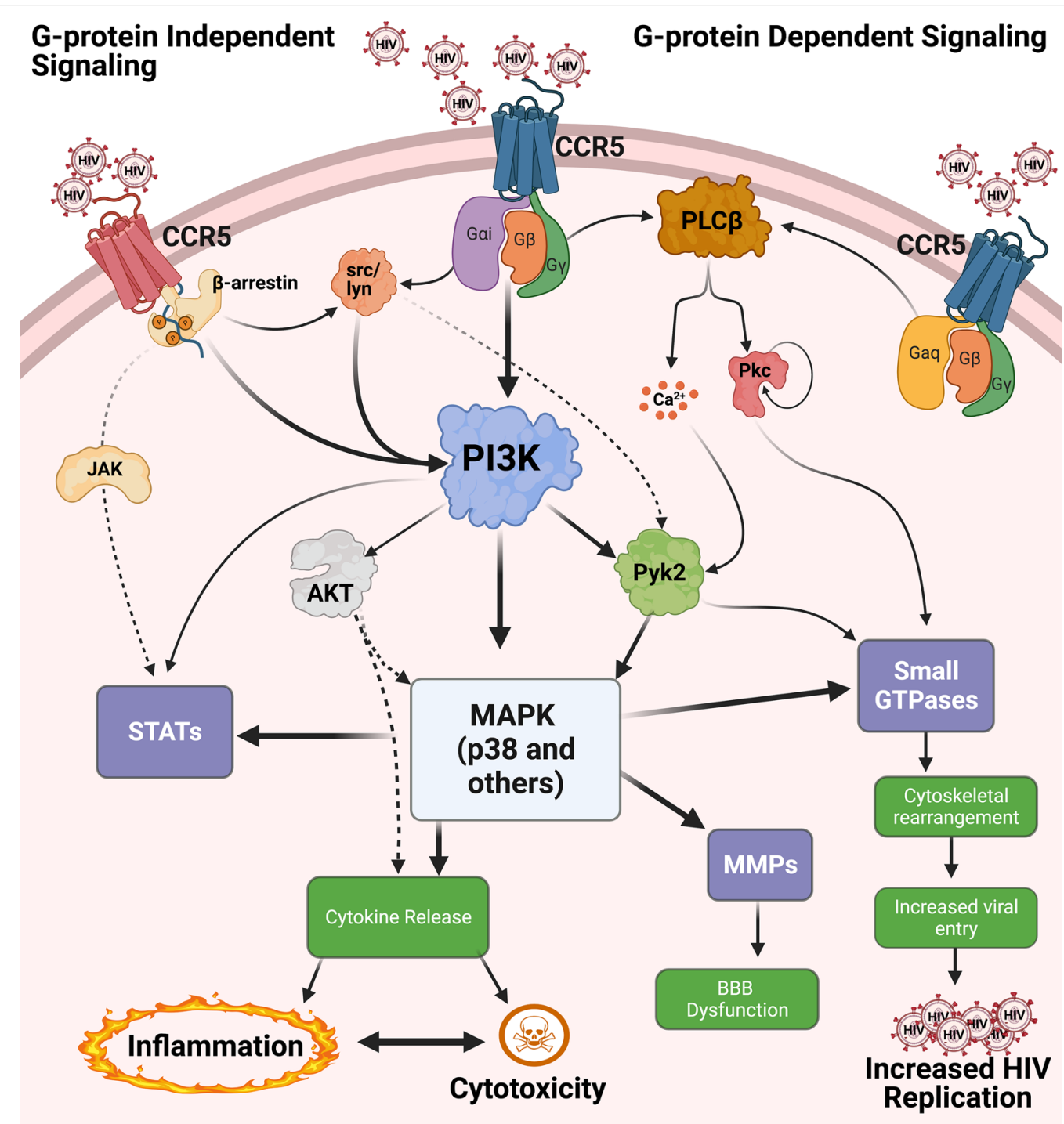

Fig. 2 Co-receptor signaling mediated by HIV envelope. The viral envelope glycoprotein gp120 can interact with both CCR5 and CXCR4 during the attachment and entry process, initiating both G-protein dependent and independent signaling. Pathways activated through CCR5-gp120 interactions are shown here as representatives. Activation of both $G_{a i}$ and $G_{a q}$ has been reported in response to gp120. Signaling through $G_{a q}$ mediates activation of PLC $\beta$, calcium release, and downstream activation of small GTPases, which are critical for viral entry, replication, and changes in actin dynamics. Signaling through $\mathrm{G}_{\beta \gamma}$ can also activate PLC $\beta$, as well as PI3K, both of which are linked to the activation of MAPKs. The most prominent MAPK shown to be involved in these processes is P38 MAPK, although other MAPK are also involved. The activation of MAPKs regulates a large number of downstream pathways, including but not limited to, the activation of STATS, activation of GTPases, the activation of MMPs, and the release of chemokines and cytokines. $G_{a i}$ and $G$-protein independent interactions with $\beta$-arrestins can also activate the Src family of kinases, which are also linked to PI3K and MAPK activation. Activation of all of these pathways can mediate a number of deleterious processes during HIV infection of the CNS, including neuroinflammation, blood-brain barrier dysfunction and increased migration of infected cells to the CNS, increased viral replication, and neurotoxicity. Many of these pathways overlap, meaning that gp120-coreceptor interactions can influence these pathogenic processes through several different, interacting pathways depending on the cell type and system in which they are being studied. Solid arrows represent defined, published pathways while dashed lines indicate pathways that have not been directly demonstrated, but are presumed to occur based on what is known in the literature

surrounding glial cells and/or co-receptor independent effects of gp120 [47, 48].

As $\mathrm{Ca}^{2+}$ is a prominent $2^{\text {nd }}$ messenger, it is not clear which specific $\mathrm{Ca}^{2+}$ activated pathways are associated with HIV entry. However, Harmon et. al. used human U87 astrocytes to show that blocking $G_{\alpha q}$-mediated $\mathrm{Ca}^{2+}$ flux by inhibiting ryanodine or $\mathrm{IP}_{3}$ receptors blocks cell-cell fusion [281]. Data from our lab show that the 
dopamine-mediated increase in HIV entry in hMDM requires dopamine-mediated $\mathrm{Ca}^{2+}$ release [373], supporting the importance of $\mathrm{Ca}^{2+}$ in the entry process. These data suggest that while the two types of gp120 have similar effects on $\mathrm{Ca}^{2+}$, the magnitude and therefore outcome of envelope mediated $\mathrm{Ca}^{2+}$ release is distinct between X4- and R5- tropic gp120.

G-protein coupled receptors are also associated with ion channel activity [374]. R5-gp120 can suppress the activity of the voltage gated $\mathrm{K}^{+}$channel BEC1 in $293 \mathrm{~T}$ cells [377] and X4-tropic envelope can increase the phosphorylation of Kv1.3 channels and induce membrane depolarization in T-cell lines [378]. In human macrophages, $\mathrm{X} 4$ and $\mathrm{R} 5$ gp120 can elicit $\mathrm{Ca}^{2+}$-activated $\mathrm{K}^{+}$ currents, $\mathrm{Cl}^{-}$currents, and $\mathrm{Ca}^{2+}$-permeant nonselective cation currents, which are blocked by the specific CXCR4 antagonist, AMD3100, or in cells from donors homozygous for the CCR5- $\Delta 32$ mutation, respectively $[374,379]$. This indicates that currents through this channel were mediated specifically by the co-receptors and not CD4 [374]. Ionic signaling via gp120 has also been reported in other cell types as well; exposure of rat primary astrocytes or primary microglia to X4 gp120 stimulated $\mathrm{Na}^{+} / \mathrm{H}^{+}$antiport and $\mathrm{K}^{+}$conductance [380-382]. Interestingly, there are differences in the ability of natural ligands and gp120 to activate some of these ion channels; whereas non-selective cation channels are activated by R5 and X4 gp120, they were not activated by CXCL12 or CCL4 in hMDM [374]. Further, while the overall pattern of $\mathrm{Na}^{+}$and $\mathrm{K}^{+}$signaling between $\mathrm{R} 5$ and $\mathrm{X} 4$ gp120 in these hMDM was similar, there were differences in magnitude and kinetics. For example, X4 gp120 induced less frequent $\mathrm{K}^{+}$current activation compared to $\mathrm{R} 5$ envelope $[374,379]$. Although the precise physiological relevance of these differences is not clear, these studies suggest variability and potentially biased co-receptor signaling in response to different types of gp120, and to gp120 relative to natural ligands.

\section{Tyrosine and MAP kinase signaling}

Downstream of $\mathrm{Ca}^{2+}$, gp120 acts on a number of kinases, such as the focal adhesion-related tyrosine kinase Pyk2 [213, 273, 282, 284, 285, 370, 383, 384]. This kinase plays a critical role in R5 gp120 mediated cytokine and chemokine secretion [264, 273, 282-284], dendritic cell migration [285], activation of small GTPases such as Rac1 [281], and activation of MAPKs such as p38 MAPK [273, 282-285, 385]. Pyk2 activation in response to both R5 and X4 gp120 has now been demonstrated in a large number of systems, including primary $\mathrm{CD} 4+\mathrm{T}$-cells and T-cell lines [213, 370, 383, 384], hMDM [264, 273, 282-284], dendritic cells [285], and astrocytic models of
HIV [281], indicating its importance in gp120 mediated signaling.

In addition to Pyk2, and often downstream of it, gp120 can activate several distinct but often overlapping signaling cascades, several of which are also activated by cognate chemokines of both CCR5 and CXCR4 [273, 277, 286]. These include several different MAPK pathways, such as p38 MAPK [273, 277, 282-285, 386-388], JNK/SAPK [273, 282-284], and ERK cascades [286, 363, $368,389,390]$, all of which can be activated by both R5 and X4 gp120, although the activation of these varies by stimulus and cell type [273, 363, 391]. In hMDM, for example, both types of gp120 can activate p38 MAPK, but X4 gp120 inconsistently induced activation of JNK/ SAPK compared to the more consistent activity induced by an R5 envelope [273]. In unstimulated human primary CD4 + T cells, high levels of gp120 increased ERK1/2 phosphorylation, although other studies show ERK1/2 is only activated when T-cells are pre stimulated through the T-cell receptor (TCR) [384, 389, 391]. There is also conflicting evidence regarding ERK1/2 activation by R5 gp120, as studies in both artificial cell systems [277] and primary macrophages [273] reported no effect of R5 gp120 on ERK1/2 phosphorylation. However, others show a robust effect after treatment with gp120 from R5 HIV [273, 286, 363, 390, 392, 393]. Neither differences in cell type nor gp120 strain fully explain these discrepancies in ERK1/2 activity, as several studies used identical cell types and concentrations of gp120 [273, 390]. Given many studies were done with primary human cells, these discrepancies may suggest that population specific heterogeneity plays a significant role in the human signaling response to gp120. It is also unclear whether these signaling events are physiological at the concentrations of gp120 present in vivo as gp120 is often used at extra physiologic levels [172].

Given the importance of Pyk2 and MAPK signaling activation, it is unsurprising that several G-protein-mediated pathways have been implicated in the modulation of Pyk2 and MAPK activity. $\mathrm{G}_{\alpha \mathrm{i}}$-activated signaling has been linked to PI3K and downstream activation of Pyk2, p38 MAPK, and ERK1/2 [213, 220, 273, 363, 390, 393, 394], while $G_{\alpha q}$ signaling can activate PLC $\beta$ and lead to $\mathrm{Ca}^{2+}$-mediated activation of Pyk2 [273, 281, 395], as discussed above. Given the variability of gp120 subtypes and cell systems used to define HIV signaling, it is possible that the coupling of CCR5 and/or CXCR4 to specific G-proteins varies with cell type and with X4 or R5 gp120 [36, 197, 215]. Irrespective of the G-proteins involved, data indicate that the activation of the MAPK signaling pathway in response to both R5 and X4 gp120 is a common mediator of gp120 signaling, occurs in a wide variety of cell types, and is linked to a number of downstream 
pathways that may play a role in the neuropathogenesis of HIV.

Indeed, in many studies, the functional outcome of both R5 and X4 gp120 mediated activation of the MAPK cascade, and in particular, p38 MAPK, has been associated with neuronal dysfunction and death [50, 386, 396-401]. Notably, activation of MAPK signaling cascades by X4 gp120 has been suggested to play a role in the neurotoxic effects of gp120 compared to the protective effects of CXCR4 [160,167, 400], supporting the concept of differential signaling induced by HIV and chemokine engagement of co-receptors. The clinical relevance of data showing gp120 mediated neurotoxicity is not well understood, and it is unclear if and how R5 and $\mathrm{X} 4$ gp120 directly interact with neuronal co-receptors to drive these effects, as neurons lack the CD4 receptor [402]. Further, the amount of neuronal death observed in the brains of cART-treated PLWH has declined substantially $[3,133]$, suggesting that the current effects of co-receptor activation by virion associated gp120 are not inducing neurotoxicity. Still, the robust amount of data in this area suggests that co-receptor mediated activation of MAPK, specifically p38 MAPK, has an important role in HIV-induced neuropathogenesis.

\section{HIV-mediated signaling downstream of MAP kinases}

Signaling through MAPK regulates a variety of functions, including but not limited to; the release of inflammatory chemokines and cytokines, the activation of STATs, and the activation of MMPs [36, 197, 215, 273, 282, 286, 390, $393,403,404]$. Secretion of inflammatory cytokines is of particular interest given the central role of these factors in driving $\mathrm{HIV}$-associated neuroinflammation. Exposure to both R5 and X4 envelopes can lead to the production of a large number of chemokines and cytokines, including TNF $\alpha$, MIP- $1 \alpha$, MIP- $1 \beta$, IFN- $\gamma$, IL-1, IL-6, IL-10, MCP-1, CCL2, and CCL5 [246, 264, 273, 283, 284, 286, 389, 397, 405]. Exposing macrophages and $\mathrm{T}$ cells to gp120 also leads to the translocation of several transcription factors critical to cytokine and chemokine secretion, including AP-1, NF-кB, and C/EBP [36, 197, 215, 246, 389, 406]. In addition to promoting inflammation, these chemotactic and inflammatory mediators can modulate HIV replication [407] and recruit uninfected macrophages and T-cells that provide new targets for viral spread.

In hMDM, gp120 mediated release of the inflammatory cytokines IL- $1 \beta$ and TNF $\alpha$ is PI3K dependent [264, 390], although IL-1 $\beta$ secretion was also $G_{\alpha i}$ dependent, suggesting $G_{\alpha i}$-mediated PI3K activation [264]. Both p38 MAPK and ERK1/2 may also mediate the release of these cytokines, potentially through independent signaling pathways [288, 390, 398, 404, 408, 409]. One of these pathways may involve the activation of the Src family of kinases, as Src activation has been linked to R5 gp120 mediated increases in both IL-1 $\beta$ and TNF $\alpha$ in hMDM [264, 286]. Src kinases mediate GPCRinduced phosphorylation of the epidermal growth factor receptor (EGFR) [410], which then activates the PI3K/AKT signaling cascade and/or Pyk2 to mediate MAPK activation [410-412]. Src kinases are also linked to MAPK signaling through $\beta$-arrestins and Pyk2, suggesting overlap between G-protein dependent and independent pathways [200, 413]. This suggests that G-protein dependent and independent mechanisms work in concert to promote cytokine and chemokine dysregulation, potentially via the MAPK pathway.

In addition to cytokines, STATs are also upregulated in response to R5 and X4 gp120 [403, 414-416]. Canonically, activation of these latent cytoplasmic transcription factors is mediated by JAKs [417-419] in response to inflammatory and regulatory stimuli [419, 420], although JAK independent mechanisms have been described [403, 415, 421]. Gp120-mediated activation of STATs 1 and 3 leads to activation of IL-6 in monocyte derived dendritic cells (MDDC) and HBMECs [403, 414, 415], although the mechanisms leading to this activation differed. In MDDCs, activation involved p38 MAPK and activation of NF-kB [403], whereas in HBMECs it involved activation of PI3K $[414,415]$. In MDDC, the actions of gp120 were distinct from those of CCL4, which did not induce STAT3 activation [403], although other studies have found that CCR5 ligands can activate the canonical JAK/STAT pathway [214, 271, 272, 287, 349]. In HMBECs, HIV virions were also shown to activate STATs 1 and 3 and induce production of inflammatory cytokines. Several of these studies further demonstrated that HIV released from infected cells activated STATs $[415,420]$, potentially disrupting the blood-brain barrier. These studies also suggest that there may be differences in HIV-associated STAT activation between cell types, and that HIV may activate certain STATs in a JAK-independent manner. In contrast to the number of pathways activating STATs, the upregulation of MMPs, which are responsible for the degradation of extracellular matrix (ECM), appears to be largely mediated by p38 MAPK [277, 387, 422]. Gp120 mediated increases in MMPs have been shown in a number of cell types, including MDDC, T-cells, and astroglioma cells [277, 387, 423]. The signaling underlying this process is not clear, but it is likely regulated by the G-protein dependent and independent mechanisms described above. Together, these data further support the critical role of the MAPK cascade in mediating the effects of HIV on both target cells and surrounding cells. 


\section{Changes in the actin cytoskeleton}

Binding of gp120 to CCR5 and CXCR4 is also linked to alterations in the cytoskeleton, which may be important in both pre-and post-entry stages of infection. Both HIV and gp120 can activate Rho and Rac GTPases, predominantly Rho, cdc42, and Rac [281, 359, 424-426]. These GTPases are linked to cytoskeletal dynamics, including organization of actin and microtubules. Harmon et al., demonstrated the importance of these pathways in an astrocyte model of viral entry, showing that R5 gp120 initiates a signaling cascade, via $G_{\alpha q}$, that activates Rac1 and is required for viral fusion [281]. The need for activation of the $G_{\alpha q}$ cascade, particularly PKC, in early entry and replication events is supported by other studies that show inhibition of PKC delta significantly decreased HIV replication, but not entry, in hMDM [360]. Thus, co-receptor mediated changes in the cytoskeleton that allow viral fusion seem to require $G_{\alpha q}$ mediated activation of small GTPases.

Both X4 and R5 gp120 mediate viral fusion through changes in Rac and Rho GTPase activity, but X4 gp120 has specific effects on the actin cytoskeleton that are critical for infection of resting $\mathrm{T}$ cells [366]. Static cortical actin in resting $\mathrm{T}$ cells blocks productive infection, and gp120-CXCR4 signaling helps to overcome this inhibition through activation of cofilin, a cellular actin-depolymerizing factor critical for actin dynamics and viral nuclear migration [366]. The effects of gp120 on actin dynamics are dose and conformation dependent [366, 427]. At high doses, gp120 acts more like CXCL12, triggering rapid cofilin phosphorylation and actin polymerization, followed by cofilin dephosphorylation and actin depolymerization [366, 368]. At lower doses, gp120 is incapable of triggering rapid changes, instead mediating gradual cofilin dephosphorylation and actin depolymerization [366, 427].

Alteration of the actin cytoskeleton by other modulators have also been reported. WAVE2 is part of a multiprotein complex linking receptor signaling to actin nucleation and filament branching through Arp2/3. Gp120 triggers WAVE2 phosphorylation through both CXCR4 and CCR5, acting through early $G_{\alpha i}$ independent and late $G_{\alpha i}$ dependent mechanisms [428], and inhibition of Arp2/3 activity significantly attenuated HIV-1 nuclear migration and infection of CD4 $+\mathrm{T}$ cells [428]. Additionally, both R5 and X4 gp120 alter LIMK/cofilin signaling, which regulates actin depolymerization at the pointed (-) ends of actin filaments [365, 366, 428]. LIMK regulates cortical actin dynamics in CD4+T-cells, and LIMK knockdown significantly inhibited early HIV viral DNA synthesis and CXCR4 internalization in these cells [365]. As both LIMK and WAVE2 are activated by Rac1 [359, 365, 429], and are key players in regulating actin dynamics [429], these data suggest small GTPase regulation of cofilin and ARP2/3 dynamics by gp120 allows HIV to hijack the actin cytoskeleton machinery to regulate actin treadmilling, promoting HIV nuclear migration.

Thus, co-receptor-mediated changes in key cytoskeletal proteins present a mechanism by which distinct signaling pathways mediate viral entry and replication in a number of different cell models. Co-receptor-mediated cytoskeletal alterations may also be important in establishing viral latency, particularly in T-cell populations [183, 367], although a discussion of this is beyond the scope of this review. While the precise signaling pathways and effectors mediating the effects of gp120 may vary, it seems clear that co-receptor signaling plays an indispensable role in both the replication of HIV and the effects of HIV on surrounding cells.

\section{Co-receptor signaling in HIV neuropathogenesis}

There are two prevailing hypotheses regarding HIV neuropathology, the direct injury hypothesis and the bystander effect theory [105]. The vast majority of research examining these areas in the context of gp120co-receptor signaling studies co-receptor activation via application or expression of specific gp120 proteins. These data show that gp120 mediated activation of both co-receptors contributes to both mechanisms of injury, as well as to the spread of CNS infection [49, 50, 386, 430433]. While these theories are not mutually exclusive, we did not find any studies from the post-cART era that show gp120 levels reach concentrations high enough in the CNS or periphery to have any biological effects [172]. In addition, although multiple CNS cell types express both CXCR4 and CCR5, including neurons, astrocytes, and dendritic cells [18, 114, 240, 241], neurons do not express CD4 [402], and CD4 is generally thought to be required for efficient binding of gp120 to either CCR5 or CXCR4 $[69,70]$. Thus, it remains unclear whether direct interactions between monomeric gp120 and neuronal co-receptors have physiological relevance, and it may be that HIV-mediated neuronal injury is largely due to indirect effects driven by low levels of active replication in microglia and perivascular macrophages [47, 48, 50, 172]. However, several in vitro studies have indicated a role for neuronal CCR5 or CXCR4 in the actions of gp120, suggesting there may also be a role for CD4 independent interactions in neuropathogenesis $[47,49,162,163,216$, 431, 434-436].

Given these data, we will only briefly discuss indirect effects of co-receptor signaling on neuronal injury and focus primarily on the role of the previously defined co-receptor signaling cascades and effectors in driving HIV neuroinflammation, as well as how external factors such as drug abuse can alter these events. As with our 
discussion on HIV-mediated co-receptor signaling, we will largely discuss studies that have relied solely on monomeric gp120 concentrations unlikely to be found in the CNS, as these represent the majority of the literature pertaining to this subject and provide valuable insight into how the specific activity and signaling pathways activated by discrete co-receptors can drive neuroinflammation and neuroHIV as a whole.

\section{Neuroinflammation}

Activation of both CCR5 and CXCR4 by gp120 can induce the production of a number of inflammatory cytokines and chemokines [218, 273, 286, 387-390, $403-405,437]$, increase the transmigration of inflammatory and infected monocytes and T-cells [414, 420, $425,438]$, activate macrophage and glial populations [103, 284, 439], alter BBB integrity [277, 415, 438, 440] and induce oxidative stress, which can exacerbate these effects [423, 439, 441-443]. The majority of these events occur in infected and uninfected myeloid cells, including both transmigrated peripheral monocytes, hMDM, and CNS resident cells such perivascular macrophages and microglia [50, 101, 444-448]. Astrocytes may also be involved [112, 444, 449, 450]. All myeloid cells express both co-receptors, with much higher levels of CCR5 [18, $19]$, and in response to interactions with gp120 they produce cytokines and chemokines that increase inflammation and recruit additional immune cells to combat infection. The cytokines associated with activation of co-receptors include TNF- $\alpha$, IL-1 $\beta$, CCL2, CCL3, CCL4, CCL5, CXCL10, CXCL12, IL-6, and IL-8, many of which are induced by MAPK-dependent signaling events, particularly p38 MAPK [273, 282, 286, 390, 392, 393, 397, $403,405,414,430,446,451]$. Elevated concentrations of TNF- $\alpha$ are found in the brains and cerebral spinal fluid (CSF) of HAND patients [452-455] and upregulated IL-1 $\beta$ mRNA has been found in cognitively impaired individuals [456]. Both cytokines are early regulators of the inflammatory response, and their release leads to activation of immune cells such as macrophages and microglia [454]. IL-1 $\beta$ also activates astrocytes, stimulating NF- $\mathrm{BB}$ activity [457] and the production of other inflammatory cytokines, including TNF $\alpha$ [454]. These cytokines can also act on neurons, contributing to synaptic injury and suggesting a mechanism by which gp120induced production of chemokines can promote both inflammation and neuronal dysfunction [154].

Co-receptor induced increases in TNF- $\alpha$ could promote increased monocyte migration and dysregulation of the BBB by inducing the expression of adhesion molecules such as ICAM on endothelial cells [458] and promoting the production of chemoattractants, such as CCL2 and CCL4 [50, 459], which are released from macrophages and microglia. While early studies suggested CCL4 could inhibit the interactions between CCR5 and gp120 [460, 461], this is unlikely to occur in vivo given the ability of HIV to utilize different conformations of CCR 5 to escape inhibition by endogenous chemokines [293, 462]. Thus, increased production of CCL4 could further activate CCR5, increasing the production of chemokines and cytokines that both recruit infected monocytes into the CNS and draw uninfected CNS cells to the site of infection, thereby promoting the spread of HIV [97, 187, 463, 464]. A variety of additional factors, including other viral proteins, cell debris, and aberrant levels of neurotransmitters such as dopamine and glutamate [465-471], further enhance the release of some of these chemokines from macrophages and microglia. In the pre-cART era, increased levels of these chemokines were observed in the CNS of individuals suffering from HIVE [452, 472], though this is far less common in the era of cART.

The development of neuroHIV is also influenced by the interactions of gp120 with co-receptors on nonmyeloid populations, including both CNS dendritic cells and endothelial cells $[285,403,414,420]$. Many of these effects are induced by gp120-CCR5 interactions that release STATs and MMPs. For instance, gp120-CCR5 interactions on dendritic cells activate several signaling cascades including the $\mathrm{p} 38$ MAPK pathway, driving dendritic cell migration and the release of inflammatory cytokines via downstream STAT signaling [285, 403]. As the number of dendritic cells in the CNS is greatly increased during neuroinflammatory diseases [473], dendritic cell exposure to infected myeloid cells or viral proteins could drive the recruitment of more dendritic cells to vulnerable areas of the CNS, further contributing to neuroinflammation and neuronal dysfunction. Co-receptor-gp120 interaction on endothelial cells comprising the $\mathrm{BBB}$ can also result in increased myeloid cell recruitment, as several in vitro models of the BBB show that gp120 can drive increased monocyte migration and damage the $\mathrm{BBB}$. This occurs via reduced expression of tight junction proteins and increasing expression of the inflammatory factors IL- 6 and IL-8 [414, 415, 420, 425, 438, 474]. The precise mechanisms underlying these results are unclear, but is likely due to multiple mechanisms, including PI3Kmediated STAT activation [414, 415, 438], activation of Rac1 and other GTPases [425], and PKC activation [438].

The activation of MMPs, which are upregulated in the CNS of HIV-infected individuals [475-477], may also play a critical role in the recruitment of infected cells into the CNS. These factors, such as MMP9, are associated with inflammatory diseases and increased permeability of the BBB [423, 440]. Both T-lymphocytes and C6 astroglioma cells increased MMP9 secretion in a p38 MAPK 
dependent manner in response to R5 and X4 gp120 [277], and both HIV and gp120 also increase MMP9 secretion in macrophages [387]. Further, activation of MMPs is also associated with drug abuse, particularly the use of methamphetamine [387, 478]. This demonstrates one of many potential mechanisms by which substances of abuse can exacerbate HIV-associated neuropathology, with a number of additional potential overlaps between HIV and substance abuse discussed in subsequent sections. Overall, these and many other studies indicate that co-receptor-gp120 interactions act through a variety of distinct but overlapping signaling mechanisms, including p38 MAPK, PI3K, STAT and MMP activation, to participate in the inflammatory impact of HIV in the CNS. Although much progress has been made, further studies are needed to tease out the relative importance and role of these different pathways, and how they may work together to promote the production of inflammatory factors, migration of infected cells and other processes involved in neuroinflammation.

\section{Co-receptor mediated neuronal injury}

Although the mechanisms by which HIV interactions with neuronal co-receptors can directly drive neurotoxicity are not clear, several studies indicate that glial cells and macrophages can mediate the neurotoxic effects of gp120 [50, 154, 386, 479-482]. For example, inactivation or depletion of macrophages and microglia abrogates gp120-mediated neurotoxicity [50, 480]; additionally, activation of CXCR4 on macrophages/microglia is a prerequisite for gp120 neuronal injury [50,386, 481], suggesting these effects are driven by co-receptors on glial populations. Additionally, microglial activation is required for R5 gp120-induced synaptic degradation in primary cortical cultures [482], and X4 gp120-induced upregulation of ferritin heavy chain (FHC), which is associated with cognitive deficits, only occurred in neuronal/ glial co-cultures [154]. Many of these neurotoxic effects are also seen in patients with HAND, suggesting that gp120-mediated effects play a role in the development of neurological disease $[483,484]$. Thus, while shed gp120 may not play a direct role in HIV-driven neurotoxicity, co-receptor activation by HIV virions in CNS immune cells and glia is still likely to contribute to neuronal damage.

As mentioned previously, activation of p38 MAPK is central to these neurotoxic effects, and this also seems to be mediated through non-neuronal cells. Activation of p38 MAPK was found in gp120-treated mixed cortical cultures (containing neurons, astrocytes, and microglia) and this was dependent on the presence of microglia [386]. Increases in glial p38 MAPK were necessary for gp120-mediated neuronal apoptosis in mixed neuronal-glial cultures [386], and in rat cerebral cortical cultures, gp120 appeared to indirectly induce neuronal apoptosis via activation of the p38 MAPK pathway in macrophages and microglia [50]. Downstream of p38 MAPK, the activation of MMPs from infected macrophages has been demonstrated to contribute to gp120induced neurotoxicity, as these proteins can cleave CXCL12 into a neurotoxic product aa5-67 CXCL12. This cleaved form of CXCL12 is unable to properly bind to CXCR4; instead, it stimulates an alternative receptor, CXCR3, promoting neurotoxicity [485]. Upregulation of MMPs and cleavage of CXCL12 have been reported in HIV + brains and is suggested to contribute to neuropathology in humans [486]. Additionally, changes in various inflammatory cytokines, such as TNF- $\alpha$ and IL-1 $\beta$, may further indirectly promote neurotoxicity through a variety of mechanisms, including $\mathrm{Ca}^{2+}$ overload [484], alterations in dendritic spine length [153, 154], and axonal degeneration [479], all of which are associated with cognitive deficits, particularly in the cART era [104-106]. Thus, many of the same signaling cascades implicated in co-receptor mediated neuroinflammation may also indirectly contribute to neuronal damage via glial-neuron interactions. This suggests that advancing our understanding of co-receptor mediated neurotoxicity will require models that enable the careful dissection of cross cell type interactions.

\section{Substance abuse and co-receptor-mediated neuropathology}

Substance use disorders (SUD) have been comorbid with HIV infection since the start of the epidemic. Rates of SUD vary widely by region, substance, and specific subpopulation, but are found in roughly in $9-48 \%$ of HIVinfected individuals globally, compared to $0.7-8.6 \%$ of the population as a whole [487-495]. There are particularly high rates of HIV infection among individuals who inject drugs-twenty-two times higher than in the general population [487, 488, 496]. The impact of SUD is especially important when considering neuroHIV, as the use of addictive substances is associated with increased neuropsychiatric comorbidities and is strongly correlated with cognitive decline, even with effective cART [497500]. This is likely because use of illicit substances can promote neuroinflammation and alter the progression of HIV-associated neuropathology [501-504], increasing HIV replication and dysregulating cytokine secretion and other immune functions in myeloid cells such as macrophages and microglia [502, 504-507]. These effects can add to or synergize with the impact of HIV virions and viral proteins, including gp120, and host factors, exacerbating inflammation and damage to the $\mathrm{BBB}$ and recruiting more myeloid cells to enhance the spread of infection. 
Psychostimulants and opioids represent the major drug classes associated with SUDs in PLWH and have subsequently been the most studied in relation to gp120 and HIV neuropathogenesis.

Stimulants include methamphetamine (Meth), cocaine, and prescription drugs used to treat conditions such as ADHD, all of which act by directly increasing CNS dopamine [508-510]. Dopamine, and by extension substance abuse, has been shown to modulate HIV infection, replication and inflammation, as well as alter the efficacy of the CCR5 entry inhibitor Maraviroc [66, 373, 465, 509, 511-513], although a comprehensive discussion of the role of dopamine in HIV neuropathogenesis is beyond the scope of this review. However, studies also show that stimulants can directly synergize with gp120 to exacerbate neuropathology [387, 408, 437, 514-520]. Injection of cocaine and gp120 into rodent brains induced higher levels of apoptosis than either treatment alone [518], and treatment of rat primary neurons with gp120 and cocaine also enhanced apoptosis through an apoptotic pathway involving intracellular ROS production, mitochondrial membrane potential loss, and activation of the NF-kB and ERK, p38 and JNK/SAPK signaling pathways [514]. While this study did not demonstrate a direct role of co-receptors, these signaling pathways are activated by HIV interactions with co-receptors [273, 277, 282-286, 363, 385-390, 406], suggesting HIV-mediated activation of co-receptors on surrounding glia could indirectly exacerbate the effects of these drugs. This is further supported by studies demonstrating that cocaine and gp120 together may enhance microglial neurotoxicity, as data show cocaine + gp120 alters energy metabolism and AMPK expression to impair the function of CHME-5 microglia [521]. In transgenic rats expressing gp120, long term exposure to both gp120 and Meth synergized to impair learning and memory, dysregulate the components of GABAergic and glutamatergic neurotransmission systems and induce a loss of neuronal dendrites and presynaptic terminals in the hippocampus [522]. Learning deficits induced by Meth and gp120 exposure were also seen in gp 120 + transgenic mice, with similar patterns of impairment as seen in HIV infected Meth users [523]. Moreover, exposure to both Meth and gp120 induced greater PBMC transmigration and greater decreases in trans-endothelial resistance and expression of tight junction proteins than either meth or gp120 alone [515].

These affects may be further amplified through the direct interaction of stimulants with CCR5. Cocaine can increase mesolimbic CCR5 expression, and the conditioned place preference behaviors associated with cocaine are reduced by the use of maraviroc, a CCR 5 antagonist [524]. Meth has been shown to increase CCR5 expression in cultured macrophages and in the myeloid cells of SIV infected macaques [507, 525-527]. We and others have shown that dopamine can increase the expression of certain CCR5 conformations on the surface of human macrophages [498] and THP-1 cells [528]. As small changes in surface expression of CCR5 can induce substantial changes in infection [529-532], drugassociated changes in CCR5 expression or conformation could promote greater levels of viral infection, leading to increased levels of neurotoxic viral particles and an expanded viral reservoir. Together, these data suggest that the use of stimulants and the dopamine release they induce may synergize to increase infection and inflammation in CNS cells, increasing the spread of HIV and expanding the CNS reservoir while also exacerbating the development of neuroinflammation.

Opioids are also commonly abused in HIV-infected populations and can exacerbate the symptoms of HAND [316, 533-535], potentially through interactions with both CXCR4 and CCR5 on glia and neurons. Opioids can increase both CCR5 expression and the expression of toll-like receptors in astrocytic model systems, potentially increasing the magnitude of the inflammatory response to gp120 [437, 536-538]. Opioid receptors may also heterodimerize with CCR5, with some studies showing mu opioid receptor (MOR) agonists reduce the chemotactic effects of CCR5 [539, 540], while others show that CCR5 ligands dampen the analgesic effects of MOR agonists [541, 542]. Stimulation of the MOR can inhibit homeostatic CXCR4 signaling in the CNS via the FHC protein [543], and stimulation of neurons co-expressing CXCR4 and MORs with morphine or the MOR agonist DAMGO inhibited intracellular pathways activated by CXCL12, preventing CXCL12-mediated neuroprotection and CXCR4 phosphorylation [543, 544]. This results in long-lasting inhibition of the receptor that is distinct from more common opioid-chemokine cross regulatory mechanisms including heterologous desensitization [542] and receptor dimerization [545]. Further, HIV gp120 can upregulate $\mathrm{FHC}$ in neuronal/glial cocultures via an IL-1 $\beta$ dependent mechanism [154], suggesting opioid use and HIV infection may act through overlapping or shared mechanisms to induce cognitive impairment. Several studies have also indicated that CCR5 plays a central role in modulating tat-morphine interactions, with the loss of CCR5 blocking tat-induced neurotoxicity, morphine tolerance and the release of pro-inflammatory cytokines, including CCL2 [448, 541]. This suggests crosstalk between CCR5 signaling and MOR signaling could lead to unique signaling effectors that exacerbate neuroinflammation and neuronal damage. Overall, these data indicate that the interactions between drugs of abuse and co-receptors can lead to a variety of detrimental effects, 
increasing both HIV infection within the CNS and contributing to neuropathology. Defining these processes more precisely is critical, as the mechanism(s) by which distinct substances of abuse exacerbate neuroHIV are unclear, hindering development of therapeutics specific to the vulnerable and growing population of HIVinfected drug abusers.

\section{Co-receptors as targets in antiretroviral therapy}

Co-receptors are essential for HIV entry and therefore make an attractive target for anti-retroviral therapeutics. Blocking cell entry prevents viral replication, and when combined with other drugs this can achieve sustained suppression, halting disease progression. Further, the role of co-receptor signaling in modulating neuroinflammation suggests that targeting the downstream signaling events may reduce the inflammatory effects of HIV, particularly in combination with other antiretrovirals. However, despite more than 30 years of antiretroviral development and numerous claims that co-receptor targeting was an emerging, promising therapy [546-549], there is currently only one antiretroviral that acts on a co-receptor, the CCR5 inhibitor Maraviroc. There are several CCR5 inhibitors that were halted or are in ongoing, late-stage clinical trials [44], and there is a CXCR4 inhibitor, Plerixafor (AMD3100), but it is only approved for mobilization of hematopoietic stem cells, due to severe off-target effects associated with CXCR4 inhibition $[42,550]$. A number of small molecular inhibitors and monoclonal antibodies have also been investigated as potential methods for blocking HIV interactions with CCR5, but most have not progressed past phase II trials, and none to date have been approved by the FDA $[37,547,551,552]$, although the monoclonal antibody leronlimab (PRO 140) has been granted fast-track status [551]. And although they do not target the co-receptors directly, the anti-CD4 antibody Trogarzo, the gp120-targeting attachment inhibitor Fostemsavir, and the fusion inhibitor Enfurvitide also inhibit the entry process mediated by CCR 5 and CXCR4 [553-555].

There are a number of reasons co-receptors are difficult to target, including the ability of HIV to utilize multiple different conformations [293, 300] and interference of therapeutics with homeostatic signaling leading to offtarget effects $[43,556]$. The latter is particularly problematic for targeting CXCR4, as the essential function of CXCR4 in numerous homeostatic processes precludes the development of inhibitors targeting this receptor $[43,557]$. Targeting CCR5 and CXCR4 are both associated with their own unique set of challenges; therefore, we will address these challenges and the current state of therapeutics separately. We will then address how we can utilize overlaps in the signaling processes associated with
HIV binding to both receptors to potentially develop therapies to ameliorate both HIV infection and associated neuroinflammation.

\section{CCR5}

Early in the HIV epidemic, it was observed that individuals homozygous for the CCR5- $\Delta 32$ mutation, which renders CCR5 nonfunctional, were resistant to HIV infection and lacked significant immunological defects $[558,559]$. The importance of CCR5 as an antiretroviral target was confirmed when the "Berlin patient" received a stem cell transplant from an individual homozygous for CCR5- $\triangle 32$ and was functionally cured of HIV [560]. Another patient receiving the same treatment is also in successful long-term remission from HIV infection [561], and CCR5-targeted drug Maraviroc is an effective antiretroviral. However, Maraviroc is highly susceptible to resistance mutations [45], necessitating the development of alternative methods of targeting CCR5 [562]. Unfortunately, effectively interfering with viral binding to CCR5 is much more complex than had initially been anticipated. Early structural studies showed gp120 binds to the N-terminus of CCR5, the same region targeted by endogenous ligands, and in vitro studies showing that CCL3, CCL4, and CCL5 have potent antiretroviral activity against R5 viruses [190, 460-462, 563]. However, newer studies suggest gp120 interacts with CCR5 differently than do natural ligands [257, 292-294, 300] and the antiretroviral activity of endogenous CCR 5 ligands has not replicated across cell systems or in vivo [260, 299, 564].

This may be due to the capacity for gp 120 to efficiently interact with CCR5 in multiple structural conformations, whereas natural ligands and inhibitors such as Maraviroc can only target specific conformations [293, 294, 298, 300, 301]. Mutational studies and those using antibodies targeting distinct CCR5 conformations confirm that CCR5 exists in multiple conformations and oligomerization states on a single cell, and these different states alter the binding affinity of multiple ligands $[215,257$, 268, 292, 294, 299, 300, 565]. Indeed, changes in CCR5 conformation or mutations in gp120 can lead to a loss of efficacy for Maraviroc due to altered binding interactions between CCR5 and gp120 [45, 293, 300, 565]. In addition, antiretrovirals that bind directly to CCR 5 can still induce downstream signaling events, many of which can potentiate the impact of HIV on the CNS [37, 260]. For these reasons, the use of cognate CCR5 ligands is not considered a viable method to block HIV binding to this receptor.

This has led to an interest in developing biased ligands or small molecules that promote the internalization of CCR5 or bias signaling pathways to prevent HIV entry 
without stimulating downstream signaling [38, 39, 215, $256,262,566]$. Several different groups have designed effective chemokine analogues that target CCR5, promoting the internalization and delaying the recycling of CCR5, rather than competing with other ligands for the binding site [38, 214, 256, 258, 260, 290, 302]. These molecules have up to 200 times the inhibitory potency of Maraviroc on the viral entry process. Perhaps more importantly, they may not promote intracellular signaling cascades, instead biasing the receptor towards association with $\beta$-arrestins and internalization $[38,39,256,262$, $263,566]$. These analogues may be more effective than binding inhibitors like Maraviroc because they reduce the surface levels of CCR5, diminishing the impact of changes in gp120 binding regions or CCR5 conformations [256]. Additionally, it is possible that these molecules could exploit the ability of CCR5 to oligomerize with other receptors; a number of in vitro studies have suggested that homo- or hetero-oligomerization of CCR5 can block HIV infection and replication [244, 269, 270]. However, the impact of the formation of these oligomers on chemokine-induced signaling and their in vivo relevance is incompletely understood and requires a more complete understanding of chemokine and HIV-induced signaling.

\section{CXCR4}

While blocking CCR5 has been considered a more promising strategy for inhibition of viral entry and replication, an increasing number of patients are developing X4 tropic or dual-tropic viral strains that can bind to CXCR4 [557]. This suggests that targeting CXCR4 may be particularly beneficial for patients in the later stages of infection. Early chemical screening and medicinal chemistry efforts identified several CXCR4 antagonist peptides, including Plerixafor (AMD3100), one of the first CXCR4 antagonists to enter clinical trials for antiHIV activity [550]. Although AMD3100 appears to have a distinct binding site from the region occupied by the $\mathrm{N}$-terminus of CXCL12, it still produced severe off-target effects, including cardiotoxicity, and these trials were terminated [567]. Several derivatives of AMD3100 have been developed that inhibit CXCR4 at sub-nanomolar concentrations; however, clinical utility of these compounds is limited due to their lack of oral bioavailability, which is related to their high positive charge at physiological $\mathrm{pH}$ [556]. Current studies have moved away from the early peptides and are using natural CXCR4 ligands as design templates, similar to the chemokine analoguebased strategies described for CCR5. The N-terminus of CXCL12 has been shown to be essential for CXCR4 recognition, signal transduction, and antiretroviral activity; however, peptides targeting this region are less potent than native CXCL12, limiting their clinical effectiveness [556]. In a similar strategy, the $\mathrm{N}$-terminus of another chemokine, viral macrophage inflammatory protein-II (vMIP-II) from human herpesvirus-8, was used as the design template for various classes of highly potent and selective CXCR4 peptide antagonists. While these peptides display high CXCR4 affinity, anti-HIV activity, and the ability to mobilize hematopoietic stem cells in mice, they are still in the preclinical phase [568].

There are two primary challenges associated with developing CXCR4-targeting therapies, accommodating receptor oligomerization and minimizing undesirable side effects due to the normal, homeostatic functions of CXCR4. The ability of receptors to affect one another through oligomerization makes it essential to consider the in vivo state of CXCR4, particularly because CXCR4 may homodimerize in both the absence [569] or presence of ligand $[244,570]$ soon after protein translation. Additionally, CXCR4 may also form heterodimers with other chemokine receptors like CCR2 [244, 570], as well as non-chemokine receptors, including $\mathrm{CD} 4$, opioid receptors, and glycoproteins [351]. Although some studies have suggested that the induction of these dimers could be used as a strategy to target both R5 and X4-mediated infection $[244,269]$, the functional consequences of oligomerization are not fully understood. This makes it difficult to predict the effects of pharmacological compounds if they do not target oligomerization states CXCR4 exist as in vivo. However, oligomerization may also be beneficial, designing drugs that target unique receptor complexes, though this will be technically more challenging.

The biggest challenge in the development of CXCR4targeted HIV entry inhibitors is overcoming undesirable side effects that result from inhibition of CXCR4, as this receptor has essential roles in numerous homeostatic functions in the periphery and CNS. Studies on two of the CXCR4 antagonists brought into clinical testing (AMD3100 and AMD11070) were terminated early due to toxicity [557]. Thus, it is essential to develop molecules with potent anti-HIV activity, while preserving CXCL12 signaling. A number of small molecules and nanobodies have shown promise in vitro in blocking HIV binding while preserving CXCL12 interactions, but it remains unclear if this will translate to clinically useful drugs with an adequate safety profile in vivo [43, 571, 572]. A more promising way to address these off-target effects is the development of allosteric agonists that can activate CXCR4 in the presence of other CXCR4 antagonists and antibodies [43]. These allosteric agonists, such as RSVM and ASLW [331], may be useful in combination with small-molecule antagonists to block viral entry but still maintain homeostatic activation of CXCR4. However, this will require further understanding of the intracellular 
signaling mediating both homeostatic receptor activation and viral entry.

\section{Strategies to target co-receptor signaling pathways}

While strategies to target CCR5 and CXCR4 via small molecules, antibodies, and chemokine analogues are promising, none of these holds promise in blocking both receptors concurrently. Dual co-receptor antagonists have been described [549], but the majority have only undergone in vitro and in silico evaluation, and many show inadequate safety profiles and poor pharmacokinetics. Given differences in the requirements for CCR5 and CXCR4 under homeostatic conditions, effective inhibition may require different approaches to ensure the functionality of CXCR4 in particular. An alternative method to target both co-receptors may lie in drugs targeting common downstream signaling effectors induced by HIV-co-receptor interactions [41]. Although such drugs may not serve as antiretrovirals on their own, as they do not sufficiently block the viral life cycle, they could potentially act to ameliorate co-receptor mediated neuroinflammation and pathology. Given the prominent role of persistent neuroinflammation in driving neuropathology in the cART era, there is a critical need to target mechanisms of inflammation within the CNS.

CCR5 and CXCR4 have a number of common pathways, with several specific effectors such Pyk2 and p38 MAPK that are involved in a number of HIV-associated pathologies. These effectors are also involved in other diseases, including cancer $[573,574]$, so a number of inhibitors are already on the market, or in drug pipelines, and could be repurposed as HIV drugs. Inhibitors of tyrosine and MAP kinases may have anti-HIV activity [575, 576], and p38 MAPK inhibitors have been examined as potential therapeutics in several inflammatory diseases and cancers [577]. A recent primate study using a p38 MAPK inhibitor in combination with cART showed this combination reduced markers of immune activation, although only in the periphery [576]. But despite over 20 candidates in clinical trials, no specific MAPK inhibitors have been clinically approved [577], likely due to the substantial number of signaling pathways and pathological and physiological processes in which this kinase plays a role. A more promising avenue may be to focus on tyrosine kinase inhibitors (TKIs), which are directed against Src family kinases $[573,578]$. The Src family of kinases is linked to both the PI3K/AKT and MAPK signaling cascades via multiple mechanisms [410, 412, 413], and, in hMDM, can mediate changes in IL- $1 \beta$ and TNF $\alpha$ in response to R5 gp120 [264, 286]. These have been examined largely in the context of inhibiting replication and the establishment of the viral reservoir in T-cells [573, 578], and TKIs such as dasatinib can both protect against
HIV infection in humanized mice [579] and inhibit HIV replication in T-cells [580]. This suggests TKIs could be a useful adjuvant during early HIV infection to prevent establishment of viral reservoirs [581], and the centrality of both PI3K and MAPK signaling to co-receptor mediated neuroinflammation suggests they could be promising targets in the CNS as well. Despite the fact that some of these therapeutics, such as dasatinib, have been approved for some cancers [582], they have not been sufficiently proven as an effective anti-HIV therapeutic [573]. Additionally, these studies have not addressed the potential use of these therapeutics in specifically ameliorating CNS pathology driven by HIV-co-receptor interactions, despite in vitro evidence demonstrating a role for Src and its regulation of the MAPK and PI3K cascades in these effects [264, 286, 412, 413].

\section{Conclusion}

A huge body of work indicates co-receptor signaling pathways activated by HIV are not only critical to the viral entry and replication process, but also to the broader neuroinflammatory and neurotoxic impact of HIV in the CNS. There have been numerous attempts to develop therapeutics targeting CXCR4 and CCR5, but most of these candidates did not or have not yet advanced out of trials, and many failed due either lack of efficacy or serious side effects $[43,583-587]$. The lack of success highlights the gap in our knowledge regarding how these effectors are activated by gp120 and natural ligands, their role in mediating physiological CCR5 and CXCR4 signaling, and the impact of their downstream signaling effectors on homeostatic and pathological processes. The signaling cascades initiated through both CCR 5 and CXCR4 have a wide array of downstream consequences, mediated by a variety of overlapping pathways triggered by both HIV and chemokine interactions. Defining which of these pathways is associated with a specific ligand, G-protein, set of downstream effectors, and/or receptor conformations is critical to understanding of how to target them. The emerging data suggesting that discrete receptor conformations induce distinct downstream events, and that these events are also cell-type specific, speaks to a need for comprehensive examinations of the conformations targeted by specific ligands, the signaling pathways and kinetics of each signaling event, and the downstream consequences for the specific cell and body as a whole. Filling in this knowledge gap is essential to the development of therapeutics targeting specific signaling pathways and highlights the need for rigorous studies in a more physiologically relevant context.

It is important to note that the majority of studies discussed here have been performed using highly artificial conditions. Thus, while they suggest a critical role for 
co-receptors, they preclude drawing a definitive conclusion regarding the impact of co-receptor signaling on HIV neuropathogenesis. This further highlights the need for future studies to make use of physiologically relevant cell types, and take advantage of new technologies, such as $3 \mathrm{D}$ culture systems and iPSC-derived primary cells, as well as animal models that more closely parallel the human immune system. Many of the neuroinflammatory effects of HIV-co-receptor interaction involve multiple cell types and show distinct activity in co-cultures relative to monocultures. Therefore, the development and use of mixed culture systems and organoids using combinations of neurons, glia and other myeloid cells will be critical to better mimic the interactions in the CNS. Combining data from these systems with more reductionist, single cell models that capitalize on newer technologies such as CRISPR and single cell genomic analyses such as single cell RNA sequencing (scRNAseq) and single cell Assay for Transposase Accessible Chromatin (scATACseq), will enable targeted analyses of changes in the expression, transcription and or function of specific effectors within different signaling pathways. Moreover, pairing these assays with conformational studies will enable precise assessment of the effects of specific conformational changes on HIV binding and signaling though CXCR4 and CCR5. These new systems should be combined with experimental consistency and physiological accuracy in regard to the use of HIV concentration and treatment paradigms. This is particularly true in the use of monomeric gp120 versus intact HIV virions, given the lack of a demonstrable role of gp120 in driving neuroHIV in the cART era. The use of monomeric gp120 has been valuable in a number of areas, including studies highlighting the complexity of signaling pathways associated with HIV activation of co-receptors. However, the field needs to better address signaling in response to HIV virions, as this may reveal distinct differences in co-receptor engagement and point towards more physiologically relevant signaling effectors that can be targeted.

A better understanding of the dynamic interaction between HIV and the CXCR4 / CCR5 co-receptors should enable the efficient development of ligands that precisely target only the signaling processes involved in entry. More broadly, both CXCR4 and CCR5 affect a wide array of diseases and homeostatic processes, from cancer to cardiac disease, indicating that effectively targeting co-receptors and manipulating their signaling could be a useful tool in the treatment of a number of diseases. Thus, these same studies, experimental pipelines and drug candidates will be used to develop therapeutics that not only inhibit the effects of co-receptors on HIV neuropathogenesis but could potentially be used to treat a number of other important human diseases.

\section{Abbreviations}

HIV: Human immunodeficiency; AIDS: Acquired immunodeficiency syndrome; PLWH: People living with HIV; ART: Antiretroviral therapy; GPCR: G-protein coupled receptor; CNS: Central nervous system; CART: Combined antiretroviral therapy; HAND: HIV-associated neurocognitive disorders; BBB: Blood-brain barrier; PFC: Prefrontal cortex; HIVE: HIV encephalitis; MAPK: Mitogen activated protein kinases; PI3K: PI3 kinase; GRK: GPCR kinases; CAMP: Cyclic AMP; PLC $\beta$ : Phospholipase C-beta; $\mathrm{PIP}_{2}$ : Phosphatidylinositol 4,5-bisphosphate; DAG: Diacylglycerol; IP : Inositol triphosphate; $\mathrm{Ca}^{2+}$ : Calcium; TGN: Trans-golgi network; PTX: Pertussis toxin; JAK: Janus kinases; STAT: Signal transducers and activators of transcription; AMPK: AMP-activated protein kinases; MMPs: Matrix metalloproteinase; NT: N-terminal; ECL: Extracellular loop; hMDM: Human monocyte derived macrophages; MDDC: Monocyte derived dendritic cells; HBMEC: Human brain microvascular endothelial cells; TCR: T-cell receptor; ECM: Extracellular matrix; CSF: Cerebral spinal fluid; BDNF: Brain derived neurotrophic factor; KCC2: $\mathrm{K}^{+}$-Cl-cotransporter 2; Rb: Retinoblastoma gene; FHC: Ferritin heavy chain; FKN: Fractalkine; Meth: Methamphetamine; ROS: Reactive oxygen species; MOR: Mu opioid receptor.

\section{Acknowledgements}

We would like to thank all members of the Gaskill lab for useful scientific discussions and ideas during the development of this manuscript.

\section{Authors' contributions}

EN and PJG conceived the review and worked with LF and OM to generate an outline of the manuscript. EN and LF wrote the initial manuscript, EN and PJG created the figures and EN, LF, OM and PJG added to and edited subsequent drafts of the manuscript. All authors read and approved the final manuscript.

\section{Funding}

This work was supported by grants from the National Institutes of Drug Abuse (DA039005, DA049227 to PJG and DA015014, DA032444, DA040519 to OM) and the W.W. Smith Charitable Trust (A2003 to PJG). LF is a trainee of the T32 grant "Training Program in HIV Pathogenesis, Vaccination, and Cure" from the National Institute of Allergy and Infectious Disease (Al007632). EN is a trainee of the T32 grant "Interdisciplinary and Translational Research Training in neuroAIDS" from the National Institute of Mental Health (MH079785).

Availability of data and materials

Not applicable.

\section{Declarations}

Ethics approval and consent to participate

Not applicable.

\section{Consent for publication}

Not applicable.

\section{Competing Interests}

The authors declare they have no competing interests.

\section{Author details}

${ }^{1}$ Department of Pharmacology and Physiology, Drexel University College of Medicine, 245 N. 15th Street, Philadelphia, PA 19102, USA. 'Department of Basic and Translational Sciences, School of Dental Medicine, University of Pennsylvania, 240 S. 40th Street, Philadelphia, PA 19104, USA. ${ }^{3}$ Department of Microbiology and Immunology, Drexel University College of Medicine, Philadelphia, PA 19102, USA.

Received: 17 March 2021 Accepted: 11 August 2021

Published online: 24 August 2021 


\section{References}

1. UNAIDS. Seizing the moment: tackling entrenched inequalities to end epidemics. Switzerland: Joint United Nations Programme on HIV/AIDS 2020

2. Wing EJ. HIV and aging. Int J Infect Dis. 2016;53:61-8.

3. Saylor D, Dickens AM, Sacktor N, Haughey N, Slusher B, Pletnikov M, et al. HIV-associated neurocognitive disorder-pathogenesis and prospects for treatment. Nat Rev Neurol. 2016;12(4):234-48.

4. Combadiere C, Ahuja SK, Tiffany HL, Murphy PM. Cloning and functional expression of CC CKR5, a human monocyte CC chemokine receptor selective for MIP-1(alpha), MIP-1 (beta), and RANTES. J Leukoc Biol. 1996:60(1):147-52.

5. Raport CJ, Gosling J, Schweickart VL, Gray PW, Charo IF. Molecular cloning and functional characterization of a novel human CC chemokine receptor (CCR5) for RANTES, MIP-1 beta, and MIP-1alpha. J Biol Chem. 1996:271(29):17161-6.

6. Samson M, Labbe O, Mollereau C, Vassart G, Parmentier M. Molecular cloning and functional expression of a new human CC-chemokine receptor gene. Biochemistry. 1996;35(11):3362-7.

7. Loetscher M, Geiser T, O'Reilly T, Zwahlen R, Baggiolini M, Moser B. Cloning of a human seven-transmembrane domain receptor, LESTR, that is highly expressed in leukocytes. J Biol Chem. 1994;269(1):232-7.

8. Alkhatib G, Combadiere C, Broder CC, Feng Y, Kennedy PE, Murphy PM et al. CC CKR5: a RANTES, MIP-1alpha, MIP-1 beta receptor as a fusion cofactor for macrophage-tropic HIV-1. Science. 1996;272(5270):1955-8.

9. Deng H, Liu R, Ellmeier W, Choe S, Unutmaz D, Burkhart M, et al. Identification of a major co-receptor for primary isolates of HIV-1. Nature. 1996;381(6584):661-6

10. Choe H, Farzan M, Sun Y, Sullivan N, Rollins B, Ponath PD, et al. The betachemokine receptors CCR3 and CCR5 facilitate infection by primary HIV-1 isolates. Cell. 1996:85(7):1135-48.

11. Dragic T, Litwin V, Allaway GP, Martin SR, Huang Y, Nagashima KA, et al. HIV-1 entry into CD4+ cells is mediated by the chemokine receptor CC-CKR-5. Nature. 1996;381(6584):667-73.

12. Feng $Y$, Broder CC, Kennedy PE, Berger EA. HIV-1 entry cofactor: functional cDNA cloning of a seven-transmembrane $G$ protein-coupled receptor. Science. 1996;272(5263):872-7.

13. Zhang L, Huang Y, He T, Cao Y, Ho DD. HIV-1 subtype and second-receptor use. Nature. 1996;383(6603):768.

14. Berson JF, Long D, Doranz BJ, Rucker J, Jirik FR, Doms RW. A seventransmembrane domain receptor involved in fusion and entry of T-cell-tropic human immunodeficiency virus type 1 strains. J Virol. 1996;70(9):6288-95

15. Tscherning C, Alaeus A, Fredriksson R, Bjorndal A, Deng H, Littman DR, et al. Differences in chemokine coreceptor usage between genetic subtypes of HIV-1. Virology. 1998;241(2):181-8.

16. Alkhatib G, Broder CC, Berger EA. Cell type-specific fusion cofactors determine human immunodeficiency virus type 1 tropism for T-cell lines versus primary macrophages. J Virol. 1996:70(8):5487-94.

17. Shioda T, Levy JA, Cheng-Mayer C. Macrophage and T cell-line tropisms of HIV-1 are determined by specific regions of the envelope gp!20 gene. Nature. 1991;349(6305):167-9.

18. Albright AV, Shieh JT, Itoh T, Lee B, Pleasure D, O'Connor MJ, et al. Microglia express CCR5, CXCR4, and CCR3, but of these, CCR5 is the principal coreceptor for human immunodeficiency virus type 1 dementia isolates. J Virol. 1999;73(1):205-13.

19. Lee B, Sharron M, Montaner LJ, Weissman D, Doms RW. Quantification of CD4, CCR5, and CXCR4 levels on lymphocyte subsets, dendritic cells, and differentially conditioned monocyte-derived macrophages. Proc Natl Acad Sci. 1999;96(9):5215

20. Bleul CC, Wu L, Hoxie JA, Springer TA, Mackay CR. The HIV coreceptors CXCR4 and CCR5 are differentially expressed and regulated on human T lymphocytes. Proc Natl Acad Sci. 1997;94(5):1925.

21. Kunkel EJ, Boisvert J, Murphy K, Vierra MA, Genovese MC, Wardlaw $A J$, et al. Expression of the chemokine receptors CCR4, CCR5, and CXCR3 by human tissue-infiltrating lymphocytes. Am J Pathol. 2002;160(1):347-55.

22. Simmons G, Reeves JD, McKnight Á, Dejucq N, Hibbitts S, Power CA, et al. CXCR4 as a functional coreceptor for human immunodeficiency virus type 1 infection of primary macrophages. J Virol. 1998;72(10):8453.
23. Yi Y, Isaacs SN, Williams DA, Frank I, Schols D, De Clercq E, et al. Role of CXCR4 in cell-cell fusion and infection of monocyte-derived macrophages by primary human immunodeficiency virus type 1 (HIV-1) strains: two distinct mechanisms of HIV-1 dual tropism. J Virol. 1999:73(9):7117-25

24. Connor RI, Sheridan KE, Ceradini D, Choe S, Landau NR. Change in Coreceptor Use Correlates with Disease Progression in HIV-1-Infected Individuals. J Exp Med. 1997;185(4):621-8.

25. Goodenow MM, Collman RG. HIV-1 coreceptor preference is distinct from target cell tropism: a dual-parameter nomenclature to define viral phenotypes. J Leukoc Biol. 2006;80(5):965-72.

26. Berger EA, Doms RW, Fenyo EM, Korber BT, Littman DR, Moore JP, et al. A new classification for HIV-1. Nature. 1998;391(6664):240.

27. Doranz BJ, Rucker J, Yi Y, Smyth RJ, Samson M, Peiper SC, et al. A dualtropic primary HIV-1 isolate that uses fusin and the beta-chemokine receptors CKR-5, CKR-3, and CKR-2b as fusion cofactors. Cell. 1996;85(7):1149-58.

28. Hughes CE, Nibbs RJB. A guide to chemokines and their receptors. FEBS J. 2018;285(16):2944-71.

29. Wu Y, Yoder A. Chemokine coreceptor signaling in HIV-1 infection and pathogenesis. PLoS Pathog. 2009;5(12):e1000520.

30. Rossi D, Zlotnik A. The biology of chemokines and their receptors. Annu Rev Immunol. 2000;18:217-42.

31. Kuang $Y$, Wu $Y$, Jiang $H$, Wu D. Selective $G$ protein coupling by $C-C$ chemokine receptors. J Biol Chem. 1996;271(8):3975-8.

32. Alfano M, Schmidtmayerova H, Amella CA, Pushkarsky T, Bukrinsky $M$. The B-oligomer of pertussis toxin deactivates CC chemokine receptor 5 and blocks entry of M-tropic HIV-1 strains. J Exp Med. 1999;190(5):597-605.

33. Aramori I, Ferguson SS, Bieniasz PD, Zhang J, Cullen B, Cullen MG. Molecular mechanism of desensitization of the chemokine receptor CCR-5: receptor signaling and internalization are dissociable from its role as an HIV-1 co-receptor. Embo j. 1997;16(15):4606-16.

34. Oppermann M. Chemokine receptor CCR5: insights into structure, function, and regulation. Cell Signal. 2004;16(11):1201-10.

35. Leach $\mathrm{K}$, Charlton SJ, Strange PG. Analysis of second messenger pathways stimulated by different chemokines acting at the chemokine receptor CCR5. Biochem Pharmacol. 2007;74(6):881-90.

36. Arai $\mathrm{H}$, Charo IF. Differential regulation of $\mathrm{G}$-protein-mediated signaling by chemokine receptors. J Biol Chem. 1996;271(36):21814-9.

37. Brelot A, Chakrabarti LA. CCR5 revisited: how mechanisms of HIV entry govern AIDS pathogenesis. J Mol Biol. 2018;430(17):2557-89.

38. Hartley O, Dorgham K, Perez-Bercoff D, Cerini F, Heimann A, Gaertner $\mathrm{H}$, et al. Human immunodeficiency virus type 1 entry inhibitors selected on living cells from a library of phage chemokines. J Virol. 2003:77(12):6637-44.

39. Hartley O, Gaertner H, Wilken J, Thompson D, Fish R, Ramos A, et al. Medicinal chemistry applied to a synthetic protein: development of highly potent HIV entry inhibitors. Proc Natl Acad Sci U S A. 2004;101(47):16460-5.

40. Venuti A, Pastori C, Lopalco L. The role of natural antibodies to CC chemokine receptor 5 in HIV infection. Front Immunol. 2017;8:1358.

41. Jones KL, Smyth RP, Pereira CF, Cameron PU, Lewin SR, Jaworowski A, et al. Early events of HIV-1 infection: can signaling be the next therapeutic target? J Neuroimmune Pharmacol. 2011;6(2):269-83.

42. Wang J, Tannous BA, Poznansky MC, Chen H. CXCR4 antagonist AMD3100 (plerixafor): From an impurity to a therapeutic agent. Pharmacol Res. 2020;159:105010.

43. Zhang C, Zhu R, Cao Q, Yang X, Huang Z, An J. Discoveries and developments of CXCR4-targeted HIV-1 entry inhibitors. Exp Biol Med (Maywood). 2020;245(5):477-85

44. Latinovic OS, Reitz M, Heredia A. CCR5 inhibitors and HIV-1 infection. J AIDS HIV Treat. 2019;1(1):1-5.

45. Jiang X, Feyertag F, Meehan CJ, McCormack GP, Travers SA, Craig C, et al. Characterizing the diverse mutational pathways associated with R5-tropic maraviroc resistance: HIV-1 that uses the drug-bound CCR5 coreceptor. J Virol. 2015;89(22):11457-72.

46. Nath A. Human immunodeficiency virus (HIV) proteins in neuropathogenesis of HIV dementia. J Infect Dis. 2002;186(Suppl 2):S193-8. 
47. Mocchetti I, Bachis A, Avdoshina V. Neurotoxicity of human immunodeficiency virus-1: viral proteins and axonal transport. Neurotox Res. 2012;21(1):79-89.

48. Mocchetti I, Bachis A, Esposito G, Turner SR, Taraballi F, Tasciotti E, et al. Human immunodeficiency virus-associated dementia: a link between accumulation of viral proteins and neuronal degeneration. Curr Trends Neurol. 2014;8:71-85.

49. Meucci O, Fatatis A, Simen AA, Bushell TJ, Gray PW, Miller RJ. Chemokines regulate hippocampal neuronal signaling and gp120 neurotoxicity. Proc Natl Acad Sci U S A. 1998;95(24):14500-5.

50. Kaul M, Lipton SA. Chemokines and activated macrophages in HIV gp120-induced neuronal apoptosis. Proc Natl Acad Sci U S A. 1999:96(14):8212-6.

51. Kaul M, Lipton SA. Mechanisms of neuronal injury and death in HIV-1 associated dementia. Curr HIV Res. 2006;4(3):307-18.

52. Lucas S, Nelson AM. HIV and the spectrum of human disease. J Pathol. 2015;235(2):229-41.

53. Fox $\mathrm{CH}$, Cottler-Fox M. The pathobiology of HIV infection. Immunol Today. 1992;13(9):353-6.

54. Cihlar T, Fordyce M. Current status and prospects of HIV treatment. Curr Opin Virol. 2016;18:50-6.

55. Boender TS, Smit C, Sighem AV, Bezemer D, Ester CJ, Zaheri S, et al. AIDS therapy evaluation in the Netherlands (ATHENA) national observational HIV cohort: cohort profile. BMJ Open. 2018;8(9):e022516.

56. Spudich S, Robertson KR, Bosch RJ, Gandhi RT, Cyktor JC, Mar H, et al. Persistent HIV-infected cells in cerebrospinal fluid are associated with poorer neurocognitive performance. J Clin Invest. 2019;129(8):3339-46.

57. Kumar AM, Borodowsky I, Fernandez B, Gonzalez L, Kumar M. Human immunodeficiency virus type 1 RNA Levels in different regions of human brain: quantification using real-time reverse transcriptasepolymerase chain reaction. J Neurovirol. 2007;13(3):210-24.

58. Canestri A, Lescure FX, Jaureguiberry S, Moulignier A, Amiel C, Marcelin $A G$, et al. Discordance between cerebral spinal fluid and plasma HIV replication in patients with neurological symptoms who are receiving suppressive antiretroviral therapy. Clin Infect Dis. 2010;50(5):773-8.

59. Ko A, Kang G, Hattler JB, Galadima HI, Zhang J, Li Q, et al. Macrophages but not astrocytes harbor HIV DNA in the brains of HIV-1-infected aviremic individuals on suppressive antiretroviral therapy. J Neuroimmune Pharmacol. 2019;14(1):110-9.

60. Anderson AM, Munoz-Moreno JA, McClernon DR, Ellis RJ, Cookson D, Clifford DB, et al. Prevalence and correlates of persistent HIV-1 RNA in cerebrospinal fluid during antiretroviral therapy. J Infect Dis. 2017;215(1):105-13.

61. Eggers C, Arendt G, Hahn K, Husstedt IW, Maschke M, Neuen-Jacob E, et al. HIV-1-associated neurocognitive disorder: epidemiology, pathogenesis, diagnosis, and treatment. J Neurol. 2017;264(8):1715-27.

62. Grabar S, Weiss L, Costagliola D. HIV infection in older patients in the HAART era. J Antimicrob Chemother. 2006;57(1):4-7.

63. Heaton RK, Clifford DB, Franklin DR Jr, Woods SP, Ake C, Vaida F, et al. HIV-associated neurocognitive disorders persist in the era of potent antiretroviral therapy: CHARTER Study. Neurology. 2010;75(23):2087-96.

64. Watkins CC, Treisman GJ. Neuropsychiatric complications of aging with HIV. J Neurovirol. 2012;18(4):277-90.

65. Matt SM, Gaskill PJ. Dopaminergic impact of CART and anti-depressants on HIV neuropathogenesis in older adults. Brain Res. 2019;1723:146398.

66. Nickoloff-Bybel EA, Calderon TM, Gaskill PJ, Berman JW. HIV neuropathogenesis in the presence of a disrupted dopamine system. J Neuroimmune Pharmacol. 2020;15(4):729-42.

67. Koenig S, Gendelman HE, Orenstein JM, Dal Canto MC, Pezeshkpour $\mathrm{GH}$, Yungbluth $\mathrm{M}$, et al. Detection of AIDS virus in macrophages in brain tissue from AIDS patients with encephalopathy. Science. 1986:233(4768):1089-93.

68. Fauci AS, Pantaleo G, Stanley S, Weissman D. Immunopathogenic mechanisms of HIV infection. Ann Intern Med. 1996:124(7):654-63.

69. Fanales-Belasio E, Raimondo M, Suligoi B, Buttò S. HIV virology and pathogenetic mechanisms of infection: a brief overview. Ann Ist Super Sanita. 2010;46(1):5-14.

70. Wilen CB, Tilton JC, Doms RW. HIV: cell binding and entry. Cold Spring Harb Perspect Med. 2012. https://doi.org/10.1101/cshperspect.a0068 66.
71. Wu L, Gerard NP, Wyatt R, Choe H, Parolin C, Ruffing N, et al. CD4induced interaction of primary HIV-1 gp120 glycoproteins with the chemokine receptor CCR-5. Nature. 1996;384(6605):179-83.

72. Sattentau QJ, Moore JP. Conformational changes induced in the human immunodeficiency virus envelope glycoprotein by soluble CD4 binding. J Exp Med. 1991;174(2):407-15.

73. Weissenhorn W, Wharton SA, Calder LJ, Earl PL, Moss B, Aliprandis E, et al. The ectodomain of HIV-1 env subunit gp41 forms a soluble, alphahelical, rod-like oligomer in the absence of gp120 and the N-terminal fusion peptide. Embo j. 1996;15(7):1507-14.

74. Wyatt R, Sodroski J. The HIV-1 envelope glycoproteins: fusogens, antigens, and immunogens. Science. 1998;280(5371):1884-8.

75. Arhel N. Revisiting HIV-1 uncoating. Retrovirology. 2010;7:96.

76. Novikova M, Zhang Y, Freed EO, Peng K. Multiple roles of HIV-1 capsid during the virus replication cycle. Virol Sin. 2019;34(2):119-34.

77. Chin CR, Perreira JM, Savidis G, Portmann JM, Aker AM, Feeley EM, et al. Direct visualization of HIV-1 replication intermediates shows that capsid and CPSF6 modulate HIV-1 intra-nuclear invasion and integration. Cell Rep. 2015;13(8):1717-31.

78. Peng K, Muranyi W, Glass B, Laketa V, Yant SR, Tsai L, et al. Quantitative microscopy of functional HIV post-entry complexes reveals association of replication with the viral capsid. Elife. 2014;3:e04114.

79. Engelman AN, Singh PK. Cellular and molecular mechanisms of HIV-1 integration targeting. Cell Mol Life Sci. 2018;75(14):2491-507.

80. Karn J, Stoltzfus CM. Transcriptional and posttranscriptional regulation of HIV-1 gene expression. Cold Spring Harb Perspect Med. 2012:2(2):a006916.

81. Freed EO. HIV-1 assembly, release and maturation. Nat Rev Microbiol. 2015;13(8):484-96.

82. Bukrinskaya AG. HIV-1 assembly and maturation. Arch Virol. 2004;149(6):1067-82.

83. Sundquist WI, Krausslich HG. HIV-1 assembly, budding, and maturation. Cold Spring Harb Perspect Med. 2012;2(7):a006924.

84. Welsch S, Groot F, Kräusslich HG, Keppler OT, Sattentau QJ. Architecture and regulation of the HIV-1 assembly and holding compartment in macrophages. J Virol. 2011;85(15):7922-7.

85. Benaroch P, Billard E, Gaudin R, Schindler M, Jouve M. HIV-1 assembly in macrophages. Retrovirology. 2010;7(1):29.

86. Nkwe DO, Pelchen-Matthews A, Burden JJ, Collinson LM, Marsh M. The intracellular plasma membrane-connected compartment in the assembly of HIV-1 in human macrophages. BMC Biol. 2016;14(1):50.

87. Navia BA, Cho ES, Petito CK, Price RW. The AIDS dementia complex: II. Neuropathology Ann Neurol. 1986;19(6):525-35.

88. Davis LE, Hjelle BL, Miller VE, Palmer DL, Llewellyn AL, Merlin TL, et al. Early viral brain invasion in iatrogenic human immunodeficiency virus infection. Neurology. 1992;42(9):1736-9.

89. Heaton RK, Franklin DR, Ellis RJ, McCutchan JA, Letendre SL, Leblanc S, et al. HIV-associated neurocognitive disorders before and during the era of combination antiretroviral therapy: differences in rates, nature, and predictors. J Neurovirol. 2011;17(1):3-16.

90. Thakur KT, Boubour A, Saylor D, Das M, Bearden DR, Birbeck GL. Global HIV neurology: a comprehensive review. AIDS. 2019;33(2):163-84.

91. Antinori A, Arendt G, Becker JT, Brew BJ, Byrd DA, Cherner M, et al. Updated research nosology for HIV-associated neurocognitive disorders. Neurology. 2007:69(18):1789-99.

92. Heaton RK, Franklin DR Jr, Deutsch R, Letendre S, Ellis RJ, Casaletto K, et al. Neurocognitive change in the era of HIV combination antiretroviral therapy: the longitudinal CHARTER study. Clin Infect Dis. 2015;60(3):473-80.

93. Valcour V, Chalermchai T, Sailasuta N, Marovich M, Lerdlum S, Suttichom $D$, et al. Central nervous system viral invasion and inflammation during acute HIV infection. J Infect Dis. 2012;206(2):275-82.

94. Kolson D. Neurologic complications in persons with HIV infection in the era of antiretroviral therapy. Top Antivir Med. 2017;25(3):97-101.

95. Peluso R, Haase A, Stowring L, Edwards M, Ventura P. A Trojan Horse mechanism for the spread of visna virus in monocytes. Virology. 1985;147(1):231-6.

96. Crowe S, Zhu T, Muller WA. The contribution of monocyte infection and trafficking to viral persistence, and maintenance of the viral reservoir in HIV infection. J Leukoc Biol. 2003;74(5):635-41. 
97. Williams DW, Calderon TM, Lopez L, Carvallo-Torres L, Gaskill PJ, Eugenin $E A$, et al. Mechanisms of HIV entry into the CNS: increased sensitivity of HIV infected CD14(+)CD16(+) monocytes to CCL2 and key roles of CCR2, JAM-A, and ALCAM in diapedesis. PLoS ONE. 2013;8(7):e69270.

98. Williams JL, Holman DW, Klein RS. Chemokines in the balance: maintenance of homeostasis and protection at CNS barriers. Front Cell Neurosci. 2014:8:154.

99. Haase AT. Pathogenesis of lentivirus infections. Nature. 1986:322(6075):130-6.

100. Hazleton JE, Berman JW, Eugenin EA. Novel mechanisms of central nervous system damage in HIV infection. HIV AIDS (Auckl). 2010;2:39-49.

101. Minagar A, Shapshak P, Fujimura R, Ownby R, Heyes M, Eisdorfer C. The role of macrophage/microglia and astrocytes in the pathogenesis of three neurologic disorders: HIV-associated dementia, Alzheimer disease, and multiple sclerosis. J Neurol Sci. 2002;202(1):13-23.

102. Rappaport J, Volsky DJ. Role of the macrophage in HIV-associated neurocognitive disorders and other comorbidities in patients on effective antiretroviral treatment. J Neurovirol. 2015;21(3):235-41.

103. Kraft-Terry SD, Buch SJ, Fox HS, Gendelman HE. A coat of many colors: neuroimmune crosstalk in human immunodeficiency virus infection. Neuron. 2009;64(1):133-45.

104. Saylor D, Dickens AM, Sacktor N, Haughey N, Slusher B, Pletnikov M, et al. HIV-associated neurocognitive disorder - pathogenesis and prospects for treatment. Nat Rev Neurol. 2016;12(5):309.

105. Gonzalez-Scarano F, Martin-Garcia J. The neuropathogenesis of AIDS. Nat Rev Immunol. 2005:5(1):69-81.

106. Irollo E, Luchetta J, Ho C, Nash B, Meucci O. Mechanisms of neuronal dysfunction in HIV-associated neurocognitive disorders. Cell Mol Life Sci. 2021. https://doi.org/10.1007/s00018-021-03785-y.

107. Kaul M, Garden GA, Lipton SA. Pathways to neuronal injury and apoptosis in HIV-associated dementia. Nature. 2001;410(6831):988-94.

108. Mocchetti I, Campbell LA, Harry GJ, Avdoshina V. When human immunodeficiency virus meets chemokines and microglia: neuroprotection or neurodegeneration? J Neuroimmune Pharmacol. 2013;8(1):118-31.

109. Eugenin EA, Berman JW. Gap junctions mediate human immunodeficiency virus-bystander killing in astrocytes. J Neurosci. 2007:27(47):12844-50.

110. Eugenin EA, Clements JE, Zink MC, Berman JW. Human immunodeficiency virus infection of human astrocytes disrupts blood-brain barrier integrity by a gap junction-dependent mechanism. J Neurosci. 2011;31(26):9456-65.

111. Churchill MJ, Wesselingh SL, Cowley D, Pardo CA, McArthur JC, Brew BJ, et al. Extensive astrocyte infection is prominent in human immunodeficiency virus-associated dementia. Ann Neurol. 2009;66(2):253-8.

112. Gorry PR, Ong C, Thorpe J, Bannwarth S, Thompson KA, Gatignol A, et al. Astrocyte infection by HIV-1: mechanisms of restricted virus replication, and role in the pathogenesis of HIV-1-associated dementia. Curr HIV Res. 2003;1 (4):463-73.

113. Russell RA, Chojnacki J, Jones DM, Johnson E, Do T, Eggeling C, et al. Astrocytes resist HIV-1 fusion but engulf infected macrophage material. Cell Rep. 2017;18(6):1473-83.

114. Boutet A, Salim H, Taoufik Y, Lledo PM, Vincent JD, Delfraissy JF, et al. Isolated human astrocytes are not susceptible to infection by $\mathrm{M}$ - and T-tropic HIV-1 strains despite functional expression of the chemokine receptors CCR5 and CXCR4. Glia. 2001;34(3):165-77.

115. Lawrence DM, Major EO. HIV-1 and the brain: connections between HIV-1-associated dementia, neuropathology and neuroimmunology. Microbes Infect. 2002;4(3):301-8.

116. Vazeux R, Brousse N, Jarry A, Henin D, Marche C, Vedrenne C, et al. AIDS subacute encephalitis. Identification of HIV-infected cells. Am J Pathol. 1987;126(3):403-10

117. Masliah E, Ge N, Achim CL, Hansen LA, Wiley CA. Selective neuronal vulnerability in HIV encephalitis. J Neuropathol Exp Neurol. 1992;51(6):585-93.

118. McArthur JC, Sacktor N, Selnes O. Human immunodeficiency virusassociated dementia. Semin Neurol. 1999;19(2):129-50.

119. Everall IP, Hansen LA, Masliah E. The shifting patterns of HIV encephalitis neuropathology. Neurotox Res. 2005;8(1):51-61.

120. Glass JD, Johnson RT. Human immunodeficiency virus and the brain. Annu Rev Neurosci. 1996:19:1-26.
121. Fujimura RK, Goodkin K, Petito CK, Douyon R, Feaster DJ, Concha M, et al. HIV-1 proviral DNA load across neuroanatomic regions of individuals with evidence for HIV-1-associated dementia. J Acquir Immune Defic Syndr Hum Retrovirol. 1997;16(3):146-52.

122. Wiley CA, Soontornniyomkij V, Radhakrishnan L, Masliah E, Mellors J, Hermann SA, et al. Distribution of brain HIV load in AIDS. Brain Pathol. 1998:8(2):277-84.

123. O'Connor EE, Zeffiro TA, Zeffiro TA. Brain structural changes following HIV infection: meta-analysis. AJNR Am J Neuroradiol. 2018:39(1):54-62.

124. Aylward EH, Henderer JD, MCArthur JC, Brettschneider PD, Harris GJ, Barta PE, et al. Reduced basal ganglia volume in HIV-1-associated dementia: results from quantitative neuroimaging. Neurology. 1993:43(10):2099-104.

125. Itoh $\mathrm{K}$, Mehraein P, Weis S. Neuronal damage of the substantia nigra in HIV-1 infected brains. Acta Neuropathol. 2000;99(4):376-84.

126. Sacktor N. Changing clinical phenotypes of HIV-associated neurocognitive disorders. J Neurovirol. 2018;24(2):141-5.

127. Vago L, Bonetto S, Nebuloni M, Duca P, Carsana L, Zerbi P, et al. Pathological findings in the central nervous system of AIDS patients on assumed antiretroviral therapeutic regimens: retrospective study of 1597 autopsies. AIDS (London, England). 2002;16(14):1925-8.

128. Nath A, Haughey NJ, Jones M, Anderson C, Bell JE, Geiger JD. Synergistic neurotoxicity by human immunodeficiency virus proteins Tat and gp120: protection by memantine. Ann Neurol. 2000;47(2):186-94.

129. Jones MV, Bell JE, Nath A. Immunolocalization of HIV envelope gp120 in HIV encephalitis with dementia. AIDS (London, England). 2000;14(17):2709-13.

130. Robertson K, Fiscus S, Kapoor C, Robertson W, Schneider G, Shepard R, et al. CSF, plasma viral load and HIV associated dementia. J Neurovirol. 1998:4(1):90-4.

131. McArthur JC, McClernon DR, Cronin MF, Nance-Sproson TE, Saah AJ, St Clair M, et al. Relationship between human immunodeficiency virusassociated dementia and viral load in cerebrospinal fluid and brain. Ann Neurol. 1997;42(5):689-98.

132. Brew BJ, Pemberton L, Cunningham P, Law MG. Levels of human immunodeficiency virus type 1 RNA in cerebrospinal fluid correlate with AIDS dementia stage. J Infect Dis. 1997;175(4):963-6.

133. Gelman BB. Neuropathology of HAND with suppressive antiretroviral therapy: encephalitis and neurodegeneration reconsidered. Curr HIV/ AIDS Rep. 2015;12(2):272-9.

134. Anthony IC, Ramage SN, Carnie FW, Simmonds P, Bell JE. Influence of HAART on HIV-related CNS disease and neuroinflammation. J Neuropathol Exp Neurol. 2005;64(6):529-36.

135. Becker JT, Sanders J, Madsen SK, Ragin A, Kingsley L, Maruca V, et al. Subcortical brain atrophy persists even in HAART-regulated HIV disease. Brain Imaging Behav. 2011;5(2):77-85.

136. Ipser JC, Brown GG, Bischoff-Grethe A, Connolly CG, Ellis RJ, Heaton RK, et al. HIV infection is associated with attenuated frontostriatal intrinsic connectivity: a preliminary study. J Int Neuropsychol Soc. 2015;21(3):203-13.

137. Ortega M, Brier MR, Ances BM. Effects of HIV and combination antiretroviral therapy on cortico-striatal functional connectivity. AIDS. 2015;29(6):703-12.

138. Alakkas A, Ellis RJ, Watson CW, Umlauf A, Heaton RK, Letendre S, et al. White matter damage, neuroinflammation, and neuronal integrity in HAND. J Neurovirol. 2019;25(1):32-41.

139. Valcour $V$, Sithinamsuwan $P$, Letendre $S$, Ances B. Pathogenesis of HIV in the central nervous system. Curr HIV/AIDS Rep. 2011;8(1):54-61.

140. Sevigny JJ, Albert SM, MCDermott MP, MCArthur JC, Sacktor N, Conant $\mathrm{K}$, et al. Evaluation of HIV RNA and markers of immune activation as predictors of HIV-associated dementia. Neurology. 2004;63(11):2084-90.

141. McArthur JC. HIV dementia: an evolving disease. J Neuroimmunol. 2004;157(1-2):3-10.

142. Tavazzi E, Morrison D, Sullivan P, Morgello S, Fischer T. Brain inflammation is a common feature of HIV-infected patients without HIV encephalitis or productive brain infection. Curr HIV Res. 2014;12(2):97-110.

143. Carroll A, Brew B. HIV-associated neurocognitive disorders: recent advances in pathogenesis, biomarkers, and treatment. F1000Res. 2017;6:312

144. Hsu DC, Sunyakumthorn P, Wegner M, Schuetz A, Silsorn D, Estes JD, et al. Central nervous system inflammation and infection during early, 
nonaccelerated simian-human immunodeficiency virus infection in rhesus macaques. J Virol. 2018. https://doi.org/10.1128/JVI.00222-18.

145. Vera JH, Guo Q, Cole JH, Boasso A, Greathead L, Kelleher P, et al. Neuroinflammation in treated HIV-positive individuals: A TSPO PET study. Neurology. 2016;86(15):1425-32.

146. Finzi D, Hermankova M, Pierson T, Carruth LM, Buck C, Chaisson RE, et al. Identification of a reservoir for HIV-1 in patients on highly active antiretroviral therapy. Science. 1997;278(5341):1295-300.

147. Rouzine IM, Weinberger AD, Weinberger LS. An evolutionary role for HIV latency in enhancing viral transmission. Cell. 2015;160(5):1002-12.

148. Ruelas DS, Greene WC. An integrated overview of HIV-1 latency. Cell. 2013;155(3):519-29.

149. Burdo TH, Lentz MR, Autissier P, Krishnan A, Halpern E, Letendre S, et al. Soluble CD163 made by monocyte/macrophages is a novel marker of HIV activity in early and chronic infection prior to and after anti-retroviral therapy. J Infect Dis. 2011;204(1):154-63.

150. Lyons JL, Uno H, Ancuta P, Kamat A, Moore DJ, Singer EJ, et al. Plasma sCD14 is a biomarker associated with impaired neurocognitive test performance in attention and learning domains in HIV infection. J Acquir Immune Defic Syndr. 2011;57(5):371-9.

151. Kamat A, Lyons JL, Misra V, Uno H, Morgello S, Singer EJ, et al. Monocyte activation markers in cerebrospinal fluid associated with impaired neurocognitive testing in advanced HIV infection. J Acquir Immune Defic Syndr. 2012;60(3):234-43.

152. Eden A, Price RW, Spudich S, Fuchs D, Hagberg L, Gisslen M. Immune activation of the central nervous system is still present after $>4$ years of effective highly active antiretroviral therapy. J Infect Dis, 2007;196(12):1779-83.

153. Kim HJ, Shin AH, Thayer SA. Activation of cannabinoid type 2 receptors inhibits HIV-1 envelope glycoprotein gp120-induced synapse loss. Mol Pharmacol. 2011:80(3):357-66.

154. Festa L, Gutoskey CJ, Graziano A, Waterhouse BD, Meucci O. Induction of interleukin-1 beta by human immunodeficiency virus-1 viral proteins leads to increased levels of neuronal ferritin heavy chain, synaptic injury, and deficits in flexible attention. J Neurosci. 2015;35(29):10550-61.

155. Avdoshina V, Mahoney M, Gilmore SF, Wenzel ED, Anderson A, Letendre $\mathrm{SL}$, et al. HIV influences microtubule associated protein-2: potential marker of HIV-associated neurocognitive disorders. AIDS (London, England). 2020;34(7):979-88

156. Clifford KM, Samboju V, Cobigo Y, Milanini B, Marx GA, Hellmuth JM, et al. Progressive brain atrophy despite persistent viral suppression in HIV patients older than 60 years. J Acquir Immune Defic Syndr. 2017:76(3):289-97.

157. Nichols MJ, Gates TM, Soares JR, Moffat KJ, Rae CD, Brew BJ, et al. Atrophic brain signatures of mild forms of neurocognitive impairment in virally suppressed HIV infection. AIDS (London, England). 2019;33(1):55-66.

158. Gongvatana A, Harezlak J, Buchthal S, Daar E, Schifitto G, Campbell T, et al. Progressive cerebral injury in the setting of chronic HIV infection and antiretroviral therapy. J Neurovirol. 2013;19(3):209-18.

159. Bell JE. An update on the neuropathology of HIV in the HAART era. Histopathology. 2004:45(6):549-59.

160. Festa L, Meucci O. Effects of opiates and HIV proteins on neurons: the role of ferritin heavy chain and a potential for synergism. Curr HIV Res. 2012;10(5):453-62.

161. Meucci O, Miller RJ. gp120-induced neurotoxicity in hippocampal pyramidal neuron cultures: protective action of TGF-beta1. J Neurosci. 1996;16(13):4080-8.

162. Miller RJ, Meucci O. AIDS and the brain: is there a chemokine connection? Trends Neurosci. 1999;22(10):471-9.

163. Bardi G, Sengupta R, Khan MZ, Patel JP, Meucci O. Human immunodeficiency virus gp120-induced apoptosis of human neuroblastoma cells in the absence of CXCR4 internalization. J Neurovirol. 2006:12(3):211-8.

164. Wenzel ED, Speidell A, Flowers SA, Wu C, Avdoshina V, Mocchetti I. Histone deacetylase 6 inhibition rescues axonal transport impairments and prevents the neurotoxicity of HIV-1 envelope protein gp120. Cell Death Dis. 2019;10(9):674

165. Khan MZ, Brandimarti R, Musser BJ, Resue DM, Fatatis A, Meucci O. The chemokine receptor $C X C R 4$ regulates cell-cycle proteins in neurons. J Neurovirol. 2003:9(3):300-14
166. Brandimarti R, Khan MZ, Fatatis A, Meucci O. Regulation of cell cycle proteins by chemokine receptors: a novel pathway in human immunodeficiency virus neuropathogenesis? J Neurovirol. 2004;10(Suppl 1):108-12.

167. Khan MZ, Brandimarti R, Patel JP, Huynh N, Wang J, Huang Z, et al. Apoptotic and antiapoptotic effects of CXCR4: is it a matter of intrinsic efficacy? Implications for HIV neuropathogenesis. AIDS Res Hum Retroviruses. 2004;20(10):1063-71.

168. Khan MZ, Shimizu S, Patel JP, Nelson A, Le MT, Mullen-Przeworski A, et al. Regulation of neuronal P53 activity by CXCR 4. Mol Cell Neurosci. 2005;30(1):58-66.

169. Acquas E, Bachis A, Nosheny RL, Cernak I, Mocchetti I. Human immunodeficiency virus type 1 protein gp 120 causes neuronal cell death in the rat brain by activating caspases. Neurotox Res. 2004;5(8):605-15.

170. Bansal AK, Mactutus CF, Nath A, Maragos W, Hauser KF, Booze RM. Neurotoxicity of HIV-1 proteins gp120 and Tat in the rat striatum. Brain Res. 2000;879(1-2):42-9.

171. Alirezaei M, Watry DD, Flynn CF, Kiosses WB, Masliah E, Williams BR, et al. Human immunodeficiency virus-1/surface glycoprotein 120 induces apoptosis through RNA-activated protein kinase signaling in neurons. J Neurosci. 2007;27(41):11047-55.

172. Klasse PJ, Moore JP. Is there enough gp120 in the body fluids of HIV1 -infected individuals to have biologically significant effects? Virology. 2004:323(1):1-8.

173. Nightingale S, Winston A, Letendre S, Michael BD, MCArthur JC, Khoo S, et al. Controversies in HIV-associated neurocognitive disorders. Lancet Neurol. 2014:13(11):1139-51.

174. Dailey AF, Hoots BE, Hall HI, Song R, Hayes D, Fulton P Jr, et al. Vital signs: human immunodeficiency virus testing and diagnosis delays-United States. MMWR Morb Mortal Wkly Rep. 2017;66(47):1300-6.

175. Réu P, Khosravi A, Bernard S, Mold JE, Salehpour M, Alkass K, et al. The lifespan and turnover of microglia in the human brain. Cell Rep. 2017:20(4):779-84.

176. Honeycutt JB, Thayer WO, Baker CE, Ribeiro RM, Lada SM, Cao Y, et al. HIV persistence in tissue macrophages of humanized myeloid-only mice during antiretroviral therapy. Nat Med. 2017;23(5):638-43.

177. Le Douce V, Herbein G, Rohr O, Schwartz C. Molecular mechanisms of HIV-1 persistence in the monocyte-macrophage lineage. Retrovirology. 2010;7:32.

178. Asahchop EL, Meziane O, Mamik MK, Chan WF, Branton WG, Resch L, et al. Reduced antiretroviral drug efficacy and concentration in HIVinfected microglia contributes to viral persistence in brain. Retrovirology. 2017;14(1):47.

179. Calcagno A, Barco A, Trunfio M, Bonora S. CNS-targeted antiretroviral strategies: when are they needed and what to choose. Curr HIV/AIDS Rep. 2018. https://doi.org/10.1007/s11904-018-0375-2.

180. Churchill MJ, Cowley DJ, Wesselingh SL, Gorry PR, Gray LR. HIV-1 transcriptional regulation in the central nervous system and implications for HIV cure research. J Neurovirol. 2015;21(3):290-300.

181. Ferrara M, Bumpus NN, Ma Q, Ellis RJ, Soontornniyomkij V, Fields JA, et al. Antiretroviral drug concentrations in brain tissue of adult decedents. AIDS (London, England). 2020;34(13):1907-14.

182. Gavegnano C, Schinazi RF. Antiretroviral therapy in macrophages: implication for HIV eradication. Antivir Chem Chemother. 2009;20(2):63-78.

183. Wang Z, Shang H, Jiang Y. Chemokines and chemokine receptors: accomplices for human immunodeficiency virus infection and latency. Front Immunol. 2017:8:1274

184. López-Cotarelo P, Gómez-Moreira C, Criado-García O, Sánchez L, Rodríguez-Fernández JL. Beyond chemoattraction: multifunctionality of chemokine receptors in leukocytes. Trends Immunol. 2017;38(12):927-41

185. Cartier L, Hartley O, Dubois-Dauphin M, Krause KH. Chemokine receptors in the central nervous system: role in brain inflammation and neurodegenerative diseases. Brain Res Brain Res Rev. 2005;48(1):16-42.

186. Jones KL, Maguire JJ, Davenport AP. Chemokine receptor CCR5: from AIDS to atherosclerosis. Br J Pharmacol. 2011:162(7):1453-69.

187. Daniela Angela C, Michela S, Laura F. The CCL2/CCR2 axis in the pathogenesis of HIV-1 infection: a new cellular target for therapy? Curr Drug Targets. 2016;17(1):76-110. 
188. Evans VA, Khoury G, Saleh S, Cameron PU, Lewin SR. HIV persistence: chemokines and their signalling pathways. Cytokine Growth Factor Rev. 2012;23(4-5):151-7.

189. Gorry PR, Ancuta P. Coreceptors and HIV-1 pathogenesis. Curr HIV/AIDS Rep. 2011;8(1):45-53.

190. Bjorndal A, Deng H, Jansson M, Fiore JR, Colognesi C, Karlsson A, et al. Coreceptor usage of primary human immunodeficiency virus type 1 isolates varies according to biological phenotype. J Virol. 1997:71(10):7478-87.

191. Marinissen MJ, Gutkind JS. G-protein-coupled receptors and signaling networks: emerging paradigms. Trends Pharmacol Sci. 2001;22(7):368-76.

192. Hilger D, Masureel M, Kobilka BK. Structure and dynamics of GPCR signaling complexes. Nat Struct Mol Biol. 2018;25(1):4-12

193. Smrcka AV. G protein $\beta$ y subunits: central mediators of $G$ protein-coupled receptor signaling. Cell Mol Life Sci. 2008;65(14):2191-214.

194. Smrcka AV, Fisher I. G-protein betagamma subunits as multi-functional scaffolds and transducers in G-protein-coupled receptor signaling. Cell Mol Life Sci. 2019. https://doi.org/10.1007/s00018-019-03275-2.

195. Neptune ER, Bourne HR. Receptors induce chemotaxis by releasing the betagamma subunit of Gi, not by activating Gq or Gs. Proc Natl Acad Sci U S A. 1997;94(26):14489-94.

196. Defea K. Beta-arrestins and heterotrimeric G-proteins: collaborators and competitors in signal transduction. Br J Pharmacol. 2008;153(Suppl 1):S298-309.

197. Amarandi RM, Hjorto GM, Rosenkilde MM, Karlshoj S. Probing Biased Signaling in Chemokine Receptors. Methods Enzymol. 2016;570:155-86

198. Lefkowitz RJ, Shenoy SK. Transduction of receptor signals by betaarrestins. Science. 2005;308(5721):512-7.

199. DeWire SM, Ahn S, Lefkowitz RJ, Shenoy SK. Beta-arrestins and cell signaling. Annu Rev Physiol. 2007;69:483-510.

200. Jean-Charles PY, Kaur S, Shenoy SK. G Protein-Coupled Receptor Signaling Through beta-Arrestin-Dependent Mechanisms. J Cardiovasc Pharmacol. 2017:70(3):142-58.

201. Luttrell LM, Ferguson SS, Daaka Y, Miller WE, Maudsley S, Della Rocca GJ, et al. Beta-arrestin-dependent formation of beta2 adrenergic receptorSrc protein kinase complexes. Science. 1999;283(5402):655-61.

202. Ganju RK, Brubaker SA, Meyer J, Dutt P, Yang Y, Qin S, et al. The alphachemokine, stromal cell-derived factor-1alpha, binds to the transmembrane G-protein-coupled CXCR-4 receptor and activates multiple signal transduction pathways. J Biol Chem. 1998:273(36):23169-75.

203. Sun Y, Cheng Z, Ma L, Pei G. Beta-arrestin 2 is critically involved in CXCR4-mediated chemotaxis, and this is mediated by its enhancement of p38 MAPK activation. J Biol Chem. 2002;277(51):49212-9.

204. Luttrell LM, Roudabush FL, Choy EW, Miller WE, Field ME, Pierce KL, et al. Activation and targeting of extracellular signal-regulated kinases by beta-arrestin scaffolds. Proc Natl Acad Sci U S A. 2001;98(5):2449-54

205. DeFea KA, Zalevsky J, Thoma MS, Déry O, Mullins RD, Bunnett NW. beta-arrestin-dependent endocytosis of proteinase-activated receptor 2 is required for intracellular targeting of activated ERK1/2. J Cell Biol. 2000;148(6):1267-81.

206. Povsic TJ, Kohout TA, Lefkowitz RJ. Beta-arrestin1 mediates insulin-like growth factor 1 (IGF-1) activation of phosphatidylinositol 3-kinase (PI3K) and anti-apoptosis. J Biol Chem. 2003;278(51):51334-9.

207. Ferguson SS, Zhang J, Barak LS, Caron MG. Molecular mechanisms of G protein-coupled receptor desensitization and resensitization. Life Sci. 1998:62(17-18):1561-5.

208. Krupnick JG, Benovic JL. The role of receptor kinases and arrestins in G protein-coupled receptor regulation. Annu Rev Pharmacol Toxicol. 1998;38:289-319.

209. Claing A, Laporte SA, Caron MG, Lefkowitz RJ. Endocytosis of G proteincoupled receptors: roles of $\mathrm{G}$ protein-coupled receptor kinases and beta-arrestin proteins. Prog Neurobiol. 2002;66(2):61-79.

210. Zhang J, Barak LS, Winkler KE, Caron MG, Ferguson SS. A central role for beta-arrestins and clathrin-coated vesicle-mediated endocytosis in beta2-adrenergic receptor resensitization. Differential regulation of receptor resensitization in two distinct cell types. J Biol Chem. 1997:272(43):27005-14.
211. Böhm SK, Grady EF, Bunnett NW. Regulatory mechanisms that modulate signalling by G-protein-coupled receptors. Biochem J. 1997:322:1-18.

212. Bonsch C, Munteanu M, Rossitto-Borlat I, Furstenberg A, Hartley O. Potent anti-HIV chemokine analogs direct post-endocytic sorting of CCR5. PLOS ONE. 2015;10(4):e0125396.

213. Davis CB, Dikic I, Unutmaz D, Hill CM, Arthos J, Siani MA, et al. Signal transduction due to HIV-1 envelope interactions with chemokine receptors CXCR4 or CCR5. J Exp Med. 1997;186(10):1793-8.

214. Rodríguez-Frade JM, Vila-Coro AJ, Martín A, Nieto M, Sánchez-Madrid $F$, Proudfoot $A E$, et al. Similarities and differences in RANTES- and (AOP)-RANTES-triggered signals: implications for chemotaxis. J Cell Biol. 1999; 144(4):755-65.

215. Lorenzen E, Ceraudo E, Berchiche YA, Rico CA, Fürstenberg A, Sakmar TP, et al. G protein subtype-specific signaling bias in a series of CCR5 chemokine analogs. Sci Signal. 2018. https://doi.org/10.1126/scisi gnal.aao6152.

216. Zheng J, Ghorpade A, Niemann D, Cotter RL, Thylin MR, Epstein L, et al. Lymphotropic virions affect chemokine receptor-mediated neural signaling and apoptosis: implications for human immunodeficiency virus type 1-associated dementia. J Virol. 1999;73(10):8256-67.

217. Drury LJ, Ziarek JJ, Gravel S, Veldkamp CT, Takekoshi T, Hwang ST, et al. Monomeric and dimeric CXCL12 inhibit metastasis through distinct CXCR4 interactions and signaling pathways. Proc Natl Acad Sci U S A. 2011;108(43):17655-60.

218. Cheung R, Malik M, Ravyn V, Tomkowicz B, Ptasznik A, Collman RG. An arrestin-dependent multi-kinase signaling complex mediates MIP-1 beta/CCL4 signaling and chemotaxis of primary human macrophages. J Leukoc Biol. 2009;86(4):833-45.

219. Tyner JW, Uchida O, Kajiwara N, Kim EY, Patel AC, O'Sullivan MP, et al. CCL5-CCR5 interaction provides antiapoptotic signals for macrophage survival during viral infection. Nat Med. 2005;11(11):1180-7.

220. Pace AM, Faure M, Bourne HR. Gi2-mediated activation of the MAP kinase cascade. Mol Biol Cell. 1995;6(12):1685-95.

221. Goldsmith ZG, Dhanasekaran DN. G protein regulation of MAPK networks. Oncogene. 2007;26(22):3122-42

222. Mochizuki N, Ohba Y, Kiyokawa E, Kurata T, Murakami T, Ozaki T, et al. Activation of the ERK/MAPK pathway by an isoform of rap1GAP associated with G alpha(i). Nature. 1999;400(6747):891-4.

223. Ottonello L, Montecucco F, Bertolotto M, Arduino N, Mancini M, Corcione A, et al. CCL3 (MIP-1alpha) induces in vitro migration of GM-CSF-primed human neutrophils via CCR5-dependent activation of ERK 1/2. Cell Signal. 2005;17(3):355-63.

224. Sotsios Y, Whittaker GC, Westwick J, Ward SG. The CXC chemokine stromal cell-derived factor activates a Gi-coupled phosphoinositide 3-kinase in T lymphocytes. J Immunol. 1999;163(11):5954-63.

225. Vicente-Manzanares M, Rey M, Jones DR, Sancho D, Mellado M, Rodriguez-Frade JM, et al. Involvement of phosphatidylinositol 3-kinase in stromal cell-derived factor-1 alpha-induced lymphocyte polarization and chemotaxis. J Immunol. 1999;163(7):4001-12.

226. Bartolome RA, Galvez BG, Longo N, Baleux F, Van Muijen GN, Sanchez-Mateos $P$, et al. Stromal cell-derived factor-1alpha promotes melanoma cell invasion across basement membranes involving stimulation of membrane-type 1 matrix metalloproteinase and Rho GTPase activities. Cancer Res. 2004;64(7):2534-43.

227. Henschler R, Piiper A, Bistrian R, Mobest D. SDF-1alpha-induced intracellular calcium transient involves Rho GTPase signalling and is required for migration of hematopoietic progenitor cells. Biochem Biophys Res Commun. 2003;311(4):1067-71.

228. Jin T, Xu X, Hereld D. Chemotaxis, chemokine receptors and human disease. Cytokine. 2008;44(1):1-8.

229. Neptune ER, liri T, Bourne HR. Galphai is not required for chemotaxis mediated by Gi-coupled receptors. J Biol Chem. 1999;274(5):2824-8.

230. Weiss-Haljiti C, Pasquali C, Ji H, Gillieron C, Chabert C, Curchod ML, et al. Involvement of phosphoinositide 3-kinase gamma, Rac, and PAK signaling in chemokine-induced macrophage migration. J Biol Chem. 2004;279(41):43273-84.

231. Sasaki AT, Chun C, Takeda K, Firtel RA. Localized Ras signaling at the leading edge regulates PI3K, cell polarity, and directional cell movement. J Cell Biol. 2004;167(3):505-18. 
232. Park D, Jhon DY, Lee CW, Lee KH, Rhee SG. Activation of phospholipase $C$ isozymes by $\mathrm{G}$ protein beta gamma subunits. J Biol Chem. 1993;268(7):4573-6.

233. Zhu X, Birnbaumer L. G protein subunits and the stimulation of phospholipase $\mathrm{C}$ by Gs-and Gi-coupled receptors: Lack of receptor selectivity of Galpha(16) and evidence for a synergic interaction between Gbeta gamma and the alpha subunit of a receptor activated $\mathrm{G}$ protein. Proc Natl Acad Sci U S A. 1996;93(7):2827-31.

234. Flanagan CA. Receptor conformation and constitutive activity in CCR5 chemokine receptor function and HIV infection. Adv Pharmacol. 2014;70:215-63.

235. Busillo JM, Benovic JL. Regulation of CXCR4 signaling. Biochem Biophys Acta. 2007:1768(4):952-63.

236. Pozzobon T, Goldoni G, Viola A, Molon B. CXCR4 signaling in health and disease. Immunol Lett. 2016;177:6-15.

237. Blanpain C, Migeotte I, Lee B, Vakili J, Doranz BJ, Govaerts C, et al. CCR5 binds multiple CC-chemokines: MCP-3 acts as a natural antagonist. Blood. 1999;94(6):1899-905.

238. Menten P, Wuyts A, Van Damme J. Macrophage inflammatory protein-1. Cytokine Growth Factor Rev. 2002;13(6):455-81.

239. Tuttle DL, Harrison JK, Anders C, Sleasman JW, Goodenow MM. Expression of CCR5 increases during monocyte differentiation and directly mediates macrophage susceptibility to infection by human immunodeficiency virus type 1. J Virol. 1998;72(6):4962-9.

240. Flynn G, Maru S, Loughlin J, Romero IA, Male D. Regulation of chemokine receptor expression in human microglia and astrocytes. J Neuroimmunol. 2003;136(1-2):84-93.

241. van der Meer P, Ulrich AM, Gonźalez-Scarano F, Lavi E. Immunohistochemical analysis of CCR2, CCR3, CCR5, and CXCR4 in the human brain: potential mechanisms for HIV dementia. Exp Mol Pathol. 2000;69(3):192-201.

242. Chien HC, Chan PC, Tu CC, Day YJ, Hung LM, Juan CC, et al. Importance of PLC-dependent PI3K/AKT and AMPK signaling in RANTES/CCR5 mediated macrophage chemotaxis. Chin J Physiol. 2018;61(5):266-79.

243. Ganju RK, Brubaker SA, Chernock RD, Avraham S, Groopman JE. Betachemokine receptor CCR5 signals through SHP1, SHP2, and Syk. J Biol Chem. 2000;275(23):17263-8.

244. Rodríguez-Frade JM, del Real G, Serrano A, Hernanz-Falcón P, Soriano SF, Vila-Coro AJ, et al. Blocking HIV-1 infection via CCR5 and CXCR4 receptors by acting in trans on the CCR2 chemokine receptor. Embo j. 2004;23(1):66-76.

245. Tang $\mathrm{CH}$, Hsu CJ, Fong YC. The CCL5/CCR5 axis promotes interleukin-6 production in human synovial fibroblasts. Arthritis Rheum. 2010;62(12):3615-24.

246. Fantuzzi L, Spadaro F, Purificato C, Cecchetti S, Podo F, Belardelli F, et al. Phosphatidylcholine-specific phospholipase $C$ activation is required for CCR5-dependent, NF-kB-driven CCL2 secretion elicited in response to HIV-1 gp120 in human primary macrophages. Blood. 2008;111(7):3355-63.

247. Castellino F, Huang AY, Altan-Bonnet G, Stoll S, Scheinecker C, Germain RN. Chemokines enhance immunity by guiding naive CD8 + T cells to sites of CD4+ T cell-dendritic cell interaction. Nature. 2006:440(7086):890-5.

248. Glass WG, Lane TE. Functional expression of chemokine receptor CCR5 on CD4(+) T cells during virus-induced central nervous system disease. J Virol. 2003;77(1):191-8

249. Jiao X, Velasco-Velázquez MA, Wang M, Li Z, Rui H, Peck AR, et al. CCR5 governs DNA damage repair and breast cancer stem cell expansion. Can Res. 2018;78(7):1657.

250. Singh SK, Mishra MK, Eltoum IEA, Bae S, Lillard JW, Singh R. CCR5/CCL5 axis interaction promotes migratory and invasiveness of pancreatic cancer cells. Sci Rep. 2018;8(1):1323.

251. Mueller A, Mahmoud NG, Strange PG. Diverse signalling by different chemokines through the chemokine receptor CCR5. Biochem Pharmacol. 2006;72(6):739-48.

252. Kraft K, Olbrich H, Majoul I, Mack M, Proudfoot A, Oppermann M. Characterization of sequence determinants within the carboxyl-terminal domain of chemokine receptor CCR5 that regulate signaling and receptor internalization. J Biol Chem. 2001;276(37):34408-18.
253. Olbrich H, Proudfoot AE, Oppermann M. Chemokine-induced phosphorylation of CC chemokine receptor 5 (CCR5). J Leukoc Biol. 1999;65(3):281-5

254. Escola JM, Kuenzi G, Gaertner H, Foti M, Hartley O. CC chemokine receptor 5 (CCR5) desensitization: cycling receptors accumulate in the trans-Golgi network. J Biol Chem. 2010;285(53):41772-80.

255. Signoret N, Pelchen-Matthews A, Mack M, Proudfoot AE, Marsh M. Endocytosis and recycling of the HIV coreceptor CCR5. J Cell Biol. 2000;151(6):1281-94.

256. Bönsch C, Munteanu M, Rossitto-Borlat I, Fürstenberg A, Hartley O. Potent anti-HIV chemokine analogs direct post-endocytic sorting of CCR5. PLOS ONE. 2015;10(4):e0125396.

257. Flegler AJ, Cianci GC, Hope TJ. CCR5 conformations are dynamic and modulated by localization, trafficking and $\mathrm{G}$ protein association. PLoS ONE. 2014;9(2):e89056.

258. Mack M, Luckow B, Nelson PJ, Cihak J, Simmons G, Clapham PR, et al. Aminooxypentane-RANTES induces CCR5 internalization but inhibits recycling: a novel inhibitory mechanism of HIV infectivity. J Exp Med. 1998;187(8):1215-24.

259. Martins E, Brodier H, Rossitto-Borlat I, Ilgaz I, Villard M, Hartley O. Arrestin recruitment to $\mathrm{C}-\mathrm{C}$ chemokine receptor 5: potent $\mathrm{C}-\mathrm{C}$ chemokine ligand 5 analogs reveal differences in dependence on receptor phosphorylation and isoform-specific recruitment bias. Mol Pharmacol. 2020:98(5):599.

260. Simmons G, Clapham PR, Picard L, Offord RE, Rosenkilde MM, Schwartz TW, et al. Potent inhibition of HIV-1 infectivity in macrophages and lymphocytes by a novel CCR5 antagonist. Science. 1997;276(5310):276-9.

261. Arenzana-Seisdedos F, Virelizier JL, Rousset D, Clark-Lewis I, Loetscher P, Moser B, et al. HIV blocked by chemokine antagonist. Nature. 1996;383(6599):400.

262. Gaertner H, Cerini F, Escola JM, Kuenzi G, Melotti A, Offord R, et al. Highly potent, fully recombinant anti-HIV chemokines: reengineering a low-cost microbicide. Proc Natl Acad Sci U S A. 2008;105(46):17706-11.

263. Hartley O, Offord RE. Engineering chemokines to develop optimized HIV inhibitors. Curr Protein Pept Sci. 2005:6(3):207-19.

264. Cheung R, Ravyn V, Wang L, Ptasznik A, Collman RG. Signaling mechanism of HIV-1 gp120 and virion-induced IL-1 beta release in primary human macrophages. J Immunol. 2008;180(10):6675-84.

265. Weissman D, Rabin RL, Arthos J, Rubbert A, Dybul M, Swofford R, et al. Macrophage-tropic HIV and SIV envelope proteins induce a signal through the CCR5 chemokine receptor. Nature. 1997;389(6654):981-5.

266. Di Marzio P, Dai WW, Franchin G, Chan AY, Symons M, Sherry B. Role of Rho family GTPases in CCR1- and CCR5-induced actin reorganization in macrophages. Biochem Biophys Res Commun. 2005;331(4):909-16.

267. Morrison DK. MAP kinase pathways. Cold Spring Harb Perspect Biol. 2012. https://doi.org/10.1101/cshperspect.a011254.

268. Mellado M, Rodríguez-Frade JM, Vila-Coro AJ, Fernández S, de Martín Ana A, Jones DR, et al. Chemokine receptor homo- or heterodimerization activates distinct signaling pathways. EMBO J. 2001;20(10):2497-507.

269. Martinez-Munoz L, Barroso R, Dyrhaug SY, Navarro G, Lucas $P$, Soriano SF, et al. CCR5/CD4/CXCR4 oligomerization prevents HIV-1 gp120IIIB binding to the cell surface. Proc Natl Acad Sci U S A. 2014;111(19):E1960-9.

270. Vila-Coro AJ, Mellado M, de Martin Ana A, Lucas P, del Real G, Martinez AC, et al. HIV-1 infection through the CCR5 receptor is blocked by receptor dimerization. Proc Natl Acad Sci U S A. 2000;97(7):3388-93.

271. Wong M, Uddin S, Majchrzak B, Huynh T, Proudfoot AE, Platanias LC, et al. Rantes activates Jak2 and Jak3 to regulate engagement of multiple signaling pathways in T cells. J Biol Chem. 2001;276(14):11427-31.

272. Mueller A, Strange PG. CCL3, acting via the chemokine receptor CCR5, leads to independent activation of Janus kinase 2 (JAK2) and Gi proteins. FEBS Lett. 2004;570(1-3):126-32.

273. Del Corno M, Liu Q-H, Schols D, de Clerca E, Gessani S, Freedman BD, et al. HIV-1 gp120 and chemokine activation of Pyk2 and mitogen-activated protein kinases in primary macrophages mediated by calciumdependent, pertussis toxin-insensitive chemokine receptor signaling. Blood. 2001;98(10):2909.

274. Shaheen ZR, Naatz A, Corbett JA. CCR5-dependent activation of $\mathrm{mTORC} 1$ regulates translation of inducible NO synthase and 
COX-2 during encephalomyocarditis virus infection. J Immunol. 2015;195(9):4406-14.

275. Mangmool S, Kurose H. G(i/o) protein-dependent and -independent actions of Pertussis Toxin (PTX). Toxins (Basel). 2011;3(7):884-99.

276. Ganju RK, Dutt P, Wu L, Newman W, Avraham H, Avraham S, et al. Betachemokine receptor CCR5 signals via the novel tyrosine kinase RAFTK. Blood. 1998;91(3):791-7.

277. Missé D, Esteve PO, Renneboog B, Vidal M, Cerutti M, St Pierre Y, et al HIV-1 glycoprotein 120 induces the MMP-9 cytopathogenic factor production that is abolished by inhibition of the p38 mitogen-activated protein kinase signaling pathway. Blood. 2001;98(3):541-7.

278. Li Z, Jiang H, Xie W, Zhang Z, Smrcka AV, Wu D. Roles of PLC-beta2 and -beta3 and PI3Kgamma in chemoattractant-mediated signal transduction. Science. 2000;287(5455):1046-9.

279. Cargnello M, Roux PP. Activation and function of the MAPKs and their substrates the MAPK activated protein kinases. Microbiol Mol Biol Rev. 2011;75(1):50-83.

280. Turner L, Ward SG, Westwick J. RANTES-activated human T lymphocytes A role for phosphoinositide 3-kinase. J Immunol. 1995;155(5):2437-44.

281. Harmon B, Ratner L. Induction of the Galpha(q) signaling cascade by the human immunodeficiency virus envelope is required for virus entry. J Virol. 2008;82(18):9191-205.

282. Freedman BD, Liu QH, Del Corno M, Collman RG. HIV-1 gp120 chemokine receptor-mediated signaling in human macrophages. Immunol Res. 2003;27(2-3):261-76.

283. Yi Y, Lee C, Liu QH, Freedman BD, Collman RG. Chemokine receptor utilization and macrophage signaling by human immunodeficiency virus type $1 \mathrm{gp} 120$ : Implications for neuropathogenesis. J Neurovirol. 2004;10(Suppl 1):91-6.

284. Lee C, Liu Q-H, Tomkowicz B, Yi Y, Freedman BD, Collman RG. Macrophage activation through CCR5- and CXCR4-mediated gp120-elicited signaling pathways. J Leukoc Biol. 2003;74(5):676-82.

285. Anand AR, Prasad A, Bradley RR, Deol YS, Nagaraja T, Ren X, et al. HIV-1 gp120-induced migration of dendritic cells is regulated by a novel kinase cascade involving Pyk2, p38 MAP kinase, and LSP1. Blood. 2009;114(17):3588-600.

286. Tomkowicz B, Lee C, Ravyn V, Cheung R, Ptasznik A, Collman RG. The Src kinase Lyn is required for CCR5 signaling in response to MIP-1 beta and R5 HIV-1 gp120 in human macrophages. Blood. 2006;108(4):1145-50.

287. Wong M, Fish EN. RANTES and MIP-1alpha activate stats in T cells. J Biol Chem. 1998;273(1):309-14.

288. Cuenda A, Rousseau S. p38 MAP-kinases pathway regulation, function and role in human diseases. Biochem Biophys Acta. 2007;1773(8):1358-75.

289. Krishna $M$, Narang $H$. The complexity of mitogen-activated protein kinases (MAPKs) made simple. Cell Mol Life Sci. 2008:65(22):3525-44.

290. Proudfoot AE, Buser R, Borlat F, Alouani S, Soler D, Offord RE, et al. Amino-terminally modified RANTES analogues demonstrate differential effects on RANTES receptors. J Biol Chem. 1999;274(45):32478-85.

291. Wong MM, Fish EN. Chemokines: attractive mediators of the immune response. Semin Immunol. 2003;15(1):5-14.

292. Blanpain C, Vanderwinden JM, Cihak J, Wittamer V, Le Poul E, Issafras $\mathrm{H}$, et al. Multiple active states and oligomerization of CCR5 revealed by functional properties of monoclonal antibodies. Mol Biol Cell. 2002;13(2):723-37.

293. Colin P, Benureau Y, Staropoli I, Wang Y, Gonzalez N, Alcami J, et al. HIV-1 exploits CCR5 conformational heterogeneity to escape inhibition by chemokines. Proc Natl Acad Sci U S A. 2013;110(23):9475-80.

294. Lee B, Sharron M, Blanpain C, Doranz BJ, Vakili J, Setoh P, et al. Epitope mapping of CCR5 reveals multiple conformational states and distinct but overlapping structures involved in chemokine and coreceptor function. J Biol Chem. 1999:274(14):9617-26.

295. Blanpain C, Doranz BJ, Bondue A, Govaerts C, De Leener A, Vassart G, et al. The core domain of chemokines binds CCR5 extracellular domains while their amino terminus interacts with the transmembrane helix bundle. J Biol Chem. 2003:278(7):5179-87.

296. Steen A, Thiele S, Guo D, Hansen LS, Frimurer TM, Rosenkilde MM. Biased and constitutive signaling in the CC-chemokine receptor CCR5 by manipulating the interface between transmembrane helices 6 and 7. J Biol Chem. 2013;288(18):12511-21.
297. Samson M, LaRosa G, Libert F Paindavoine P, Detheux M, Vassart G, et al. The second extracellular loop of CCR5 is the major determinant of ligand specificity. J Biol Chem. 1997;272(40):24934-41.

298. Wu L, LaRosa G, Kassam N, Gordon CJ, Heath H, Ruffing N, et al. Interaction of chemokine receptor CCR5 with its ligands: multiple domains for HIV-1 gp120 binding and a single domain for chemokine binding. J Exp Med. 1997:186(8):1373-81.

299. Fox JM, Kasprowicz R, Hartley O, Signoret N. CCR5 susceptibility to ligand-mediated down-modulation differs between human T lymphocytes and myeloid cells. J Leukoc Biol. 2015;98(1):59-71.

300. Berro R, Klasse PJ, Lascano D, Flegler A, Nagashima KA, Sanders RW, et al. Multiple CCR5 conformations on the cell surface are used differentially by human immunodeficiency viruses resistant or sensitive to CCR5 inhibitors. J Virol. 2011:85(16):8227-40.

301. Colin P, Zhou Z, Staropoli I, Garcia-Perez J, Gasser R, Armani-Tourret M, et al. CCR5 structural plasticity shapes HIV-1 phenotypic properties. PLoS Pathog. 2018;14(12):e1007432.

302. Jin J, Colin P, Staropoli I, Lima-Fernandes E, Ferret C, Demir A, et al. Targeting spare CC chemokine receptor 5 (CCR5) as a principle to inhibit HIV-1 entry. J Biol Chem. 2014;289(27):19042-52.

303. McGrath KE, Koniski AD, Maltby KM, McGann JK, Palis J. Embryonic expression and function of the chemokine SDF-1 and its receptor, CXCR4. Dev Biol. 1999;213(2):442-56.

304. Yu L, Cecil J, Peng SB, Schrementi J, Kovacevic S, Paul D, et al. Identification and expression of novel isoforms of human stromal cell-derived factor 1. Gene. 2006;374:174-9.

305. Bernhagen J, Krohn R, Lue H, Gregory JL, Zernecke A, Koenen RR, et al, MIF is a noncognate ligand of CXC chemokine receptors in inflammatory and atherogenic cell recruitment. Nat Med. 2007;13(5):587-96.

306. Saini V, Marchese A, Majetschak M. CXC chemokine receptor 4 is a cell surface receptor for extracellular ubiquitin. J Biol Chem. 2010;285(20):15566-76.

307. Juarez J, Bendall L. SDF-1 and CXCR4 in normal and malignant hematopoiesis. Histol Histopathol. 2004;19(1):299-309.

308. Lataillade JJ, Domenech J, Le Bousse-Kerdiles MC. Stromal cell-derived factor-1 (SDF-1)\CXCR4 couple plays multiple roles on haematopoietic progenitors at the border between the old cytokine and new chemokine worlds: survival, cell cycling and trafficking. Eur Cytokine Netw. 2004;15(3):177-88.

309. Cinamon G, Shinder V, Alon R. Shear forces promote lymphocyte migration across vascular endothelium bearing apical chemokines. Nat Immunol. 2001:2(6):515-22.

310. Tissir F, Wang CE, Goffinet AM. Expression of the chemokine receptor Cxcr4 mRNA during mouse brain development. Brain Res Dev Brain Res. 2004;149(1):63-71

311. Bagri A, Gurney T, He X, Zou YR, Littman DR, Tessier-Lavigne M, et al. The chemokine SDF1 regulates migration of dentate granule cells. Development. 2002;129(18):4249-60.

312. Stumm RK, Zhou C, Ara T, Lazarini F, Dubois-Dalcq M, Nagasawa T, et al. CXCR4 regulates interneuron migration in the developing neocortex. J Neurosci. 2003:23(12):5123-30.

313. Chalasani SH, Sabelko KA, Sunshine MJ, Littman DR, Raper JA. A chemokine, SDF-1, reduces the effectiveness of multiple axonal repellents and is required for normal axon pathfinding. J Neurosci. 2003;23(4):1360-71.

314. Chalasani SH, Sabol A, Xu H, Gyda MA, Rasband K, Granato M, et al. Stromal cell-derived factor-1 antagonizes slit/robo signaling in vivo. J Neurosci. 2007;27(5):973-80.

315. Nicolai J, Burbassi S, Rubin J, Meucci O. CXCL12 inhibits expression of the NMDA receptor's NR2B subunit through a histone deacetylasedependent pathway contributing to neuronal survival. Cell Death Dis. 2010;1:e33.

316. Pitcher J, Abt A, Myers J, Han R, Snyder M, Graziano A, et al. Neuronal ferritin heavy chain and drug abuse affect HIV-associated cognitive dysfunction. J Clin Invest. 2014;124(2):656-69.

317. Festa LK, Irollo E, Platt BJ, Tian Y, Floresco S, Meucci O. CXCL12-induced rescue of cortical dendritic spines and cognitive flexibility. Elife. 2020. https://doi.org/10.7554/eLife.49717.

318. Arno B, Grassivaro F, Rossi C, Bergamaschi A, Castiglioni V, Furlan R, et al. Neural progenitor cells orchestrate microglia migration and positioning into the developing cortex. Nat Commun. 2014;5:5611. 
319. Pan JH, Sukhova GK, Yang JT, Wang B, Xie T, Fu H, et al. Macrophage migration inhibitory factor deficiency impairs atherosclerosis in low-density lipoprotein receptor-deficient mice. Circulation. 2004;109(25):3149-53.

320. Bachelerie F, Ben-Baruch A, Burkhardt AM, Combadiere C, Farber JM, Graham GJ, et al. International Union of Basic and Clinical Pharmacology [corrected] LXXXIX. Update on the extended family of chemokine receptors and introducing a new nomenclature for atypical chemokine receptors. Pharmacol Rev. 2014;66(1):1-79.

321. Saini V, Staren DM, Ziarek JJ, Nashaat ZN, Campbell EM, Volkman BF, et al. The CXC chemokine receptor 4 ligands ubiquitin and stromal cellderived factor-1alpha function through distinct receptor interactions. J Biol Chem. 2011;286(38):33466-77.

322. Signoret N, Oldridge J, Pelchen-Matthews A, Klasse PJ, Tran T, Brass LF, et al. Phorbol esters and SDF-1 induce rapid endocytosis and down modulation of the chemokine receptor CXCR4. J Cell Biol. 1997;139(3):651-64

323. Orsini MJ, Parent JL, Mundell SJ, Marchese A, Benovic JL. Trafficking of the HIV coreceptor CXCR4. Role of arrestins and identification of residues in the $\mathrm{c}$-terminal tail that mediate receptor internalization. Biol Chem. 1999;274(43):31076-86.

324. Peacock JW, Jirik FR. TCR activation inhibits chemotaxis toward stromal cell-derived factor-1: evidence for reciprocal regulation between CXCR4 and the TCR. J Immunol. 1999;162(1):215-23.

325. Guinamard R, Signoret N, Ishiai M, Marsh M, Kurosaki T, Ravetch JV. B cell antigen receptor engagement inhibits stromal cell-derived factor (SDF)-1alpha chemotaxis and promotes protein kinase C (PKC)-induced internalization of CXCR4. J Exp Med. 1999;189(9):1461-6.

326. Richardson RM, Tokunaga K, Marjoram R, Sata T, Snyderman R. Interleukin-8-mediated heterologous receptor internalization provides resistance to HIV-1 infectivity. Role of signal strength and receptor desensitization. J Biol Chem. 2003;278(18):15867-73.

327. Hecht I, Cahalon L, Hershkoviz R, Lahat A, Franitza S, Lider O. Heterologous desensitization of T cell functions by CCR5 and CXCR4 ligands: inhibition of cellular signaling, adhesion and chemotaxis. Int Immunol. 2003;15(1):29-38.

328. Tarasova NI, Stauber RH, Michejda CJ. Spontaneous and ligandinduced trafficking of CXC-chemokine receptor 4. J Biol Chem. 1998;273(26):15883-6

329. Marchese A, Benovic JL. Agonist-promoted ubiquitination of the $G$ protein-coupled receptor CXCR4 mediates lysosomal sorting. J Biol Chem. 2001:276(49):45509-12.

330. Marchese A, Raiborg C, Santini F, Keen JH, Stenmark H, Benovic JL. The E3 ubiquitin ligase AIP4 mediates ubiquitination and sorting of the $G$ protein-coupled receptor CXCR4. Dev Cell. 2003;5(5):709-22.

331. Sachpatzidis A, Benton BK, Manfredi JP, Wang H, Hamilton A, Dohlman $\mathrm{HG}$, et al. Identification of allosteric peptide agonists of CXCR4. J Biol Chem. 2003;278(2):896-907.

332. Heuninck J, Perpina Viciano C, Isbilir A, Caspar B, Capoferri D, Briddon SJ, et al. Context-dependent signaling of CXC chemokine receptor 4 and atypical chemokine receptor 3. Mol Pharmacol. 2019:96(6):778-93.

333. Quoyer J, Janz JM, Luo J, Ren Y, Armando S, Lukashova V, et al. Pepducin targeting the $\mathrm{C}-\mathrm{X}-\mathrm{C}$ chemokine receptor type 4 acts as a biased agonist favoring activation of the inhibitory $G$ protein. Proc Natl Acad Sci U S A. 2013:110(52):E5088-97.

334. Kleemann P, Papa D, Vigil-Cruz S, Seifert R. Functional reconstitution of the human chemokine receptor CXCR4 with G(i)/G (o)proteins in Sf9 insect cells. Naunyn Schmiedebergs Arch Pharmacol. 2008;378(3):261-74

335. Pawig L, Klasen C, Weber C, Bernhagen J, Noels H. Diversity and interconnections in the CXCR4 chemokine receptor/ligand family: molecular perspectives. Front Immunol. 2015;6:429.

336. Zhao M, Mueller BM, DiScipio RG, Schraufstatter IU. Akt plays an important role in breast cancer cell chemotaxis to CXCL12. Breast Cancer Res Treat. 2008;110(2):211-22.

337. Cabioglu N, Summy J, Miller C, Parikh NU, Sahin AA, Tuzlali S, et al. CXCL12/stromal cell-derived factor-1alpha transactivates HER2-neu in breast cancer cells by a novel pathway involving Src kinase activation. Cancer Res. 2005;65(15):6493-7.
338. Cheng M, Zhou J, Wu M, Boriboun C, Thorne T, Liu T, et al. CXCR4-mediated bone marrow progenitor cell maintenance and mobilization are modulated by c-kit activity. Circ Res. 2010;107(9):1083-93.

339. Yang L, Jackson E, Woerner BM, Perry A, Piwnica-Worms D, Rubin JB. Blocking CXCR4-mediated cyclic AMP suppression inhibits brain tumor growth in vivo. Cancer Res. 2007;67(2):651-8

340. Tan W, Martin D, Gutkind JS. The Galpha13-Rho signaling axis is required for SDF-1-induced migration through CXCR4. J Biol Chem. 2006:281(51):39542-9.

341. Rochdi MD, Parent JL. Galphaq-coupled receptor internalization specifically induced by Galphaq signalling. Regulation by EBP50. J Biol Chem. 2003;278(20):17827-37.

342. Ngai J, Inngjerdingen M, Berge T, Tasken K. Interplay between the heterotrimeric G-protein subunits Galphaq and Galphai2 sets the threshold for chemotaxis and TCR activation. BMC Immunol. 2009;10:27

343. Shi G, Partida-Sánchez S, Misra RS, Tighe M, Borchers MT, Lee JJ, et al. Identification of an alternative G\{alpha\}q-dependent chemokine receptor signal transduction pathway in dendritic cells and granulocytes. J Exp Med. 2007;204(11):2705-18.

344. Yagi $H$, Tan W, Dillenburg-Pilla P, Armando S, Amornphimoltham $P$ Simaan M, et al. A synthetic biology approach reveals a CXCR4-G13-Rho signaling axis driving transendothelial migration of metastatic breast cancer cells. Sci Signal. 2011;4(191):ra60.

345. Rasheed SA, Teo CR, Beillard EJ, Voorhoeve PM, Zhou W, Ghosh S, et al. MicroRNA-31 controls G protein alpha-13 (GNA13) expression and cell invasion in breast cancer cells. Mol Cancer. 2015;14:67.

346. Teicher BA, Fricker SP. CXCL12 (SDF-1)/CXCR4 pathway in cancer. Clin Cancer Res. 2010;16(11):2927-31.

347. Kumar A, Kremer KN, Dominguez D, Tadi M, Hedin KE. Galpha13 and Rho mediate endosomal trafficking of CXCR4 into Rab11+ vesicles upon stromal cell-derived factor-1 stimulation. J Immunol. 2011;186(2):951-8.

348. Fong AM, Premont RT, Richardson RM, Yu YR, Lefkowitz RJ, Patel DD. Defective lymphocyte chemotaxis in beta-arrestin2- and GRK6-deficient mice. Proc Natl Acad Sci U S A. 2002;99(11):7478-83.

349. Vila-Coro AJ, Rodriguez-Frade JM, de Martín Ana A, Moreno-Ortiz MC, Martinez AC, Mellado M. The chemokine SDF-1alpha triggers CXCR4 receptor dimerization and activates the JAK/STAT pathway. FASEB J. 1999;13(13):1699-710.

350. Soriano SF, Serrano A, Hernanz-Falcón P, de Martín Ana A, Monterrubio M, Martínez C, et al. Chemokines integrate JAK/STAT and G-protein pathways during chemotaxis and calcium flux responses. Eur J Immunol. 2003;33(5):1328-33

351. O'Hayre M, Salanga CL, Handel TM, Hamel DJ. Emerging concepts and approaches for chemokine-receptor drug discovery. Expert Opin Drug Discov. 2010;5(11):1109-22

352. Shimizu S, Brown M, Sengupta R, Penfold ME, Meucci O. CXCR7 protein expression in human adult brain and differentiated neurons. PLOS ONE. 2011;6(5):e20680.

353. Farzan M, Choe H, Martin KA, Sun Y, Sidelko M, Mackay CR, et al. HIV-1 entry and macrophage inflammatory protein-1beta-mediated signaling are independent functions of the chemokine receptor CCR5. J Biol Chem. 1997:272(11):6854-7.

354. Gosling J, Monteclaro FS, Atchison RE, Arai H, Tsou CL, Goldsmith MA, et al. Molecular uncoupling of C-C chemokine receptor 5-induced chemotaxis and signal transduction from HIV-1 coreceptor activity. Proc Natl Acad Sci U S A. 1997:94(10):5061-6.

355. Alkhatib G, Locati M, Kennedy PE, Murphy PM, Berger EA. HIV-1 coreceptor activity of CCR5 and its inhibition by chemokines: independence from $\mathrm{G}$ protein signaling and importance of coreceptor downmodulation. Virology. 1997;234(2):340-8.

356. Amara A, Vidy A, Boulla G, Mollier K, Garcia-Perez J, Alcami J, et al. G protein-dependent CCR5 signaling is not required for efficient infection of primary $T$ lymphocytes and macrophages by $R 5$ human immunodeficiency virus type 1 isolates. J Virol. 2003;77(4):2550-8.

357. Cocchi F, DeVico AL, Garzino-Demo A, Cara A, Gallo RC, Lusso P. The V3 domain of the HIV-1 gp120 envelope glycoprotein is critical for chemokine-mediated blockade of infection. Nat Med. 1996:2(11):1244-7.

358. Lin YL, Mettling C, Portales P, Reant B, Robert-Hebmann V, Reynes J, et al. The efficiency of R5 HIV-1 infection is determined by CD4 T-cell 
surface CCR5 density through $\mathrm{G}$ alpha i-protein signalling. AIDS 2006;20(10):1369-77.

359. Harmon B, Campbell N, Ratner L. Role of Abl kinase and the Wave2 signaling complex in HIV-1 entry at a post-hemifusion step. PLoS Pathog. 2010;6(6):e1000956.

360. Contreras X, Mzoughi O, Gaston F, Peterlin MB, Bahraoui E. Protein kinase C-delta regulates HIV-1 replication at an early post-entry step in macrophages. Retrovirology. 2012;9:37.

361. Arthos J, Rubbert A, Rabin RL, Cicala C, Machado E, Wildt K, et al. CCR5 signal transduction in macrophages by human immunodeficiency virus and simian immunodeficiency virus envelopes. J Virol. 2000;74(14):6418-24.

362. Lin YL, Mettling C, Portales P, Reant B, Clot J, Corbeau P. G-protein signaling triggered by R5 human immunodeficiency virus type 1 increases virus replication efficiency in primary T lymphocytes. J Virol. 2005;79(12):7938-41.

363. Mettling C, Desmetz C, Fiser AL, Reant B, Corbeau P, Lin YL. Galphai protein-dependant extracellular signal-regulated kinase-1/2 activation is required for HIV-1 reverse transcription. AIDS (London, England). 2008:22(13):1569-76.

364. Ran X, Ao Z, Trajtman A, Xu W, Kobinger G, Keynan Y, et al. HIV-1 envelope glycoprotein stimulates viral transcription and increases the infectivity of the progeny virus through the manipulation of cellular machinery. Sci Rep. 2017;7(1):9487.

365. Vorster PJ, Guo J, Yoder A, Wang W, Zheng Y, Xu X, et al. LIM kinase 1 modulates cortical actin and CXCR4 cycling and is activated by HIV-1 to initiate viral infection. J Biol Chem. 2011;286(14):12554-64.

366. Yoder A, Yu D, Dong L, Iyer SR, Xu X, Kelly J, et al. HIV envelope-CXCR4 signaling activates cofilin to overcome cortical actin restriction in resting CD4 T cells. Cell. 2008;134(5):782-92.

367. Cicala C, Arthos J, Selig SM, Dennis G Jr, Hosack DA, Van Ryk D, et al. HIV envelope induces a cascade of cell signals in non-proliferating target cells that favor virus replication. Proc Natl Acad Sci U S A. 2002;99(14):9380-5.

368. Balabanian K, Harriague J, Decrion C, Lagane B, Shorte S, Baleux F, et al. CXCR4-tropic HIV-1 envelope glycoprotein functions as a viral chemokine in unstimulated primary CD4+ T lymphocytes. J Immunol. 2004;173(12):7150-60.

369. Melar M, Ott DE, Hope TJ. Physiological levels of virion-associated human immunodeficiency virus type 1 envelope induce coreceptordependent calcium flux. J Virol. 2007;81 (4):1773-85.

370. Francois F, Klotman ME. Phosphatidylinositol 3-kinase regulates human immunodeficiency virus type 1 replication following viral entry in primary CD4+ T lymphocytes and macrophages. J Virol. 2003;77(4):2539-49.

371. Ruiz MC, Cohen J, Michelangeli F. Role of $\mathrm{Ca} 2+$ in the replication and pathogenesis of rotavirus and other viral infections. Cell Calcium. 2000;28(3):137-49.

372. Zhou Y, Frey TK, Yang JJ. Viral calciomics: interplays between Ca2+ and virus. Cell Calcium. 2009;46(1):1-17.

373. Nickoloff EA, Mackie P, Runner K, Matt SM, Khoshbouei H, Gaskill PJ. Dopamine increases HIV entry into macrophages by increasing calcium release via an alternative signaling pathway. Brain Behav Immun. 2019. https://doi.org/10.1016/j.bbi.2019.08.191

374. Liu QH, Williams DA, McManus C, Baribaud F, Doms RW, Schols D, et al. HIV-1 gp120 and chemokines activate ion channels in primary macrophages through CCR5 and CXCR4 stimulation. Proc Natl Acad Sci U S A. 2000;97(9):4832-7.

375. Sheng WS, Hu S, Hegg CC, Thayer SA, Peterson PK. Activation of human microglial cells by HIV-1 gp41 and Tat proteins. Clin Immunol. 2000;96(3):243-51.

376. Lo TM, Fallert CJ, Piser TM, Thayer SA. HIV-1 envelope protein evokes intracellular calcium oscillations in rat hippocampal neurons. Brain Res. 1992;594(2):189-96.

377. Herrmann M, Ruprecht K, Sauter M, Martinez J, van Heteren P, Glas $M$, et al. Interaction of human immunodeficiency virus gp120 with the voltage-gated potassium channel BEC1. FEBS Lett. 2010:584(16):3513-8.

378. Dellis O, Bouteau F, Guenounou M, Rona J-P. HIV-1 gp160 decreases the K+ voltage-gated current from Jurkat E6.1 T cells by up-phosphorylation. FEBS Lett. 1999;443(2):187-91.
379. Collman RG, Yi Y, Liu Q-H, Freedman BD. Chemokine signaling and HIV-1 fusion mediated by macrophage CXCR4: implications for target cell tropism. J Leukoc Biol. 2000;68(3):318-23.

380. Benos DJ, McPherson S, Hahn BH, Chaikin MA, Benveniste EN. Cytokines and HIV envelope glycoprotein gp 120 stimulate $\mathrm{Na}+/ \mathrm{H}+$ exchange in astrocytes. J Biol Chem. 1994;269(19):13811-6.

381. Holden CP, Haughey NJ, Nath A, Geiger JD. Role of $\mathrm{Na}+/ \mathrm{H}+$ exchangers, excitatory amino acid receptors and voltage-operated $\mathrm{Ca} 2+$ channels in human immunodeficiency virus type 1 gp120-mediated increases in intracellular $\mathrm{Ca} 2+$ in human neurons and astrocytes. Neuroscience. 1999;91(4):1369-78.

382. Xu C, Liu J, Chen L, Liang S, Fujii N, Tamamura H, et al. HIV-1 gp120 enhances outward potassium current via CXCR4 and CAMPdependent protein kinase A signaling in cultured rat microglia. Glia. 2011;59(6):997-1007.

383. Cicala C, Arthos J, Ruiz M, Vaccarezza M, Rubbert A, Riva A, et al. Induction of phosphorylation and intracellular association of CC chemokine receptor 5 and focal adhesion kinase in primary human CD4+T cells by macrophage-tropic HIV envelope. J Immunol. 1999;163(1):420-6.

384. Missé D, Cerutti M, Noraz N, Jourdan P, Favero J, Devauchelle G, et al. A CD4-independent interaction of human immunodeficiency virus-1 gp120 with CXCR4 induces their cointernalization, cell signaling, and T-cell chemotaxis. Blood. 1999;93(8):2454-62.

385. Pandey P, Avraham S, Kumar S, Nakazawa A, Place A, Ghanem L, et al. Activation of p38 mitogen-activated protein kinase by PYK2/related adhesion focal tyrosine kinase-dependent mechanism. J Biol Chem. 1999:274(15):10140-4.

386. Medders KE, Sejbuk NE, Maung R, Desai MK, Kaul M. Activation of p38 MAPK is required in monocytic and neuronal cells for HIV glycoprotein 120-induced neurotoxicity. J Immunol. 2010;185(8):4883-95.

387. Reynolds JL, Mahajan SD, Aalinkeel R, Nair B, Sykes DE, Schwartz SA. Methamphetamine and HIV-1 gp120 effects on lipopolysaccharide stimulated matrix metalloproteinase- 9 production by human monocyte-derived macrophages. Immunol Invest. 2011;40(5):481-97.

388. Liu X, Silverstein PS, Singh V, Shah A, Qureshi N, Kumar A. Methamphetamine increases LPS-mediated expression of IL-8, TNF-a and IL-1 $\beta$ in human macrophages through common signaling pathways. PLOS ONE. 2012;7(3):e33822.

389. Popik W, Hesselgesser JE, Pitha PM. Binding of human immunodeficiency virus type 1 to CD4 and CXCR4 receptors differentially regulates expression of inflammatory genes and activates the MEK/ERK signaling pathway. J Virol. 1998;72(8):6406-13.

390. Lee C, Tomkowicz B, Freedman BD, Collman RG. HIV-1 gp120-induced TNF-\{alpha\} production by primary human macrophages is mediated by phosphatidylinositol-3 (PI-3) kinase and mitogen-activated protein (MAP) kinase pathways. J Leukoc Biol. 2005;78(4):1016-23.

391. Kinet S, Bernard F, Mongellaz C, Perreau M, Goldman FD, Taylor N. gp120-mediated induction of the MAPK cascade is dependent on the activation state of CD4(+) lymphocytes. Blood. 2002;100(7):2546-53.

392. Popik W, Pitha PM. Early activation of mitogen-activated protein kinase kinase, extracellular signal-regulated kinase, p38 mitogen-activated protein kinase, and c-Jun N-terminal kinase in response to binding of simian immunodeficiency virus to Jurkat T cells expressing CCR5 receptor. Virology. 1998;252(1):210-7.

393. Spadaro F, Cecchetti S, Purificato C, Sabbatucci M, Podo F, Ramoni C, et al. Nuclear phosphoinositide-specific phospholipase $\mathrm{C}$ beta1 controls cytoplasmic CCL2 mRNA levels in HIV-1 gp120-stimulated primary human macrophages. PLoS ONE. 2013;8(3):e59705.

394. Cantrell DA. Phosphoinositide 3-kinase signalling pathways. J Cell Sci. 2001;114(Pt 8):1439-45.

395. Shi CS, Kehrl JH. PYK2 links G(q)alpha and G(13)alpha signaling to NFkappa B activation. J Biol Chem. 2001;276(34):31845-50.

396. Khan NA, Di Cello F, Stins M, Kim KS. Gp120-mediated cytotoxicity of human brain microvascular endothelial cells is dependent on p38 mitogen-activated protein kinase activation. J Neurovirol. 2007;13(3):242-51.

397. Liu J, Xu C, Chen L, Xu P, Xiong H. Involvement of Kv1.3 and p38 MAPK signaling in HIV-1 glycoprotein 120-induced microglia neurotoxicity. Cell Death Dis. 2012;3(1):e254.

398. Medders KE, Kaul M. Mitogen-activated protein kinase p38 in HIV infection and associated brain injury. J Neuroimmune Pharmacol. 2011;6(2):202-15. 
399. Perfettini JL, Castedo M, Nardacci R, Ciccosanti F, Boya P, Roumier $\mathrm{T}$, Larochette $\mathrm{N}$, et al. Essential role of $\mathrm{p} 53$ phosphorylation by $\mathrm{p} 38$ MAPK in apoptosis induction by the HIV-1 envelope. J Exp Med. 2005. https://doi.org/10.1084/jem.20041502.

400. Singh IN, El-Hage N, Campbell ME, Lutz SE, Knapp PE, Nath A, et al. Differential involvement of p38 and JNK MAP kinases in HIV-1 Tat and gp120-induced apoptosis and neurite degeneration in striatal neurons. Neuroscience. 2005;135(3):781-90.

401. Singh IN, Goody RJ, Dean C, Ahmad NM, Lutz SE, Knapp PE, et al. Apoptotic death of striatal neurons induced by human immunodeficiency virus-1 Tat and gp120: differential involvement of caspase-3 and endonuclease G. J Neurovirol. 2004;10(3):141-51.

402. Jordan CA, Watkins BA, Kufta C, Dubois-Dalcq M. Infection of brain microglial cells by human immunodeficiency virus type 1 is CD4 dependent. J Virol. 1991;65(2):736-42

403. Del Corno M, Donninelli G, Varano B, Da Sacco L, Masotti A, Gessani S. HIV-1 gp120 activates the STAT3/interleukin-6 axis in primary human monocyte-derived dendritic cells. J Virol. 2014;88(19):11045-55.

404. Planès R, Serrero M, Leghmari K, BenMohamed L, Bahraoui E. HIV-1 envelope glycoproteins induce the production of TNF- $a$ and IL-10 in human monocytes by activating calcium pathway. Sci Rep. 2018;8(1):17215.

405. Fantuzzi L, Canini I, Belardelli F, Gessani S. HIV-1 gp120 stimulates the production of beta-chemokines in human peripheral blood monocytes through a CD4-independent mechanism. J Immunol. 2001;166(9):5381-7.

406. Choe W, Volsky DJ, Potash MJ. Activation of NF-kappaB by R5 and X4 human immunodeficiency virus type 1 induces macrophage inflammatory protein 1alpha and tumor necrosis factor alpha in macrophages. J Virol. 2002;76(10):5274-7.

407. Kedzierska K, Crowe SM, Turville S, Cunningham AL. The influence of cytokines, chemokines and their receptors on HIV-1 replication in monocytes and macrophages. Rev Med Virol. 2003;13(1):39-56.

408. Shah A, Silverstein PS, Kumar S, Singh DP, Kumar A. Synergistic cooperation between methamphetamine and HIV-1 gsp120 through the P13K/Akt pathway induces IL-6 but not IL-8 expression in astrocytes. PLOS ONE. 2012;7(12):e52060

409. Ashwell JD. The many paths to p38 mitogen-activated protein kinase activation in the immune system. Nat Rev Immunol. 2006:6(7):532-40

410. Andreev J, Galisteo ML, Kranenburg O, Logan SK, Chiu ES, Okigaki M, Cary LA, et al. Src and Pyk2 mediate G-protein-coupled receptor activation of epidermal growth factor receptor (EGFR) but are not required for coupling to the mitogen-activated protein (MAP) kinase signaling cascade. J Biol Chem. 2001. https://doi.org/10.1074/jbc. M102307200

411. Daub H, Wallasch C, Lankenau A, Herrlich A, Ullrich A. Signal characteristics of $\mathrm{G}$ protein-transactivated EGF receptor. Embo j. 1997;16(23):7032-44.

412. Dikic l, Tokiwa G, Lev S, Courtneidge SA, Schlessinger J. A role for Pyk2 and Src in linking G-protein-coupled receptors with MAP kinase activation. Nature. 1996;383(6600):547-50.

413. Thomas SM, Brugge JS. Cellular functions regulated by SRC family kinases. Annu Rev Cell Dev Biol. 1997;13(1):513-609.

414. Yang B, Akhter S, Chaudhuri A, Kanmogne GD. HIV-1 gp120 induces cytokine expression, leukocyte adhesion, and transmigration across the blood-brain barrier: modulatory effects of STAT1 signaling. Microvasc Res. 2009;77(2):212-9.

415. Yang B, Singh S, Bressani R, Kanmogne GD. Cross-talk between STAT1 and PI3K/AKT signaling in HIV-1-induced blood-brain barrier dysfunction: role of CCR5 and implications for viral neuropathogenesis. J Neurosci Res. 2010;88(14):3090-101.

416. Kohler JJ, Tuttle DL, Coberley CR, Sleasman JW, Goodenow MM. Human immunodeficiency virus type 1 (HIV-1) induces activation of multiple STATs in CD4+ cells of lymphocyte or monocyte/macrophage lineages. J Leukoc Biol. 2003:73(3):407-16.

417. Bousoik E, Montazeri AH. "Do We Know Jack" about JAK? A closer look at JAK/STAT signaling pathway. Front Oncol. 2018;8:287.

418. Nosaka T, Kitamura T. Janus kinases (JAKs) and signal transducers and activators of transcription (STATs) in hematopoietic cells. Int J Hematol. 2000:71(4):309-19.
419. Villarino AV, Kanno Y, O'Shea JJ. Mechanisms and consequences of JakSTAT signaling in the immune system. Nat Immunol. 2017;18(4):374-84.

420. Chaudhuri A, Yang B, Gendelman HE, Persidsky Y, Kanmogne GD. STAT1 signaling modulates HIV-1-induced inflammatory responses and leukocyte transmigration across the blood-brain barrier. Blood. 2008;111(4):2062-72.

421. Nguyen H, Ramana CV, Bayes J, Stark GR. Roles of phosphatidylinositol 3-kinase in interferon-gamma-dependent phosphorylation of STAT1 on serine 727 and activation of gene expression. J Biol Chem. 2001;276(36):33361-8.

422. Sufiawati I, Tugizov SM. HIV-induced matrix metalloproteinase-9 activation through mitogen-activated protein kinase signalling promotes HSV-1 cell-to-cell spread in oral epithelial cells. J Gen Virol. 2018. https:// doi.org/10.1099/jgv.0.001075.

423. Louboutin JP, Reyes BA, Agrawal L, Van Bockstaele EJ, Strayer DS. HIV-1 gp120 upregulates matrix metalloproteinases and their inhibitors in a rat model of HIV encephalopathy. Eur J Neurosci. 2011;34(12):2015-23.

424. Lucera MB, Fleissner Z, Tabler CO, Schlatzer DM, Troyer Z, Tilton JC. HIV signaling through CD4 and CCR5 activates Rho family GTPases that are required for optimal infection of primary CD4+ T cells. Retrovirology. 2017;14(1):4.

425. Woollard SM, Li H, Singh S, Yu F, Kanmogne GD. HIV-1 induces cytoskeletal alterations and Rac1 activation during monocyte-blood-brain barrier interactions: modulatory role of CCR5. Retrovirology. 2014;11:20.

426. Pontow SE, Heyden NV, Wei S, Ratner L. Actin cytoskeletal reorganizations and coreceptor-mediated activation of rac during human immunodeficiency virus-induced cell fusion. J Virol. 2004;78(13):7138-47.

427. Wu Y, Yoder A, Yu D, Wang W, Liu J, Barrett T, et al. Cofilin activation in peripheral CD4 T cells of HIV-1 infected patients: a pilot study. Retrovirology. 2008:5:95.

428. Spear M, Guo J, Turner A, Yu D, Wang W, Meltzer B, et al. HIV-1 triggers WAVE2 phosphorylation in primary CD4 T cells and macrophages, mediating Arp2/3-dependent nuclear migration. J Biol Chem. 2014;289(10):6949-59.

429. Ospina Stella AA-O, Turville S. All-round manipulation of the actin cytoskeleton by HIV. LID. 2018. https://doi.org/10.3390/v10020063.

430. Kaul M, Ma Q, Medders KE, Desai MK, Lipton SA. HIV-1 coreceptors CCR5 and CXCR4 both mediate neuronal cell death but CCR5 paradoxically can also contribute to protection. Cell Death Differ. 2007;14(2):296-305.

431. Maung R, Medders KE, Sejbuk NE, Desai MK, Russo R, Kaul M. Genetic knockouts suggest a critical role for HIV co-receptors in models of HIV gp120-induced brain injury. J Neuroimmune Pharmacol. 2012;7(2):306-18.

432. Shepherd AJ, Loo L, Mohapatra DP. Chemokine co-receptor CCR5/ CXCR4-dependent modulation of Kv21 channel confers acute neuroprotection to HIV-1 glycoprotein gp120 exposure. PLOS ONE. 2013;8(9):e76698

433. Zhou M, Greenhill S, Huang S, Silva TK, Sano Y, Wu S, et al. CCR5 is a suppressor for cortical plasticity and hippocampal learning and memory. Elife. 2016. https://doi.org/10.7554/eLife.20985.

434. Hesselgesser J, Taub D, Baskar P, Greenberg M, Hoxie J, Kolson DL, et al. Neuronal apoptosis induced by HIV-1 gp120 and the chemokine SDF-1 alpha is mediated by the chemokine receptor CXCR4. Curr Biol. 1998:8(10):595-8.

435. Bachis A, Aden SA, Nosheny RL, Andrews PM, Mocchetti I. Axonal transport of human immunodeficiency virus type 1 envelope protein glycoprotein 120 is found in association with neuronal apoptosis. J Neurosci . 2006:26(25):6771-80.

436. Bachis A, Mocchetti I. Brain-derived neurotrophic factor is neuroprotective against human immunodeficiency virus-1 envelope proteins. Ann NY Acad Sci. 2005;1053:247-57.

437. Mahajan SD, Aalinkeel R, Reynolds JL, Nair BB, Fernandez SF, Schwartz SA, et al. Morphine exacerbates HIV-1 viral protein gp120 induced modulation of chemokine gene expression in U373 astrocytoma cells. Curr HIV Res. 2005;3(3):277-88.

438. Kanmogne GD, Schall K, Leibhart J, Knipe B, Gendelman HE, Persidsky Y. HIV-1 gp120 compromises blood-brain barrier integrity and enhances monocyte migration across blood-brain barrier: implication for viral neuropathogenesis. J Cereb Blood Flow Metab. 2007;27(1):123-34.

439. Louboutin JP, Reyes BA, Agrawal L, Van Bockstaele EJ, Strayer DS. HIV-1 gp120-induced neuroinflammation: relationship to neuron loss 
and protection by rSV40-delivered antioxidant enzymes. Exp Neurol. 2010;221(1):231-45.

440. Atluri VS, Hidalgo M, Samikkannu T, Kurapati KR, Jayant RD, Sagar V, et al. Effect of human immunodeficiency virus on blood-brain barrier integrity and function: an update. Front Cell Neurosci. 2015;9:212.

441. Holguin A, O'Connor KA, Biedenkapp J, Campisi J, Wieseler-Frank J, Milligan ED, Hansen MK, et al. HIV-1 gp120 stimulates proinflammatory cytokine-mediated pain facilitation via activation of nitric oxide synthase-I (nNOS). Pain. 2004. https://doi.org/10.1016/j.pain.2004.02 018.

442. Reddy PV, Gandhi N, Samikkannu T, Saiyed Z, Agudelo M, Yndart A, et al. HIV-1 gp120 induces antioxidant response element-mediated expression in primary astrocytes: role in HIV associated neurocognitive disorder. Neurochem Int. 2012;61(5):807-14.

443. Ronaldson PT, Bendayan R. HIV-1 viral envelope glycoprotein gp 120 produces oxidative stress and regulates the functional expression of multidrug resistance protein-1 (Mrp1) in glial cells. J Neurochem. 2008;106(3):1298-313.

444. Zheng JC, Huang Y, Tang K, Tang K, Cui M, Niemann D, Lopez A, Morgello $\mathrm{S}$, et al. HIV-1-infected and/or immune-activated macrophages regulate astrocyte CXCL8 production through IL-1 beta and TNF-alpha: involvement of mitogen-activated protein kinases and protein kinase $\mathrm{R}$. J Neuroimmunol. 2008. https://doi.org/10.1016/j.jneuroim.2008.06.015.

445. Yadav A, Collman RG. CNS inflammation and macrophage/microglial biology associated with HIV-1 infection. J Neuroimmune Pharmacol. 2009:4(4):430-47.

446. Levast B, Barblu L, Coutu M, Prévost J, Brassard N, Peres A, et al. HIV-1 gp120 envelope glycoprotein determinants for cytokine burst in human monocytes. PLoS ONE. 2017;12(3):e0174550.

447. Kong LY, Wilson BC, McMillian MK, Bing G, Hudson PM, Hong JS. The effects of the HIV-1 envelope protein gp120 on the production of nitric oxide and proinflammatory cytokines in mixed glial cell cultures. Cell Immunol. 1996;172(1):77-83.

448. Kim S, Hahn YK, Podhaizer EM, McLane VD, Zou S, Hauser KF, et al. A central role for glial CCR5 in directing the neuropathological interactions of HIV-1 Tat and opiates. J Neuroinflammation. 2018;15(1):285.

449. Shah A, Kumar A. HIV-1 gp120-mediated increases in IL-8 production in astrocytes are mediated through the NF-KB pathway and can be silenced by gp120-specific siRNA. J Neuroinflammation. 2010;7:96.

450. Ronaldson PT, Bendayan R. HIV-1 viral envelope glycoprotein gp120 triggers an inflammatory response in cultured rat astrocytes and regulates the functional expression of P-glycoprotein. Mol Pharmacol. 2006;70:1087-98.

451. Zhang X, Green MV, Thayer SA. HIV gp120-induced neuroinflammation potentiates NMDA receptors to overcome basal suppression of inhibitory synapses by p38 MAPK. J Neurochem. 2019;148(4):499-515.

452. Tyor WR, Glass JD, Griffin JW, Becker PS, McArthur JC, Bezman L, Griffin $D E$, et al. Cytokine expression in the brain during the acquired immunodeficiency syndrome. Ann Neurol. 1992;31:349-60.

453. Grimaldi LM, Martino GV, Franciotta DM, Brustia R, Castagna A, Pristera $\mathrm{R}$, et al. Elevated alpha-tumor necrosis factor levels in spinal fluid from HIV-1-infected patients with central nervous system involvement. Ann Neurol. 1991:29(1):21-5.

454. Brabers NA, Nottet HS. Role of the pro-inflammatory cytokines TNF-alpha and IL-1 beta in HIV-associated dementia. Eur J Clin Invest. 2006;36(7):447-58.

455. Achim CL, Miners DK, Burrola PG, Martin FC, Wiley CA. In vivo model of HIV infection of the human brain. Dev Neurosci. 1993;15(6):423-32.

456. Zhao ML, Kim MO, Morgello S, Lee SC. Expression of inducible nitric oxide synthase, interleukin-1 and caspase-1 in HIV-1 encephalitis. J Neuroimmunol. 2001;115(1-2):182-91

457. Jana M, Anderson JA, Saha RN, Liu X, Pahan K. Regulation of inducible nitric oxide synthase in proinflammatory cytokine-stimulated human primary astrocytes. Free Radic Biol Med. 2005:38(5):655-64.

458. Collins T, Read MA, Neish AS, Whitley MZ, Thanos D, Maniatis T. Transcriptional regulation of endothelial cell adhesion molecules: NF-kappa B and cytokine-inducible enhancers. FASEB J. 1995;9(10):899-909.

459. Glabinski AR, Bielecki B, Kolodziejski P, Kolodziejski P, Han Y, Selmaj K, Ransohoff RM. TNF-alpha microinjection upregulates chemokines and chemokine receptors in the central nervous system without inducing leukocyte infiltration. J Interferon Cytokine Res. 2003. https://doi.org/10. 1089/107999003322277874.

460. Cocchi F, DeVico AL, Garzino-Demo A, Arya SK, Gallo RC, Lusso P. Identification of RANTES, MIP-1 alpha, and MIP-1 beta as the major HIV-suppressive factors produced by CD8+T cells. Science. 1995;270(5243):1811-5.

461. Trkola A, Paxton WA, Monard SP, Hoxie JA, Siani MA, Thompson DA, et al. Genetic subtype-independent inhibition of human immunodeficiency virus type 1 replication by CC and CXC chemokines. J Virol. 1998;72(1):396-404

462. Scarlatti G, Tresoldi E, Bjorndal A, Fredriksson R, Colognesi C, Deng HK, et al. In vivo evolution of HIV-1 co-receptor usage and sensitivity to chemokine-mediated suppression. Nat Med. 1997;3(11):1259-65.

463. Eugenin EA, Osiecki K, Lopez L, Goldstein H, Calderon TM, Berman JW. CCL2/monocyte chemoattractant protein-1 mediates enhanced transmigration of human immunodeficiency virus (HIV)-infected leukocytes across the blood-brain barrier: a potential mechanism of HIV-CNS invasion and NeuroAIDS. J Neurosci. 2006;26(4):1098-106.

464. Buckner CM, Calderon TM, Willams DW, Belbin TJ, Berman JW. Characterization of monocyte maturation/differentiation that facilitates their transmigration across the blood-brain barrier and infection by HIV: implications for NeuroAIDS. Cell Immunol. 2011;267(2):109-23.

465. Nolan RA, Muir R, Runner K, Haddad EK, Gaskill PJ. Role of macrophage dopamine receptors in mediating cytokine production: implications for neuroinflammation in the context of HIV-associated neurocognitive disorders. J Neuroimmune Pharmacol. 2019;14(1):134-56.

466. Gaskill PJ, Calderon TM, Coley JS, Berman JW. Drug induced increases in CNS dopamine alter monocyte, macrophage and T cell functions: implications for HAND. J Neuroimmune Pharmacol. 2013;8(3):621-42.

467. Gaskill PJ, Calderon TM, Luers AJ, Eugenin EA, Javitch JA, Berman JW. Human immunodeficiency virus (HIV) infection of human macrophages is increased by dopamine: a bridge between HIVassociated neurologic disorders and drug abuse. Am J Pathol. 2009;175(3):1148-59.

468. Herbein G, Gras G, Khan KA, Abbas W. Macrophage signaling in HIV-1 infection. Retrovirology. 2010;7:34

469. D'Aversa TG, Eugenin EA, Berman JW. NeuroAIDS: contributions of the human immunodeficiency virus-1 proteins Tat and gp120 as well as CD40 to microglial activation. J Neurosci Res. 2005. https://doi.org/10. 1002/jnr.20486.

470. D'Aversa TG, Yu KO, Berman JW. Expression of chemokines by human fetal microglia after treatment with the human immunodeficiency virus type 1 protein Tat. J Neurovirol. 2004;10(2):86-97.

471. Eugenin EA, Dyer G, Calderon TM, Berman JW. HIV-1 tat protein induces a migratory phenotype in human fetal microglia by a CCL2 (MCP-1)-dependent mechanism: possible role in NeuroAIDS. Glia. 2005:49(4):501-10.

472. Everall IP, Hansen LA, Masliah E. The shifting patterns of HIV encephalitis neuropathology. Neurotox Res. 2005;8(1-2):51-61.

473. D'Agostino PM, Gottfried-Blackmore A, Anandasabapathy N, Bulloch K. Brain dendritic cells: biology and pathology. Acta Neuropathol. 2012;124(5):599-614.

474. Bhargavan B, Kanmogne GD. Toll-like receptor-3 mediates HIV-1-induced interleukin-6 expression in the human brain endothelium via TAK1 and JNK pathways: implications for viral neuropathogenesis. Mol Neurobiol. 2018;55(7):5976-92.

475. Schifitto G, McDermott MP, McArthur JC, Marder K, Sacktor N, McClernon DR, et al. Markers of immune activation and viral load in HIV-associated sensory neuropathy. Neurology. 2005;64(5):842-8.

476. Conant K, MCArthur JC, Griffin DE, Sjulson L, Wahl LM, Irani DN. Cerebrospinal fluid levels of MMP-2, 7, and 9 are elevated in association with human immunodeficiency virus dementia. Ann Neurol. 1999;46(3):391-8

477. Sporer B, Paul R, Koedel U, Grimm R, Wick M, Goebel FD, et al. Presence of matrix metalloproteinase-9 activity in the cerebrospinal fluid of human immunodeficiency virus-infected patients. J Infect Dis. 1998;178(3):854-7.

478. Liu Y, Brown S, Shaikh J, Fishback JA, Matsumoto RR. Relationship between methamphetamine exposure and matrix metalloproteinase 9 expression. NeuroReport. 2008;19(14):1407-9. 
479. Moss PJ, Huang W, Dawes J, Okuse K, McMahon SB, Rice ASC. Macrophage-sensory neuronal interaction in HIV-1 gp120-induced neurotoxicity. Br J Anaesth. 2015;114(3):499-508.

480. Giulian D, Wendt E, Vaca K, Noonan CA. The envelope glycoprotein of human immunodeficiency virus type 1 stimulates release of neurotoxins from monocytes. Proc Natl Acad Sci U S A. 1993;90(7):2769-73.

481. Garden GA, Guo W, Jayadev S, Tun C, Balcaitis S, Choi J, et al. HIV associated neurodegeneration requires p53 in neurons and microglia. FASEB J. 2004;18(10):1141-3.

482. Ru W, Liu X, Bae C, Shi Y, Walikonis R, Chung JM, et al. Microglia mediate HIV-1 gp120-induced synaptic degeneration in spinal pain neural circuits. J Neurosci. 2019. https://doi.org/10.1523/JNEUROSCI.2851-18. 2019.

483. Fields JA, Overk C, Adame A, Florio J, Mante M, Pineda A, et al. Neuroprotective effects of the immunomodulatory drug FK506 in a model of HIV1-gp120 neurotoxicity. J Neuroinflammation. 2016;13(1):120.

484. Haughey NJ, Mattson MP. Calcium dysregulation and neuronal apoptosis by the HIV-1 proteins Tat and gp120. J Acquir Immune Defic Syndr. 1999;2002(31 Suppl 2):S55-61.

485. Zhang K, McQuibban GA, Silva C, Butler GS, Johnston JB, Holden J, et al. HIV-induced metalloproteinase processing of the chemokine stromal cell derived factor-1 causes neurodegeneration. Nat Neurosci. 2003;6(10):1064-71.

486. Vergote D, Butler GS, Ooms M, Cox JH, Silva C, Hollenberg MD, et al. Proteolytic processing of SDF-1alpha reveals a change in receptor specificity mediating HIV-associated neurodegeneration. Proc Natl Acad Sci U S A. 2006:103(50):19182-7.

487. UNODC. World drug report 2019. New York: United Nations; 2019.

488. Degenhardt L, Peacock A, Colledge S, Leung J, Grebely J, Vickerman P, et al. Global prevalence of injecting drug use and sociodemographic characteristics and prevalence of HIV, HBV, and HCV in people who inject drugs: a multistage systematic review. Lancet Glob Health. 2017 https://doi.org/10.1016/S2214-109X(17)30375-3.

489. Shiau S, Arpadi SM, Yin MT, Martins SS. Patterns of drug use and HIV infection among adults in a nationally representative sample. Addict Behav. 2017:68:39-44

490. Pakianathan M, Whittaker W, Lee MJ, Avery J, Green S, Nathan B, et al. Chemsex and new HIV diagnosis in gay, bisexual and other men who have sex with men attending sexual health clinics. HIV Med. 2018 https://doi.org/10.1111/hiv.12629.

491. Pacek LR, Towe SL, Hobkirk AL, Nash D, Goodwin RD. Frequency of cannabis use and medical cannabis use among persons living with HIV in the United States: findings from a nationally representative sample. AIDS Educ Prev. 2018;30(2):169-81.

492. Mimiaga MJ, Reisner SL, Grasso C, Crane HM, Safren SA, Kitahata MM, et al. Substance use among HIV-infected patients engaged in primary care in the United States: findings from the Centers for AIDS Research Network of Integrated Clinical Systems cohort. Am J Public Health. 2013;103(8):1457-67.

493. Hartzler B, Dombrowski JC, Crane HM, Eron JJ, Geng EH, Christopher Mathews W, et al. Prevalence and predictors of substance use disorders among HIV care enrollees in the united States. AIDS Behav. 2017;21(4):1138-48.

494. Duko B, Ayalew M, Ayano G. The prevalence of alcohol use disorders among people living with HIV/AIDS: a systematic review and metaanalysis. Subst Abuse Treat Prev Policy. 2019;14(1):52.

495. Williams EC, Hahn JA, Saitz R, Bryant K, Lira MC, Samet JH. Alcohol use and human immunodeficiency virus (HIV) infection: current knowledge, implications, and future directions. Alcohol Clin Exp Res. 2016:40(10):2056-72.

496. Leung J, Peacock A, Colledge S, Grebely J, Cunningham EB, Hickman $M$, et al. A global meta-analysis of the prevalence of HIV, Hepatitis C Virus, and Hepatitis B virus among people who inject drugs-do gender-based differences vary by country-level indicators? J Infect Dis. 2019;220(1):78-90.

497. Gosztonyi G, Schmidt V, Nickel R, Rothschild MA, Camacho S, Siegel $G$, et al. Neuropathologic analysis of postmortal brain samples of HIV-seropositive and -seronegative iv drug addicts. Forensic Sci Int. 1993;62(1-2):101-5.
498. Meyer VJ, Rubin LH, Martin E, Weber KM, Cohen MH, Golub ET, et al. HIV and recent illicit drug use interact to affect verbal memory in women. J Acquir Immune Defic Syndr. 2013;63(1):67-76.

499. Rippeth JD, Heaton RK, Carey CL, Marcotte TD, Moore DJ, Gonzalez R, et al. Methamphetamine dependence increases risk of neuropsychological impairment in HIV infected persons. J Int Neuropsychol Soc. 2004;10(1):1-14.

500. Weber E, Morgan EE, ludicello JE, Blackstone K, Grant I, Ellis RJ, et al. Substance use is a risk factor for neurocognitive deficits and neuropsychiatric distress in acute and early HIV infection. J Neurovirol. 2013;19(1):65-74.

501. Wang SC, Maher B. Substance use disorder, intravenous injection, and HIV infection: a review. Cell Transplant. 2019;28(12):1465-71.

502. Dash S, Balasubramaniam M, Villalta F, Dash C, Pandhare J. Impact of cocaine abuse on HIV pathogenesis. Front Microbiol. 2015;6:1111.

503. Buch S, Yao H, Guo M, Mori T, Mathias-Costa B, Singh V, et al. Cocaine and HIV-1 interplay in CNS: cellular and molecular mechanisms. Curr HIV Res. 2012;10(5):425-8.

504. Hauser KF, Fitting S, Dever SM, Podhaizer EM, Knapp PE. Opiate drug use and the pathophysiology of neuroAIDS. Curr HIV Res. 2012;10(5):435-52.

505. Dhillon NK, Williams R, Peng F, Tsai YJ, Dhillon S, Nicolay B, et al. Cocaine-mediated enhancement of virus replication in macrophages: implications for human immunodeficiency virus-associated dementia. J Neurovirol. 2007;13(6):483-95.

506. Guo CJ, Li Y, Tian S, Wang X, Douglas SD, Ho WZ. Morphine enhances HIV infection of human blood mononuclear phagocytes through modulation of beta-chemokines and CCR5 receptor. J Investig Med. 2002;50(6):435-42

507. Liang H, Wang $X$, Chen $H$, Song L, Ye L, Wang SH, et al. Methamphetamine enhances HIV infection of macrophages. Am J Pathol. 2008;172(6):1617-24

508. Di Chiara G, Imperato A. Drugs abused by humans preferentially increase synaptic dopamine concentrations in the mesolimbic system of freely moving rats. Proc Natl Acad Sci U S A. 1988;85(14):5274-8.

509. Matt SM, Gaskill PJ. Where Is Dopamine and how do Immune Cells See it?: Dopamine-Mediated Immune Cell Function in Health and Disease. J Neuroimmune Pharmacol. 2020;15(1):114-64.

510. Pierce RC, Kumaresan V. The mesolimbic dopamine system: the final common pathway for the reinforcing effect of drugs of abuse? Neurosci Biobehav Rev. 2006;30(2):215-38.

511. Calderon TM, Williams DW, Lopez L, Eugenin EA, Cheney L, Gaskill PJ, et al. Dopamine Increases CD14(+)CD16(+) Monocyte Transmigration across the Blood Brain Barrier: Implications for Substance Abuse and HIV Neuropathogenesis. J Neuroimmune Pharmacol. 2017;12(2):353-70.

512. Nolan R, Gaskill PJ. The role of catecholamines in HIV neuropathogenesis. Brain Res. 2018. https://doi.org/10.1016/j.brainres.2018.04.030

513. Matt SM, Nickoloff-Bybel EA, Rong Y, Runner K, Johnson H, O'Connor $\mathrm{MH}$, et al. Dopamine levels induced by substance abuse alter efficacy of maraviroc and expression of CCR5 conformations on myeloid cells: implications for neuroHIV. Front Immunol. 2021;12:663061.

514. Yao H, Allen JE, Zhu X, Callen S, Buch S. Cocaine and human immunodeficiency virus type 1 gp120 mediate neurotoxicity through overlapping signaling pathways. J Neurovirol. 2009;15(2):164-75.

515. Mahajan SD, Aalinkeel R, Sykes DE, Reynolds JL, Bindukumar B, Adal A, et al. Methamphetamine alters blood brain barrier permeability via the modulation of tight junction expression: Implication for HIV-1 neuropathogenesis in the context of drug abuse. Brain Res. 2008;1203:133-48.

516. Liu J, Xu E, Tu G, Liu H, Luo J, Xiong H. Methamphetamine potentiates HIV-1gp120-induced microglial neurotoxic activity by enhancing microglial outward $\mathrm{K}(+)$ current. Mol Cell Neurosci. 2017:82:167-75.

517. Silverstein PS, Shah A, Weemhoff J, Kumar S, Singh DP, Kumar A. HIV-1 gp120 and drugs of abuse: interactions in the central nervous system. Curr HIV Res. 2012;10(5):369-83.

518. Bagetta G, Piccirilli S, Del Duca C, Morrone LA, Rombola L, Nappi G, et al. Inducible nitric oxide synthase is involved in the mechanisms of cocaine enhanced neuronal apoptosis induced by HIV-1 gp120 in the neocortex of rat. Neurosci Lett. 2004;356(3):183-6. 
519. Turchan J, Anderson C, Hauser KF, Sun Q, Zhang J, Liu Y, et al. Estrogen protects against the synergistic toxicity by HIV proteins, methamphetamine and cocaine. BMC Neurosci. 2001;2:3.

520. Nath A, Hauser KF, Wojna V, Booze RM, Maragos W, Prendergast M, et al. Molecular basis for interactions of HIV and drugs of abuse. J Acquir Immune Defic Syndr. 1999;2002(31 Suppl 2):S62-9.

521. Samikkannu T, Atluri VS, Nair MP. HIV and cocaine impact glial metabolism: energy sensor AMP-activated protein kinase role in mitochondrial biogenesis and epigenetic remodeling. Sci Rep. 2016;6:31784

522. Hoefer MM, Sanchez AB, Maung R, de Rozieres CM, Catalan IC, Dowling CC, et al. Combination of methamphetamine and HIV-1 gp120 causes distinct long-term alterations of behavior, gene expression, and injury in the central nervous system. Exp Neurol. 2015;263:221-34.

523. Kesby JP, Heaton RK, Young JW, Umlauf A, Woods SP, Letendre SL, et al. Methamphetamine Exposure Combined with HIV-1 Disease or gp120 Expression: Comparison of Learning and Executive Functions in Humans and Mice. Neuropsychopharmacology. 2015;40(8):1899-909.

524. Nayak SU, Cicalese S, Tallarida C, Oliver CF, Rawls SM. Chemokine CCR5 and cocaine interactions in the brain: Cocaine enhances mesolimbic CCR5 mRNA levels and produces place preference and locomotor activation that are reduced by a CCR5 antagonist. Brain Behav Immun. 2020;83:288-92.

525. Marcondes MCG, Flynn C, Watry DD, Zandonatti M, Fox HS. Methamphetamine increases brain viral load and activates natural killer cells in simian immunodeficiency virus-infected monkeys. Am J Pathol. 2010;177(1):355-61.

526. Najera JA, Bustamante EA, Bortell N, Morsey B, Fox HS, Ravasi T, et al. Methamphetamine abuse affects gene expression in brain-derived microglia of SIV-infected macaques to enhance inflammation and promote virus targets. BMC Immunol. 2016;17(1):7.

527. Nair MP, Saiyed ZM, Nair N, Gandhi NH, Rodriguez JW, Boukli N, et al. Methamphetamine enhances HIV-1 infectivity in monocyte derived dendritic cells. J Neuroimmune Pharmacol. 2009:4(1):129-39.

528. Basova L, Najera JA, Bortell N, Wang D, Moya R, Lindsey A, et al. Dopamine and its receptors play a role in the modulation of CCR5 expression in innate immune cells following exposure to Methamphetamine: Implications to HIV infection. PLoS ONE. 2018;13(6):e0199861.

529. Ostrowski MA, Justement SJ, Catanzaro A, Hallahan CA, Ehler LA Mizell SB, et al. Expression of chemokine receptors CXCR4 and CCR5 in HIV-1-infected and uninfected individuals. J Immunol. 1998;161(6):3195-201.

530. Platt EJ, Wehrly K, Kuhmann SE, Chesebro B, Kabat D. Effects of CCR5 and CD4 cell surface concentrations on infections by macrophagetropic isolates of human immunodeficiency virus type 1. J Virol. 1998;72(4):2855-64

531. Reynes J, Portales P, Segondy M, Baillat V, Andre P, Reant B, et al. CD4+ $T$ cell surface CCR5 density as a determining factor of virus load in persons infected with human immunodeficiency virus type 1. J Infect Dis. 2000;181(3):927-32.

532. Wang J, Crawford K, Yuan M, Wang H, Gorry PR, Gabuzda D. Regulation of CC chemokine receptor 5 and CD4 expression and human immunodeficiency virus type 1 replication in human macrophages and microglia by T helper type 2 cytokines. J Infect Dis. 2002;185(7):885-97.

533. Bandaru W, Patel N, Ewaleifoh O, Haughey NJ. A failure to normalize biochemical and metabolic insults during morphine withdrawal disrupts synaptic repair in mice transgenic for HIV-gp120. J Neuroimmune Pharmacol. 2011;6(4):640-9.

534. El-Hage N, Rodriguez M, Dever SM, Masvekar RR, Gewirtz DA, Shacka JJ. HIV-1 and morphine regulation of autophagy in microglia: limited interactions in the context of HIV-1 infection and opioid abuse. J Virol. 2015;89(2):1024-35

535. Xu C, Fitting S. Inhibition of GABAergic neurotransmission by HIV-1 tat and opioid treatment in the striatum involves mu-opioid receptors. Front Neurosci. 2016;10:497.

536. El-Hage N, Podhaizer EM, Sturgill J, Hauser KF. Toll-like receptor expression and activation in Astroglia: differential regulation by HIV-1 Tat, gp120, and morphine. Immunol Invest. 2011;40(5):498-522.

537. Mahajan SD, Schwartz SA, Shanahan TC, Chawda RP, Nair MP. Morphine regulates gene expression of alpha- and beta-chemokines and their receptors on astroglial cells via the opioid mu receptor. J Immunol. 2002:169(7):3589-99.
538. Mahajan SD, Schwartz SA, Aalinkeel R, Chawda RP, Sykes DE, Nair MP. Morphine modulates chemokine gene regulation in normal human astrocytes. Clin Immunol. 2005;115(3):323-32.

539. Szabo I, Chen XH, Xin L, Adler MW, Howard OM, Oppenheim JJ, et al. Heterologous desensitization of opioid receptors by chemokines inhibits chemotaxis and enhances the perception of pain. Proc Natl Acad Sci U S A. 2002;99(16):10276-81.

540. Szabo I, Wetzel MA, Zhang N, Steele AD, Kaminsky DE, Chen C, et al. Selective inactivation of CCR5 and decreased infectivity of R5 HIV-1 strains mediated by opioid-induced heterologous desensitization. J Leukoc Biol. 2003;74(6):1074-82.

541. Gonek M, McLane VD, Stevens DL, Lippold K, Akbarali HI, Knapp PE, et al. CCR5 mediates HIV-1 Tat-induced neuroinflammation and influences morphine tolerance, dependence, and reward. Brain Behav Immun. 2018;69:124-38.

542. Chen X, Geller EB, Rogers TJ, Adler MW. Rapid heterologous desensitization of antinociceptive activity between mu or delta opioid receptors and chemokine receptors in rats. Drug Alcohol Depend. 2007;88(1):36-41.

543. Sengupta R, Burbassi S, Shimizu S, Cappello S, Vallee RB, Rubin JB, et al. Morphine increases brain levels of ferritin heavy chain leading to inhibition of CXCR4-mediated survival signaling in neurons. J Neurosci 2009;29(8):2534-44

544. Patel JP, Sengupta R, Bardi G, Khan MZ, Mullen-Przeworski A, Meucci O. Modulation of neuronal CXCR4 by the micro-opioid agonist DAMGO. J Neurovirol. 2006;12(6):492-500.

545. Nash B, Meucci O. Functions of the chemokine receptor CXCR4 in the central nervous system and its regulation by mu-opioid receptors. Int Rev Neurobiol. 2014;118:105-28.

546. Leonard JT, Roy K. The HIV entry inhibitors revisited. Curr Med Chem. 2006:13(8):911-34.

547. Rao PK. CCR5 inhibitors: emerging promising HIV therapeutic strategy. Indian J Sex Transm Dis AIDS. 2009;30(1):1-9.

548. Seibert C, Sakmar TP. Small-molecule antagonists of CCR5 and CXCR4: a promising new class of anti-HIV-1 drugs. Curr Pharm Des. 2004;10(17):2041-62.

549. Grande F, Occhiuzzi MA, Rizzuti B, loele G, De Luca M, Tucci P, et al. CCR5/CXCR4 dual antagonism for the improvement of HIV infection therapy. Molecules. 2019;24(3):550.

550. De Clercq E. The AMD3100 story: the path to the discovery of a stem cell mobilizer (Mozobil). Biochem Pharmacol. 2009;77(11):1655-64.

551. Kufel WD. Antibody-based strategies in HIV therapy. Int J Antimicrob Agents. 2020;56(6):106186.

552. Bruxelle JF, Trattnig N, Mureithi MW, Landais E, Pantophlet R. HIV-1 entry and prospects for protecting against infection. Microorganisms. 2021:9(2):228

553. Tilton JC, Doms RW. Entry inhibitors in the treatment of HIV-1 infection. Antiviral Res. 2010;85(1):91-100

554. Beccari MV, Mogle BT, Sidman EF, Mastro KA, Asiago-Reddy E, Kufel WD. Ibalizumab, a novel monoclonal antibody for the management of multidrug-resistant HIV-1 infection. Antimicrob Agents Chemother. 2019. https://doi.org/10.1128/AAC.00110-19.

555. Cahn P, Fink V, Patterson P. Fostemsavir: a new CD4 attachment inhibitor. Curr Opin HIV AIDS. 2018;13(4):341-5.

556. Choi WT, Duggineni $S, X u Y$, Huang Z, An J. Drug discovery research targeting the CXC chemokine receptor 4 (CXCR4). J Med Chem. 2012;55(3):977-94.

557. Huang LSM, Snyder EY, Schooley RT. Strategies and progress in CXCR4targeted anti-HIV therapeutic development. Clin Infect Dis. 2021. https://doi.org/10.1093/cid/ciab160.

558. Dean M, Carrington M, Winkler C, Huttley GA, Smith MW, Allikmets R, et al. Genetic restriction of HIV-1 infection and progression to AIDS by a deletion allele of the CKR5 structural gene Hemophilia Growth and Development Study, Multicenter AIDS Cohort Study, Multicenter Hemophilia Cohort Study, San Francisco City Cohort ALIVE Study. Science. 1996:273(5283):1856-62.

559. Samson M, Libert F, Doranz BJ, Rucker J, Liesnard C, Farber CM, et al. Resistance to HIV-1 infection in caucasian individuals bearing mutant alleles of the CCR-5 chemokine receptor gene. Nature. 1996;382(6593):722-5. 
560. Hütter G, Nowak D, Mossner M, Ganepola S, Müssig A, Allers K, et al. Long-term control of HIV by CCR5 Delta32/Delta32 stem-cell transplantation. N Engl J Med. 2009;360(7):692-8.

561. Gupta RK, Abdul-Jawad S, McCoy LE, Mok HP, Peppa D, Salgado M, et al. HIV-1 remission following CCR5Delta32/Delta32 haematopoietic stemcell transplantation. Nature. 2019;568(7751):244-8.

562. Panos $G$, Watson DC. Effect of HIV-1 subtype and tropism on treatment with chemokine coreceptor entry inhibitors; overview of viral entry inhibition. Crit Rev Microbiol. 2015:41(4):473-87.

563. Vicenzi E, Alfano M, Ghezzi S, Gatti A, Veglia F, Lazzarin A, et al. Divergent regulation of HIV-1 replication in PBMC of infected individuals by CC chemokines: suppression by RANTES, MIP-1alpha, and MCP-3, and enhancement by MCP-1. J Leukoc Biol. 2000;68(3):405-12.

564. Moriuchi H, Moriuchi M, Combadiere C, Murphy PM, Fauci AS. CD8+ T-cell-derived soluble factor(s), but not beta-chemokines RANTES, MIP-1 alpha, and MIP-1 beta, suppress HIV-1 replication in monocyte/ macrophages. Proc Natl Acad Sci U S A. 1996;93(26):15341-5.

565. Berro R, Yasmeen A, Abrol R, Trzaskowski B, Abi-Habib S, Grunbeck A et al. Use of G-protein-coupled and -uncoupled CCR5 receptors by CCR5 inhibitor-resistant and -sensitive human immunodeficiency virus type 1 variants. J Virol. 2013;87(12):6569-81.

566. Rico CA, Berchiche YA, Horioka M, Peeler JC, Lorenzen E, Tian H, et al. High-affinity binding of chemokine analogs that display ligand bias at the HIV-1 coreceptor CCR5. Biophys J. 2019:117(5):903-19.

567. Kawatkar SP, Yan M, Gevariya H, Lim MY, Eisold S, Zhu X, et al. Computational analysis of the structural mechanism of inhibition of chemokine receptor CXCR4 by small molecule antagonists. Exp Biol Med (Maywood). 2011;236(7):844-50.

568. Mao Y, Meng Q, Song P, Zhu S, Xu Y, Snyder EY, et al. Novel bivalent and D-peptide ligands of CXCR4 mobilize hematopoietic progenitor cells to the blood in C3H/HeJ mice. Cell Transplant. 2018;27(8):1249-55.

569. Babcock GJ, Farzan M, Sodroski J. Ligand-independent dimerization of CXCR4, a principal HIV-1 coreceptor. J Biol Chem. 2003;278(5):3378-85.

570. Sohy D, Yano H, de Nadai P, Urizar E, Guillabert A, Javitch JA, et al. Hetero-oligomerization of CCR2, CCR5, and CXCR4 and the protean effects of "selective" antagonists. J Biol Chem. 2009;284(45):31270-9.

571. Van Hout A, Klarenbeek A, Bobkov V, Doijen J, Arimont M, Zhao C, et al. CXCR4-targeting nanobodies differentially inhibit CXCR4 function and HIV entry. Biochem Pharmacol. 2018;158:402-12.

572. Lapidot A, Peled A, Berchanski A, Pal B, Kollet O, Lapidot T, et al. NeoR6 inhibits HIV-1-CXCR4 interaction without affecting CXCL12 chemotaxis activity. Biochem Biophys Acta. 2008:1780(6):914-20.

573. Rodríguez-Mora S, Spivak AM, Szaniawski MA, López-Huertas MR, Alcamí J, Planelles $V$, et al. Tyrosine kinase inhibition: a new perspective in the fight against HIV. Curr HIV/AIDS Rep. 2019;16(5):414-22.

574. Polizzotto MN, Chen G, Tressler RL, Godfrey C. Leveraging cancer therapeutics for the HIV cure agenda: current status and future directions Drugs. 2015;75(13):1447-59.
575. Stantchev TS, Markovic I, Telford WG, Clouse KA, Broder CC. The tyrosine kinase inhibitor genistein blocks HIV-1 infection in primary human macrophages. Virus Res. 2007;123(2):178-89.

576. Chaudhary O, Narayan V, Lelis F, Linz B, Watkins M, Veazey R, et al. Inhibition of p38 MAPK in combination with ART reduces SIV-induced immune activation and provides additional protection from immune system deterioration. PLoS Pathog. 2018;14(8):e1007268.

577. Haller V, Nahidino P, Forster M, Laufer SA. An updated patent review of p38 MAP kinase inhibitors (2014-2019). Expert Opin Ther Pat. 2020;30(6):453-66.

578. Ambrosioni J, Coiras M, Alcamí J, Miró JM. Potential role of tyrosine kinase inhibitors during primary HIV-1 infection. Expert Rev Anti Infect Ther. 2017;15(5):421-3.

579. Salgado M, Martinez-Picado J, Gálvez C, Rodríguez-Mora S, Rivaya B, Urrea $\mathrm{V}$, et al. Dasatinib protects humanized mice from acute HIV-1 infection. Biochem Pharmacol. 2020;174:113625.

580. Bermejo M, López-Huertas MR, García-Pérez J, Climent N, Descours B, Ambrosioni J, et al. Dasatinib inhibits HIV-1 replication through the interference of SAMHD1 phosphorylation in CD4+ T cells. Biochem Pharmacol. 2016:106:30-45.

581. Bermejo M, Ambrosioni J, Bautista G, Climent N, Mateos E, Rovira C, et al. Evaluation of resistance to HIV-1 infection ex vivo of PBMCs isolated from patients with chronic myeloid leukemia treated with different tyrosine kinase inhibitors. Biochem Pharmacol. 2018;156:248-64.

582. Lindauer M, Hochhaus A. Dasatinib. Recent Results Cancer Res. 2018;212:29-68.

583. Nichols WG, Steel HM, Bonny T, Adkison K, Curtis L, Millard J, et al. Hepatotoxicity observed in clinical trials of aplaviroc (GW873140). Antimicrob Agents Chemother. 2008;52(3):858-65.

584. Debnath B, Xu S, Grande F, Garofalo A, Neamati N. Small molecule inhibitors of CXCR4. Theranostics. 2013:3(1):47-75.

585. Thompson M, Saag M, DeJesus E, Gathe J, Lalezari J, Landay AL, et al. A 48-week randomized phase $2 \mathrm{~b}$ study evaluating cenicriviroc versus efavirenz in treatment-naive HIV-infected adults with C-C chemokine receptor type 5-tropic virus. AIDS. 2016;30(6):869-78.

586. Landovitz RJ, Angel JB, Hoffmann C, Horst H, Opravil M, Long J, et al. Phase II study of vicriviroc versus efavirenz (both with zidovudine/lamivudine) in treatment-naive subjects with HIV-1 infection. J Infect Dis. 2008;198(8):1113-22.

587. Gu WG, Chen XQ. Targeting CCR5 for anti-HIV research. Eur J Clin Microbiol Infect Dis. 2014;33(11):1881-7.

\section{Publisher's Note}

Springer Nature remains neutral with regard to jurisdictional claims in published maps and institutional affiliations.
Ready to submit your research? Choose BMC and benefit from:

- fast, convenient online submission

- thorough peer review by experienced researchers in your field

- rapid publication on acceptance

- support for research data, including large and complex data types

- gold Open Access which fosters wider collaboration and increased citations

- maximum visibility for your research: over $100 \mathrm{M}$ website views per year

At BMC, research is always in progress.

Learn more biomedcentral.com/submissions 